BANCA D'ITALIA

E U R O S I S T E M A

Temi di discussione

(Working Papers)

The economic drivers of volatility and uncertainty

by Andrea Carriero, Francesco Corsello and Massimiliano Marcellino 



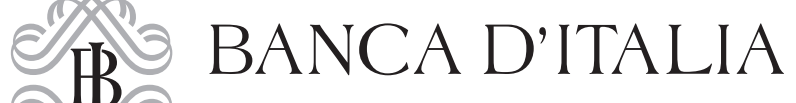

E U ROS I S T E MA

\section{Temi di discussione}

(Working Papers)

The economic drivers of volatility and uncertainty

by Andrea Carriero, Francesco Corsello and Massimiliano Marcellino

Number 1285 - July 2020 
The papers published in the Temi di discussione series describe preliminary results and are made available to the public to encourage discussion and elicit comments.

The views expressed in the articles are those of the authors and do not involve the responsibility of the Bank.

Editorial Board: Federico Cingano, Marianna Riggi, Monica Andini, Audinga Baltrunaite, Marco Bottone, Davide Delle Monache, Sara Formai, Francesco Franceschi, Salvatore lo Bello, Juho Taneli Makinen, luca Metelli, Mario Pietrunti, Marco Savegnago.

Editorial Assistants: Alessandra Giammarco, Roberto Marano.

ISSN 1594-7939 (print)

ISSN 2281-3950 (online)

Printed by the Printing and Publishing Division of the Bank of Italy 


\title{
THE ECONOMIC DRIVERS OF VOLATILITY AND UNCERTAINTY
}

\author{
by Andrea Carriero , Francesco Corsello ${ }^{* *}$ and Massimiliano Marcellino ${ }^{* * *}$
}

\begin{abstract}
We introduce a time-series model for a large set of variables in which the structural shocks identified are employed to simultaneously explain the evolution of both the level (conditional mean) and the volatility (conditional variance) of the variables. Specifically, the total volatility of macroeconomic variables is first decomposed into two separate components: an idiosyncratic component, and a component common to all of the variables. Then, the common volatility component, often interpreted as a measure of uncertainty, is further decomposed into three parts, respectively driven by the volatilities of the demand, supply and monetary/financial shocks. From a methodological point of view, the model is an extension of the homoscedastic Multivariate Autoregressive Index (MAI) model (Reinsel, 1983) to the case of time-varying volatility. We derive the conditional posterior distribution of the coefficients needed to perform estimations via Gibbs sampling. By estimating the model with US data, we find that the common component of volatility is substantial, and it explains at least 50 per cent of the overall volatility for most variables. The relative contribution of the demand, supply and financial volatilities to the common volatility component is variable specific and often timevarying, and some interesting patterns emerge.
\end{abstract}

JEL Classification: C15, C32, C38, C51, E30.

Keywords: Multivariate Autoregressive Index models, stochastic volatility, reduced rank regressions, Bayesian VARs, factor models, structural analysis.

DOI: $10.32057 / 0$. TD.2020.1285

\section{Contents}

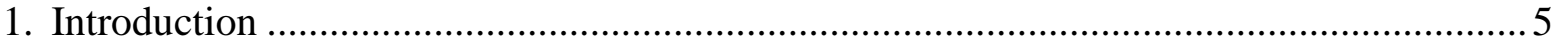

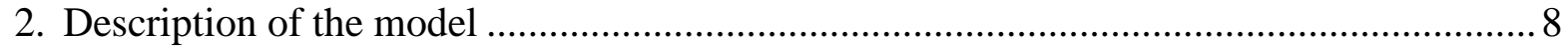

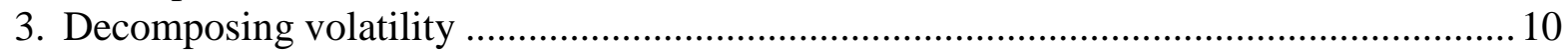

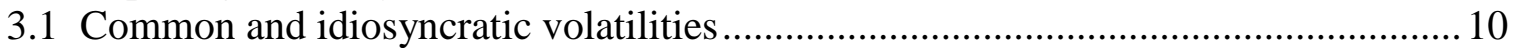

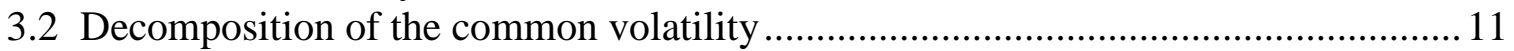

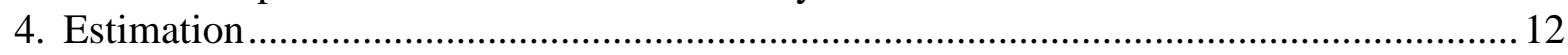

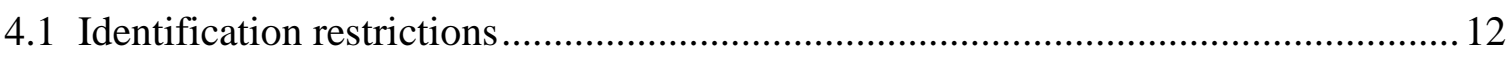

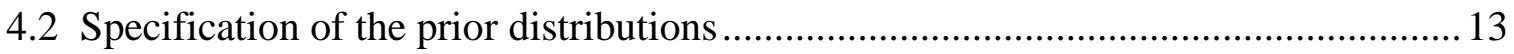

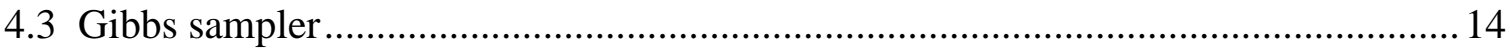

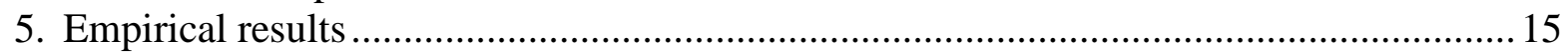

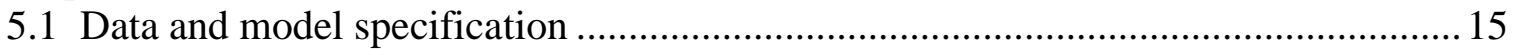

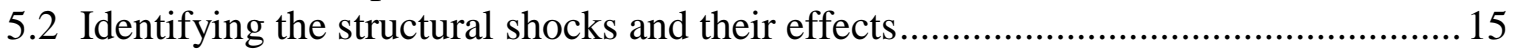

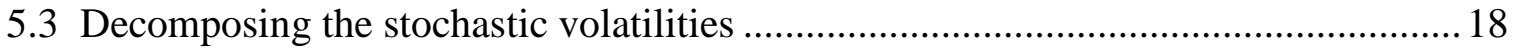

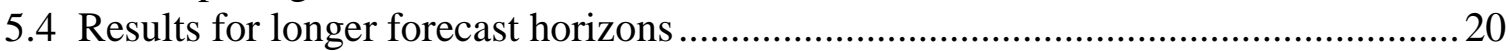

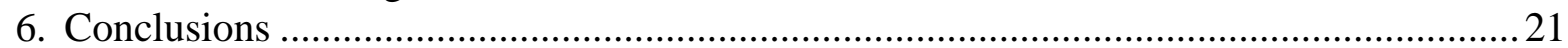

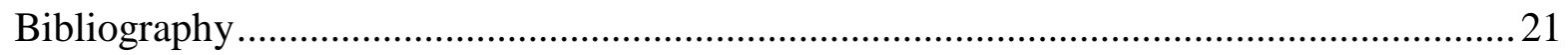

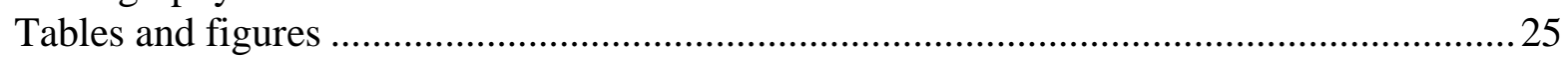

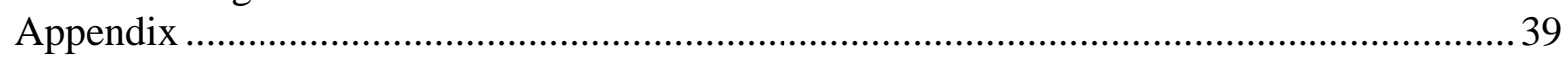

\footnotetext{
${ }^{*}$ Queen Mary, University of London.

** Bank of Italy, Economic Outlook and Monetary Policy Directorate.

*** Bocconi University, IGIER, BAFFI-CAREFIN and CEPR
} 



\section{$1 \quad$ Introduction $^{1}$}

The seminal paper by Engle (1982) emphasized the importance of changing conditional volatilities in economic and financial variables. The ensuing literature on this topic is extensive, starting with time-series contributions but then entering also the mainstream economic literature, with the debate on the Great Moderation's origin, see, e.g., Primiceri (2005), Cogley \& Sargent (2005), Sims \& Zha (2006), and Fernández-Villaverde \& RubioRamírez (2013). ${ }^{2}$ After the 2007 financial crisis there seems to be growing consensus on the importance of allowing for economic and financial shocks with particularly large variance during crisis periods, see for example Abbate, Eickmeier, Lemke \& Marcellino (2016) and references therein.

While there is by now a large literature modeling volatilities as stochastic and timevarying, the economic identification of the shocks driving this variation in conditional variances has not been investigated. This is in stark contrast with the mainstream approach to study the effects of identified structural shocks on the conditional mean of macroeconomic variables as laid out in Sims (1980).

This paper introduces a model in which the identified structural shocks are employed to simultaneously explain the evolution of both the level (conditional mean) and the volatility (conditional variance) of macroeconomic variables. In particular, we provide a strategy to decompose the total volatility of each macroeconomic variable, into two separate components: an idiosyncratic component, and a component common to all of the variables, which is often interpreted as a measure of uncertainty (see e.g. Jurado, Ludvigson \& Ng, 2015 and Carriero, Clark \& Marcellino, 2018). The common volatility component is further decomposed into three parts, respectively driven by structural demand, supply and monetary / financial shocks. All these components are orthogonal to each other, so the proposed decomposition provides a measure of the contribution of each source to the total volatility.

Methodologically, the model is an extension of the homoschedastic Multivariate Autoregressive Index (MAI) Model of Reinsel (1983) and Carriero, Kapetanios \& Marcellino (2016) [CKM16 henceforth] to the case of time varying volatility (MAI-SV). We derive the conditional posterior distributions of the model parameters, which are then used for the development of a Gibbs sampler algorithm. A key feature of our approach is the use

\footnotetext{
${ }^{1}$ We would like to thank Marco Del Negro, Barbara Rossi and participants at the GSE Summer Forum on Time Series Econometrics for useful comments on a previous draft. Marcellino is grateful to the Baffi-Carefin center for partially supporting this research.

${ }^{2}$ From a reduced form perspective, Clark \& Ravazzolo (2015) reports evidence that introducing stochastic volatilities improves the forecasting accuracy for macro-financial variables, strengthening the evidence already gathered by D'Agostino, Gambetti \& Giannone (2013) and Carriero, Clark \& Marcellino (2015).
} 
of a large information set, which is essential to avoid non-fundamentalness of the shocks and omitted variable bias, but requires efficient strategies to reduce the computational burden resulting from the large number of unobservable state variables.

Carriero, Clark \& Marcellino (2016, 2018, 2019) also analyze small and large VAR models with a factor volatility structure, where each volatility is decomposed into common and idiosyncratic components. Yet, in those papers the factor volatility structure is imposed a priori, while in this paper it emerges as a consequence of the reduced rank restrictions. Moreover, while in those papers the common volatility component is unexplained, here it is linked to the volatilities of the structural shocks driving the indexes. Further, in those papers only the variances of the errors are time varying, while here the covariances can also change over time. Finally, the estimation algorithm is different, as here we need to take the nonlinearity of the conditional mean into account.

We estimate the MAI-SV model using a dataset of 20 macroeconomic and financial variables for the U.S. ${ }^{3}$. We use a common Choleski ordering to identify the demand, supply and monetary / financial shocks in the VAR for the indexes. While simple, in our application this identification scheme produces results in line with economic theory. In particular, a (positive) demand shock boosts the output factor, the financial factor and, to a lesser extent, the price factor; a (negative) supply shock increases prices, reduces the real output factor, and overall has non significant effects on the monetary / financial factor; and a (negative) monetary / financial shock lowers the real output factor and has negative, though barely significant, effects on the price factor. ${ }^{4}$

The demand, supply and financial structural shocks appear as important drivers not only of the level of macroeconomic and financial variables but also of their changing conditional volatility. The volatility of the three structural shocks explains, in general, more than $50 \%$ of the overall volatility, in line with the results in Carriero et al. (2018) obtained with a different model for the conditional means and variances. The relative importance of the estimated volatilities for the structural shocks varies substantially across different variables, and in some cases it changes over time.

The common component of volatility seems to have broadly diminished its importance over time for real variables, while it is rather stable and substantial for nominal variables (much more so for CPI and the PCE deflator than for PPI). A similar pattern emerges also for the financial variables, with the common component explaining about half of the variation in the volatility of the Fed Funds rate and the 10 year T-Bond. Finally, the

\footnotetext{
${ }^{3}$ The series included coincide with those in Bańbura, Giannone \& Reichlin (2010) and Carriero et al. (2016), but for an extended period that covers 1964-2016.

${ }^{4}$ Our methodology could be also applied with different identification schemes, such as those discussed in Kilian \& Lütkepohl (2017).
} 
role of the common volatility component in explaining the volatility of the S\&P500 is remarkably high.

In terms of the role of the various structural shocks, we find that demand shocks are clearly dominant in explaining the volatility of industrial production and capacity utilization. The same applies to employment, but only at the beginning of the sample: for this variable the role of demand shocks has progressively declined in favor of supply and monetary/financial shocks. Supply shocks are dominant in explaining the volatility of the nominal variables, in particular for CPI and the PCE deflator. With regards to the common volatility of financial variables, the contribution of different structural shocks is overall comparable and rather stable over time. The monetary / financial shock is particularly important to explain the common component of the S\&P500 volatility, but even for this variable it only explains about $50 \%$, with the other $50 \%$ close to equally split between demand and supply shocks.

From an economic point of view, the volatility of the structural demand shock could be related to changes in the inventory mechanism (e.g., McConnell \& Perez-Quiros, 2000) or to the globalization process (e.g., Bianchi \& Civelli, 2015), while that of the supply shock can depend on the behavior of the oil market (e.g., Lee, Ni \& Ratti, 1995) or on firms' productivity (e.g., Christiano, Motto \& Rostagno, 2010), and the volatility of the financial/monetary shock can be influenced by financial innovation (e.g., Dynan, Elmendorf \& Sichel, 2006) or by changes in the conduct of monetary policy (e.g., Clarida, Gali \& Gertler, 2000). Justiniano \& Primiceri (2008) introduce a DSGE model with stochastic volatility in several structural shocks. Specifically, they find that a reduction in the variance of investment shocks, interpreted also as a proxy for unmodeled financial frictions, is the main driver of the US Great Moderation, with a limited role for changes in monetary policy. Their evidence is somewhat in line with our common volatility decomposition that shows the gradually decreasing role of the monetary/financial shock contribution from the 1980s to the Great Financial Crisis. However, our structural decomposition is based on the common part of the volatility which is only a fraction of the total volatility. Moreover, Benati \& Surico (2009) show that it can be difficult to map changes in the variance of structural VAR shocks with those in DSGE models.

The remainder of the paper is structured as follows. Section 2 describes the model. Section 3 introduces the volatility decomposition. Section 4 presents the choice of prior distributions and develops the MCMC algorithm for estimation, with additional details provided in the appendix. Section 5 discusses the empirical results. Section 6 concludes. 


\section{Description of the model}

This section presents the econometric model used in the paper. The model is an extension of the homoschedastic Multivariate Autoregressive Index (MAI) Model of Reinsel (1983) to the case of time varying volatility.

Let $y_{t}$ be a $n$-dimensional vector containing the variables of interest, and consider the following model:

$$
y_{t}=\sum_{\ell=1}^{p} A_{\ell} B_{0} y_{t-\ell}+u_{t}
$$

where $A_{\ell}$ are $n \times r$ matrices, $\ell=1, \ldots, p, B_{0}$ a is $r \times n$ matrix, and $u_{t} \stackrel{i i d}{\sim} \mathcal{M N}(0, \Omega)$ is a vector of i.i.d. disturbances. The product $A_{\ell} B_{0}$ is then a sequence of $n$-dimensional reduced rank $(r)$ matrices, $\ell=1, \ldots, p$, and defining $\Phi_{\ell}=A_{\ell} B_{0}$ makes clear that the model above is a constrained VAR. One advantage of the rank-reduction is that as the dimension of the cross-section $n$ increases, the model remains relatively parsimonious, as long as $r \ll n$. A second important advantage is that the terms $B_{0} y_{t-\ell}$ and $A_{\ell}$ have a straightforward interpretation as a set of $r$ indeces (or factors) and their loadings. ${ }^{5}$ This model was originally named Multivariate Autoregressive Index model (Reinsel (1983)). If we define the observable factors as:

$$
F_{t} \equiv B_{0} y_{t}
$$

the MAI model in (1) can be written as:

$$
y_{t}=\sum_{\ell=1}^{p} A_{\ell} F_{t-\ell}+u_{t} .
$$

As pointed out by Carriero et al. (2016) [CKM16 henceforth], by pre-multiplying (3) by $B_{0}$ it is apparent that the MAI model implies a $V A R(p)$ representation for the factors:

$$
F_{t}=\sum_{\ell=1}^{p} C_{\ell} F_{t-\ell}+\omega_{t},
$$

\footnotetext{
${ }^{5}$ Of course, as it happens also in factor models and in cointegrated VARs, it is the case that one can rotate these matrices arbitrarily, e.g. $A_{\ell} \cdot B_{0}=A_{\ell} Q^{\prime} \cdot Q B_{0}$, where $Q$ is an orthogonal matrix, and hence identification restrictions are needed to pin down only one of these possible rotations. Identification can be straightforwardly achieved e.g. as in Reinsel (1983) by assuming that the first $r$ rows and columns of $B$ are an identity matrix, $B_{0}=\left[\begin{array}{cc}I_{r} & \widetilde{B}_{0}\end{array}\right]$. Here we follow a similar approach in which the only difference is the position of the columns of the matrix $I_{r}$. In addition, due to the grouping of the variables, we also impose some additional zero restrictions, see Section 4 for details.
} 
where $C_{\ell}=B_{0} A_{\ell}, \ell=1, \ldots, p$, and $\omega_{t} \stackrel{i}{\sim} \mathcal{M N}(0, \Xi)$, with $\Xi \equiv B_{0} \Omega B_{0}^{\prime}$. Grouping (3) and (4), we obtain a factor augmented VAR (FAVAR) - type model, with the notable difference that the factors of the MAI model are observable, while the factors of a FAVAR model are considered as unobservable. In addition, the VAR model for the factors is imposed in FAVARs, while in our framework it is a consequence of the MAI model for the variables. Furthermore, factors in FAVAR are in general orthogonal, while here they can be correlated.

In this paper we generalize the MAI model by allowing the disturbances to have time varying volatility:

$$
u_{t}=G_{t}^{-1} \Sigma_{t} \varepsilon_{t}
$$

where $\varepsilon_{t} \stackrel{i i d}{\sim} \mathcal{M N}\left(0, I_{n}\right)$, and:

$$
G_{t}=\left[\begin{array}{ccccc}
1 & 0 & \ldots & \ldots & 0 \\
g_{1, t} & 1 & \ddots & & \vdots \\
g_{2, t} & g_{3, t} & 1 & \ddots & \vdots \\
\vdots & \vdots & \ddots & \ddots & 0 \\
g_{m-n+2, t} & g_{m-n+3, t} & \ldots & g_{m, t} & 1
\end{array}\right], \quad \Sigma_{t}=\left[\begin{array}{cccc}
\sigma_{1, t} & 0 & \ldots & 0 \\
0 & \sigma_{2, t} & \ddots & \vdots \\
\vdots & \vdots & \ddots & 0 \\
0 & 0 & 0 & \sigma_{n, t}
\end{array}\right]
$$

Hence, the reduced form MAI errors become $u_{t} \stackrel{i}{\sim} \mathcal{M N}\left(0, \Omega_{t}\right)$, with $\Omega_{t}=G_{t}^{-1} \Sigma_{t} \Sigma_{t}^{\prime} G_{t}^{-1 \prime}$, so that both the variances and the covariances are time-varying. ${ }^{6}$

Following Primiceri (2005), we specify the following law of motions for the $n$-dimensional vector of $(\log )$ standard deviations $\sigma_{t}$ and the $m$-dimensional vector $(m=n(n-1) / 2)$ of off-diagonal elements $g_{t}=\left(g_{1 t}, g_{2 t}, \ldots, g_{m t}\right)^{\prime}$ :

$$
\begin{aligned}
\log \sigma_{t} & =\log \sigma_{t-1}+\nu_{\sigma, t}, \\
g_{t} & =g_{t-1}+\nu_{g, t},
\end{aligned}
$$

with $\nu_{\sigma, t} \stackrel{\text { iid }}{\sim} \mathcal{M N}\left(0, Q_{\sigma}\right), \nu_{g, t} \stackrel{i i d}{\sim} \mathcal{M N}\left(0, Q_{g}\right)$, and $\forall(t, h), \nu_{\sigma, t} \perp \nu_{g, t+h}$.

Note that the errors in the $\operatorname{VAR}(p)$ for the observable factors $F_{t}$ also feature time variation in their volatilities. Specifically, the disturbances to the factor VAR in (4) have the following distribution:

$$
\omega_{t} \stackrel{i}{\sim} \mathcal{M N}\left(0, \Xi_{t}\right)
$$

where $\Xi_{t} \equiv B_{0} \Omega_{t} B_{0}^{\prime}$. The equations in (3) and (4), augmented with the error specifications

\footnotetext{
${ }^{6}$ Any positive definite matrix $\Omega_{t}$ can be decomposed as $\Omega_{t}=G_{t}^{-1} \Sigma_{t} \Sigma_{t}^{\prime} G_{t}^{-1^{\prime}}$, while of course other decompositions are possible.
} 
in (5) and (6), are similar to a FAVAR model with stochastic volatility (SV) in both the (observable) factors and idiosyncratic errors. ${ }^{7}$

When the model has a large number of variables, the off-diagonal elements contained in $G_{t}$ can create a computational bottleneck. For example, in a model with 20 variables as in our empirical application, $g_{t}$ becomes an 190-dimensional stochastic process. For this reason, in our empirical application, we consider two versions of the model. The first version only features time variation in the volatilities, while the covariances $g_{t}$ are assumed to remain constant over time. We will refer to this model as MAI-SV. The second version of the model features time variation also in the covariances. We will refer to this model as MAI-SVCV.

\section{Decomposing volatility}

In this section we present an approach to decompose the total volatility of the variables $y_{t}$ into orthogonal components. This is achieved in two stages. In the first stage, we decompose total volatility into a part which is common to all variables, which can be interpreted as a measure of uncertainty, and an idiosyncratic component. In the second stage we further decompose the common component into parts, each corresponding to a different structural shock.

\subsection{Common and idiosyncratic volatilities}

We start with decomposing the total volatility into two parts, a part which is common to all variables, and an idiosyncratic component. CKM16 introduce the following identity: ${ }^{8}$

$$
I_{n}=\Omega B_{0}^{\prime} \Xi^{-1} B_{0}+B_{0 \perp}^{\prime}\left(B_{0 \perp} \Omega^{-1} B_{0 \perp}^{\prime}\right)^{-1} B_{0 \perp} \Omega^{-1}
$$

where $B_{0 \perp}$ is a $(n-r) \times n$ matrix, such that $B_{0} B_{0 \perp}^{\prime}=\mathbf{0}_{r \times(n-r)}$. Using this decomposition in the context of the MAI-SV or MAI-SVCV models, we can then split the residuals $u_{t}$ in their projection over the subspace generated by the factors' residuals $\omega_{t}$, and their projection over the subspace generated by the $n-r$ idiosyncratic errors $\psi_{t}$ (orthogonal to $\left.\omega_{t}\right)$ :

$$
y_{t}=\sum_{\ell=1}^{p} A_{\ell} \cdot F_{t-\ell}+\Omega_{t} B_{0}^{\prime} \Xi_{t}^{-1} \underbrace{B_{0} u_{t}}_{\omega_{t}}+B_{0 \perp}^{\prime}\left(B_{0 \perp} \Omega_{t}^{-1} B_{0 \perp}^{\prime}\right)^{-1} \underbrace{B_{0 \perp} \Omega_{t}^{-1} u_{t}}_{\psi_{t}} .
$$

\footnotetext{
${ }^{7} \mathrm{~A}$ small factor model with common stochastic volatility in the innovations to both factors and idiosyncratic errors is studied by Marcellino et al. (2016).

${ }^{8}$ See also Johansen (1995) and Centoni \& Cubadda (2003).
} 
We can then further decompose the total error volatility $\Omega_{t}$ into the volatility of the common component and that of the idiosyncratic component: ${ }^{9}$

$$
\Omega_{t}=\Omega_{t}^{c o m}+\Omega_{t}^{i d i o}
$$

with $\Omega_{t}^{\text {com }}=\Omega_{t} B_{0}^{\prime} \Xi_{t}^{-1} B_{0} \Omega_{t}$ and $\Omega_{t}^{\text {idio }}=B_{0 \perp}^{\prime}\left(B_{0 \perp} \Omega_{t}^{-1} B_{0 \perp}^{\prime}\right)^{-1} B_{0 \perp}$.

The matrix $\Omega_{t}$ can be interpreted as the variance covariance matrix of the 1-step ahead forecast errors. We can apply a similar decomposition also to the variance of the h-step ahead forecast errors, to understand whether the common component contributes differently across horizons.

Finally, as mentioned in the introduction, in the MAI-SV model the variance decomposition in (9) into common and idiosyncratic components emerges from the model structure, while in Carriero et al. $(2016,2018,2019)$ it is imposed a priori (in a linear rather than nonlinear VAR model).

\subsection{Decomposition of the common volatility}

In this section we further decompose the common volatility component $\Omega_{t}^{\text {com }}$ into $r$ parts, each corresponding to a different structural shock. Starting from the shocks to the observed factors $\omega_{t}$ we can recover the structural shocks to the factors $\varepsilon_{t}^{\omega}$ using a Choleski decomposition:

$$
\omega_{t}=S_{t}^{\omega} \cdot \varepsilon_{t}^{\omega}
$$

where $S_{t}^{\omega}$ is the lower-triangular cholesky factor of $\Xi_{t}$ (i.e. the variance of $\omega_{t}$ ), and $\varepsilon_{t}^{\omega}$ is an i.i.d. standard Normal variable, which represents the structural shocks. We can now insert the structural shocks $\varepsilon_{t}^{\omega}$ into the decomposition in (8), obtaining:

$$
y_{t}=\sum_{\ell=1}^{p} A_{\ell} \cdot F_{t-\ell}+\sum_{j=1}^{r} \Omega_{t} B_{0}^{\prime} \Xi_{t}^{-1} S_{t}^{\omega} \varepsilon_{t, j}^{\omega} \cdot e_{j}+B_{0 \perp}^{\prime}\left(B_{0 \perp} \Omega_{t}^{-1} B_{0 \perp}^{\prime}\right)^{-1} \psi_{t}
$$

where $e_{j}$ is the $r \times 1$ column vector of the r-dimensional canonical base.

It follows that one can decompose the common volatility $\Omega_{t}^{c o m}$ into orthogonal com-

\footnotetext{
${ }^{9}$ The complete derivation is the following: $\Omega_{t}^{\text {com }}=\Omega_{t} B_{0}^{\prime} \Xi_{t}^{-1} \mathbb{E}\left(\omega_{t} \omega_{t}^{\prime}\right) \Xi_{t}^{-1} B_{0} \Omega_{t}=\Omega_{t} B_{0}^{\prime} \Xi_{t}^{-1} \Xi_{t} \Xi_{t}^{-1} B_{0} \Omega_{t}=\Omega_{t} B_{0}^{\prime} \Xi_{t}^{-1} B_{0} \Omega_{t}$. $\Omega_{t}^{i d i o}=B_{0 \perp}^{\prime}\left(B_{0 \perp} \Omega_{t}^{-1} B_{0 \perp}^{\prime}\right)^{-1} B_{0 \perp} \Omega_{t}^{-1} \mathbb{E}\left(u_{t} u_{t}^{\prime}\right) \Omega_{t}^{-1} B_{0 \perp}^{\prime}\left(B_{0 \perp} \Omega_{t}^{-1} B_{0 \perp}^{\prime}\right)^{-1} B_{0 \perp}=B_{0 \perp}^{\prime}\left(B_{0 \perp} \Omega_{t}^{-1} B_{0 \perp}^{\prime}\right)^{-1} B_{0 \perp}$.
} 
ponents, each associated with a structural shock:

$$
\Omega_{t}^{c o m}=\sum_{j=1}^{r} \Omega_{t} B_{0}^{\prime} \Xi_{t}^{-1}\left(S_{t}^{\omega} e_{j} \cdot e_{j}^{\prime} S_{t}^{\omega \prime}\right) \Xi_{t}^{-1} B_{0} \Omega_{t} .
$$

A similar decomposition can be applied to the common component of the h-step ahead covariance matrix, which is informative to understand whether the contribution of various structural shocks changes with the forecast horizon.

A comparable decomposition can be also applied with different shock identification methods, such as sign restrictions or external instruments, see Kilian \& Lütkepohl (2017) for an exhaustive review and analysis on shock identification. The choice of the proper structural identification method crucially depends on the empirical application of interest.

In the empirical section we will apply these formulae to decompose the estimated conditional volatilities of US macro and financial variables into their common and idiosyncratic components, further studying the contribution of various structural shocks when decomposing the common volatility component.

\section{Estimation}

In this section we discuss, in turn, the identification restrictions, the priors on model parameters, and the Gibbs Sampler to draw from the joint posterior, which is not a known distribution.

\subsection{Identification restrictions}

In order to identify the model, we need to restrict at least $r^{2}$ elements in the $r \times n$ matrix $B_{0}$. Similarly to Carriero et al. (2016), we divide the $n$ variables in $r$ subgroups or blocks, so to have as many blocks as factors. Each block may have in principle its own number of variables, i.e. $y_{t}=\left(y_{t}^{1 \prime}, y_{t}^{2 \prime}, \ldots, y_{t}^{r \prime}\right), n=\sum_{j=1}^{r} n_{j}$. The proposed identification for the observable factors $F_{t}=B_{0} y_{t}$ assumes that each factor is a linear combination of the variables in its associated block. Moreover, we normalize to 1 the weight of the first variable of each block. This is equivalent to the following representation:

$$
B_{0}=\left[\begin{array}{ccccccc}
1 & \widetilde{B}_{0,1} & 0 & \mathbf{0}_{1 \times\left(n_{2}-1\right)} & \ldots & 0 & \boldsymbol{0}_{1 \times\left(n_{r}-1\right)} \\
0 & \mathbf{0}_{1 \times\left(n_{1}-1\right)} & 1 & \widetilde{B}_{0,2} & \ldots & 0 & \mathbf{0}_{1 \times\left(n_{r}-1\right)} \\
\vdots & \vdots & \vdots & \ddots & \ddots & \ddots & \vdots \\
0 & \mathbf{0}_{1 \times\left(n_{1}-1\right)} & 0 & \mathbf{0}_{1 \times\left(n_{2}-1\right)} & \ldots & 1 & \widetilde{B}_{0, r},
\end{array}\right],
$$


which implies that the unrestricted elements are contained in each of the $1 \times\left(n_{j}-1\right)$ vectors $\widetilde{B}_{0, j}$, for a total of $n-r$ unrestricted elements in the matrix $B_{0}$.

\subsection{Specification of the prior distributions}

The set of prior distributions is constructed using a training sample. Prior knowledge for the unrestricted elements of $B_{0}$ is elicited with a Normal distribution. To calibrate these prior distributions, for each block $j=1, \ldots, r$, we compute the largest eigenvalue score via principal components analysis, so to obtain a set of $r$ score series $\left\{S_{t}^{j}\right\}_{t=1, \ldots, T}^{j=1, \ldots, r}$. Using these scores, we consider the following $n-r$ univariate regressions:

$$
S_{t}^{j}=b_{0, j, k} \cdot y_{t, k}^{j}+u_{j, k, t}, \quad u_{j, k, t} \stackrel{i i d}{\sim} \mathcal{N}\left(0, \sigma_{j, k}^{2}\right) ; \quad j=1, \ldots, r, \quad k=2, \ldots, n_{j} .
$$

The OLS estimates of these regressions, and their standard errors, are used to calibrate mean and variances of the prior distributions. Since each $b_{0, j, 1}$ is set to 1 (as shown in the previous subsection), each prior mean of the elements in $\widetilde{B}_{0,1}$ is divided by $\hat{b}_{0, j, 1}$. Prior covariances among elements are set to zero.

Defining $A \equiv\left[A_{1}|\ldots| A_{p}\right]$, the prior on $a=\operatorname{vec}\left(A^{\prime}\right)$ is multivariate Normal, centered on $\mathbf{0}$, and with diagonal variance $V_{a}$ resembling a Minnesota prior. In particular, it holds that

$$
V_{a}=\operatorname{Diag}\left(\left[\begin{array}{c}
\widehat{\sigma}_{y, 1}^{2} \\
\vdots \\
\widehat{\sigma}_{y, n}^{2}
\end{array}\right]\right) \otimes\left[\begin{array}{cccc}
\Psi_{1} & 0 & \ldots & 0 \\
0 & \Psi_{2} & \ddots & \vdots \\
\vdots & \ddots & \ddots & 0 \\
0 & \ldots & 0 & \Psi_{p}
\end{array}\right], \forall \ell, \quad \Psi_{\ell}=\frac{\lambda_{a}}{\ell^{d}} \cdot \operatorname{Diag}\left(\left[\begin{array}{c}
\widehat{\sigma}_{F, 1}^{-2} \\
\vdots \\
\widehat{\sigma}_{F, r}^{-2}
\end{array}\right]\right)
$$

where $\widehat{\sigma}_{y, j}^{2}$ and $\widehat{\sigma}_{F, s}^{2}$ are the residual variances of a univariate $\operatorname{AR}(1)$ for, respectively, each variable $j$ and each factor $s$ (computed using the prior mean of $B_{0}$ ). The parameter $\lambda_{a}$ is a tightness parameter, and $d$ is a decay parameter. We chose standard calibration borrowing from the VAR literature, i.e. $\lambda_{a}=0.2$ and $d=2$.

In the MAI-SV case, the prior for the elements of $G$ is a multivariate Normal distribution centered at zero, with large diagonal covariance matrix. In the MAI-SVCV case, the prior of the initial vector $g_{0}$ is a multivariate normal centered at zero with identity matrix. The prior for $\sigma_{0}$ is a multivariate normal, centered at $\left[\widehat{\sigma}_{y, 1}^{2}|\ldots| \widehat{\sigma}_{y, n}^{2 \prime}\right]^{\prime}$, with identity covariance matrix, as in Primiceri (2005). Prior distributions for innovation covariance matrices $Q_{g}$ and $Q_{\sigma}$ are calibrated as in de Wind \& Gambetti (2014) and Primiceri (2005). 


\subsection{Gibbs Sampler}

This subsection describes the main steps of the Gibbs Sampler used to simulate from the joint posterior distribution of both parameters and unobservable states of the MAI-SV and MAI-SVCV models. When drawing the volatility states, the algorithm makes use of the approximation of Omori et al. (2007), which requires drawing a set of mixture states $\left\{S_{t}\right\}_{t=1}^{T}$.

The algorithm is more general than the one presented in Carriero et al. (2016) since it introduces the step to draw the time-varying volatilities, following Primiceri (2005) and Del Negro \& Primiceri (2015). A Markov Chain of 10 thousand draws (with additional $30 \%$ initial draws discarded as burn-in) is simulated to obtain the posterior distributions of the coefficients and unobservable states. Convergence statistics confirm that convergence has been achieved and mixing is good.

The Gibbs Sampler steps for the MAI-SV model are:

1. Draw a history of volatilities $\left\{\sigma_{t}\right\}_{t=1}^{T} \mid \theta,\left\{S_{t}\right\}_{t=1}^{T}$,

2. Draw $\theta,\left\{S_{t}\right\}_{t=1}^{T} \mid\left\{\sigma_{t}\right\}_{t=1}^{T}$. This second step is further split as follows:

(a) Draw the elements in $\theta \mid\left\{\sigma_{t}\right\}_{t=1}^{T}$

i. Draw the covariance of volatilities' innovations $Q_{\sigma} \mid A, B_{0}, G,\left\{\sigma_{t}\right\}_{t=1}^{T}$

ii. Draw the loadings $A \mid B_{0}, G, Q_{\sigma},\left\{\sigma_{t}\right\}_{t=1}^{T}$,

iii. Draw the factor weights $B_{0} \mid A, G, Q_{\sigma},\left\{\sigma_{t}\right\}_{t=1}^{T}$,

iv. Draw the off-diagonal elements in $G \mid A, B_{0}, Q_{\sigma},\left\{\sigma_{t}\right\}_{t=1}^{T}$

(b) Draw a history of indexes of the mixture in $\left\{S_{t}\right\}_{t=1}^{T} \mid \theta,\left\{\sigma_{t}\right\}_{t=1}^{T}$

In the MAI-SVCV model, instead of drawing the time invariant off-diagonal elements in $G$, we need to draw the unobservable states $\left\{g_{t}\right\}_{t=1}^{T}$ and the covariance matrix of their innovations $Q_{g}$. The augmented sampler encompasses the following steps:

1. Draw a history of volatilities $\left\{\sigma_{t}\right\}_{t=1}^{T} \mid \theta,\left\{S_{t}\right\}_{t=1}^{T}$

2. Draw $\theta,\left\{S_{t}\right\}_{t=1}^{T} \mid\left\{\sigma_{t}\right\}_{t=1}^{T}$. This second step is further split as follows:

(a) Draw the elements in $\theta \mid\left\{\sigma_{t}\right\}_{t=1}^{T}$

i. Draw the covariance of volatilities' innovations $Q_{\sigma} \mid A, B_{0},\left\{g_{t}\right\}_{t=1}^{T}, Q_{g},\left\{\sigma_{t}\right\}_{t=1}^{T}$

ii. Draw the loadings $A \mid B_{0},\left\{g_{t}\right\}_{t=1}^{T}, Q_{g}, Q_{\sigma},\left\{\sigma_{t}\right\}_{t=1}^{T}$, 
iii. Draw the factor weights $B_{0} \mid A,\left\{g_{t}\right\}_{t=1}^{T}, Q_{g}, Q_{\sigma},\left\{\sigma_{t}\right\}_{t=1}^{T}$,

iv. Draw the TV off-diagonal elements $\left\{g_{t}\right\}_{t=1}^{T} \mid A, B_{0}, Q_{g}, Q_{\sigma},\left\{\sigma_{t}\right\}_{t=1}^{T}$,

v. Draw the covariance of TV off-diagonal elements $Q_{g} \mid A, B_{0},\left\{g_{t}\right\}_{t=1}^{T}, Q_{\sigma},\left\{\sigma_{t}\right\}_{t=1}^{T}$,

(b) Draw a history of indexes of the mixture in $\left\{S_{t}\right\}_{t=1}^{T} \mid \theta,\left\{\sigma_{t}\right\}_{t=1}^{T}$

The Gibbs Sampler steps for the MAI-SV and the MAI-SVCV are described in detail in sections A and B of the Appendix.

\section{Empirical Results}

\subsection{Data and model specification}

We collected from the FRED database 20 monthly macroeconomic variables for the period from January 1964 to December 2016. The selected series coincide with those in Bańbura, Giannone \& Reichlin (2010) and CKM16. The first 84 observations, from January 1964 to December 1970, are used as training sample to calibrate the prior distributions, while the rest of the sample is used in estimation. The variables are used in differences, standardized and demeaned. We set the number of lags to 13, following common practice for Bayesian VARs at monthly frequency.

Following CKM16, we select a specification using 3 factors. The first factor is a real factor, gathering information from the real economic activity variables; the second factor is a nominal factor, representing changes in price dynamics; the third factor is a monetary/financial factor. Table 1 lists the variables and their factor grouping ${ }^{10}$.

\subsection{Identifying the structural shocks and their effects}

In this section we discuss the identification of demand, supply and monetary/financial shocks, and their effects on the variables under analysis.

The estimated factors are reported in Figure 1, along with NBER recessions (as shaded areas) and the uncertainty events highlighted in Bloom (2009) (as black lines). Due to the

\footnotetext{
${ }^{10}$ Carriero et al. (2019) estimate a BVAR with independent stochastic volatilities for 125 variables (including macroeconomic indicators, an array of interest rates, some stock return measures, and exchange rates). A factor analysis of the volatilities indicates two components to account for the vast majority of innovations to volatilities. Here, we use three rather than two factors, even if the number of variables is smaller, to get robustness to potential omission of a third factor, as the third factor is significant in the conditional means, and the three factors can be given a meaningful economic interpretation as real, nominal and financial factors. Computing the first three principal components of the median volatility of residuals, we are able to explain more than $90 \%$ of time variation across the sample, in line with Carriero et al. (2019).
} 
definition of factors and estimated coefficients, improved economic conditions are associated with higher demand factor and lower supply and monetary/financial factors. The factors are reaching extreme values during the Oil crisis in the 1970s and in correspondence of the Great Financial Crisis, while from the mid 1980s to the early 2000s they appear less volatile (Great Moderation), even in case of recessions and rare events. It is interesting to notice how the demand and supply factors seem negatively correlated in case of supply-driven recessions, as the Oil crises, and positively correlated in other recessions as the recent Great Financial Crisis.

Structural analysis can be performed similarly as in FAVARs applications. Indeed, as shown before, the factors' law of motion is given by (4) where the variance of the shocks $\omega_{t}$ is given by $\Xi_{t} \equiv B_{0} \Omega_{t} B_{0}^{\prime}$, and where the factors are ordered as real, nominal and monetary / financial. Differently from FAVAR models, this model features observable factors (since $F_{t}=B_{0} y_{t}$ ) and heteroskedasticity in the factor innovations $\omega_{t}$.

From an economic perspective, it makes sense to expect that real activity variables take some time to react to exogenous changes in prices, while prices are likely to react contemporaneously to changes in real activity. Financial variables are likely to react immediately to changes in prices and real activity. These considerations support the use of a simple Cholesky scheme for the factor VAR in which the real activity factor is ordered first, the nominal factor second, and the financial factor is ordered last.

This identification scheme provides three orthogonal structural shocks, each featuring time-varying volatility. The posterior median of the volatilities of the structural shocks to the factors, and their posterior $68 \%$ credible bounds are reported in Figure 2, along with NBER recessions and Bloom (2009) uncertainty events. The Great Moderation is evident for all shocks, but the volatility of supply and financial shocks seems to increase again from the mid-90s, and all volatilities peak during the recent Global Financial Crisis.

From an economic point of view, the volatility of the structural demand shock could be related to changes in the inventory mechanism (e.g., McConnell \& Perez-Quiros, 2000) or to the globalization process (e.g., Bianchi \& Civelli, 2015), while that of the supply shock can depend on the behavior of the oil market (e.g., Lee et al., 1995) or on firms' productivity (e.g., Christiano et al., 2010), and the volatility of the financial/monetary shock can be influenced by financial innovation (e.g., Dynan et al., 2006) or by changes in the conduct of monetary policy (e.g., Clarida et al., 2000). Justiniano \& Primiceri (2008) introduce a DSGE model with stochastic volatility in several structural shocks. Specifically, they find that a reduction in the variance of investment shocks, interpreted also as a proxy for unmodeled financial frictions, is the main driver of the US Great Moderation, with a limited role for changes in monetary policy. Their evidence is somewhat in line 
with the gradually decreasing role of the monetary/financial shock contribution from the 1980s to the Great Financial Crisis in our common volatility decomposition. However, our structural decomposition is based on the common part of the volatility which is only a fraction of the total volatility. Moreover, Benati \& Surico (2009) show that it can be difficult to map changes in the variance of structural VAR shocks with those in DSGE models.

Fernández-Villaverde et al. (2015) estimate a DSGE model with stochastic volatilities similar to that of Justiniano \& Primiceri (2008), but using a second order approximation of the equilibrium dynamics of the economy. This approach allows changes in shock volatilities to directly affect the equilibrium solution along with the shocks, contrarily to the case of a first-order approximation of the solution. The model is estimated using a non-Bayesian methodology. In light of these methodological differences, the estimated stochastic volatilities of structural shocks show some discrepancies to analogous measures in Justiniano \& Primiceri (2008). Moreover, they don't report the contribution of stochastic volatilities in explaining unconditional variances of the observable variables. In general, they find that "the 1970s and the 1980s were more volatile than the $1960 \mathrm{~s}$ and the 1990s, creating a tougher environment for monetary policy", which is in line with our results.

We can also compare these volatilities with the uncertainty estimates of Carriero et al. (2018). Our demand factor volatility appears much correlated with their macro uncertainty estimate, even though the only large volatility spike after 1970s is observed in correspondence of the last Great Financial Crisis, and our measure of demand factor volatility reaches record lows in the end of 2016. The supply factor volatility shows a smaller degree of time variation than the demand factor during the Great Moderation, but it has been changing more since the spike of 2008, probably because of large fluctuations in commodity prices in the last years. As for the financial/monetary factor volatility, the largest spike throughout the sample is reasonably observed in coincidence of the years 2008-2009, differently from Carriero et al. (2018) financial uncertainty estimate, for which there is a comparable spike also in the early 2000s. It is interesting to observe how volatility of the monetary/financial factor is increasing in the years 2013-2016, most likely because of increased volatilities of bond yields and exchange rates.

Figure 3 reports the dynamic response of each factor after each structural shock (posterior median), measured at the NBER troughs, to assess whether there are differences across the various recessions. A (positive) demand shock boosts the output factor, the financial factor and, to a lesser extent, the price factor; a (negative) supply shock increases prices, reduces the real output factor, and overall has non significant effects on 
the financial factor; finally, a (negative) financial shock lowers the real output factor and has non-significant effects on the price factor. The fact that the estimated responses are in line with economic theory provides support for the use of our Choleski identification scheme for this application.

The temporal heterogeneity in the responses is due to different shocks' sizes (i.e. their standard deviations) and also to the time-varying simultaneous relations across variables. The price factor displays the larger degree of time variation in median posterior responses, especially at larger horizon, even though these differences among NBER troughs are barely significant when estimation uncertainty is taken into account.

Using the factor representation, it is possible to compute the response of variables $y_{t}$ to the structural shocks, again as in FAVAR models. Figures 4,5 and 6 report the responses of all variables to, respectively, the identified demand, supply and financial shocks, at the NBER troughs. The responses are broadly in line with those in CKM16: a demand shock increases output variables and decreases unemployment, and triggers an increase of both prices and Fed Funds rate, along with an appreciation of the real exchange rate and a reduction in monetary indicators. The negative supply shock increases prices and worsens the real economy indicators. Interestingly, the response of the Fed Funds rate has an opposite sign in the last two recessions with respect to the previous recessions. Instead, in almost all cases there is a depreciation of the real exchange rate. Responses to the financial/monetary shock are also in line with economic theory: real variables decrease along with monetary aggregates, while the effects on prices are not significant. In terms of time variation, there are some differences in the responses at different NBER troughs, because of different shocks' size and changing simultaneous relationships. A demand shock in November 2009 has a larger effect on Industrial Production, Capacity Utilization and Housing Starts, while a monetary/financial shock in November 2001 has a large effect on stocks and macro variables. However, when considering estimation uncertainty, such time variation is not much significant.

To provide a different measure of time variation of the responses to the structural shocks, we have also computed the temporal evolution of the responses at fixed horizons of 1, 12 and 48 months. The estimated median responses, together with $68 \%$ bands, reported in Figure 11 to Figure 19 in section $\mathrm{C}$ of the Appendix are broadly in line with those commented above.

\subsection{Decomposing the Stochastic Volatilities}

In this section we use the decompositions discussed in Section 3 to assess the contributions of different sources of volatlity to the total volatility of the macroeconomic series. 
Figure 7 reports the stochastic volatilities for the 20 variables, estimated using the MAI-SVCV model. Stochastic volatilities appear to be significantly changing over time for all variables, highlighting the importance of allowing for a time-varying conditional variance in macro-financial applications. The Great Moderation is evident in variables such as employment, earnings, consumption, CPI and the PCE deflator. The recent financial crisis is associated with volatility peaks in many real and nominal variables, including employment, earning, consumption, industrial production, housing starts, CPI, PPI. Also for monetary/financial variables, volatility peaks during the last global crisis are particularly evident for the Fed Funds rate, stock prices, money measures and reserves.

We start applying the decomposition in (9) and (10) and partition each of the reduced form volatilities into the common component, driven by innovations to the three factors and interpretable as an uncertainty measure, and the idiosyncratic components, driven by the idiosyncratic innovations, $\psi_{t}$.

Figure 7 plots also the decomposition of the total volatility for each variable into the two orthogonal components. From a graphical inspection, the common component of volatility is dominant for most variables, but a non-negligible part of variation is also driven by the idiosyncratic component. In order to obtain a more precise measure of the contribution of each component, Figure 8 reports the time-varying percentage shares of explained volatility by the common and idiosyncratic components.

In the real activity variables, the common component of volatility seems to have diminished its importance over time for employment and, less so, for earnings, personal income, and consumption, with values well below $50 \%$ at the end of the sample. The fraction of volatility explained by the common component is much higher for industrial production and capacity utilization, but it drops substantially for both variables after the financial crisis, from values around $80-90 \%$ to slightly above $50 \%$. For the unemployment rate and housing starts, the fraction is instead stable at about $50 \%$ over the entire sample.

In the price variables, the fraction of their conditional time-varying volatility explained by the common shocks is rather stable and high, much more so for CPI and the PCE deflator than for PPI, but still well above $50 \%$ for the latter.

A similar pattern emerges also for the financial variables, with values around $50 \%$ for the Fed Funds rate and the 10 year T-Bond yield but, interestingly, much higher for the S\&P500, whose time-varying volatility seems to be substantially affected by economic shocks.

We further decompose the common component share of volatility into three orthogonal sub-components, each driven by the volatility of structural demand, supply and monetary/financial shocks identified in the previous subsection. Figure 9 reports the 
time-varying percentage contribution of each structural shock in determining the common component volatility.

In the real activity variables, demand shocks are clearly dominant for industrial production and capacity utilization. The same was true for employment at the beginning of the sample, but then the role of demand shocks has progressively declined in favor of supply and monetary/financial shocks, that combined explained more than $50 \%$ of the common volatility component of employment at the end of the sample. A declining role for demand shocks is evident, though milder, also for housing starts. Instead, for earning, income, consumption and unemployment the share of demand shocks is rather stable over time, below $50 \%$ for the three variables and close to $50 \%$ for unemployment. Supply and monetary/financial shocks explain a comparable fraction of the remaning common volatility component of these four variables.

In the price variables, supply shocks are dominant, in particular for CPI and the PCE deflator, with demand shocks ranked second and monetary/financial shocks third, though slightly more important for PPI.

In the financial variables, the contribution of the three types of structural shocks is overall comparable and rather stable over time. The volatility of the monetary / financial shock is particularly important to explain the common component of the S\&P500 volatility, but even for this variable it only explains about $50 \%$, with the other $50 \%$ close to equally split between demand and supply shocks.

Overall, the structural demand, supply and financial shocks appear as important drivers not only of the level of macroeconomic and financial variables but also of their changing conditional volatility. In fact, the volatility of demand, supply and monetary / financial shocks explains, in general, more than $50 \%$ of the overall volatility, with their relative importance being variable dependent and, sometimes, changing over time.

\subsection{Results for longer forecast horizons}

In Figures 10 and 11 we report the decomposition of the 12- and 36-steps ahead forecast error covariance matrices into common and idiosyncratic components (results for longer horizons are very similar to those for $h=36$ and are available upon request). It is interesting that for virtually all variables and periods the role of the common component of volatility becomes even larger at longer horizons, suggesting that common shocks are even more important than idiosyncratic shocks at long than at short horizons. Figures 12 and 13 further decompose the common volatility component into the contribution of the supply, demand and monetary / financial shocks' volatilities. The relative contribution of each shock is rather stable across forecast horizons, but it is worth mentioning the larger 
importance at longer horizon of supply and monetary shocks for industrial production, capacity utilization and unemployment.

\section{Conclusions}

Many economic variables feature changes in their conditional volatility, and stochastic volatility specifications are commonly used in macroeconomic applications to model this feature. In models with stochastic volatility, different shocks drive the levels and volatilities of the variables, with volatility shocks left unexplained. In this paper we decompose the shocks driving the volatility processes into the volatility of structural economic shocks, in order to understand the relative importance over time of demand, supply and monetary / financial shocks as drivers of volatility.

The structural shocks are obtained from a Multivariate Autoregressive Index (MAI) model, a particular reduced rank VAR that can be also interpreted as a factor model, featuring stochastic volatility, over a large set of real, nominal and financial indicators.

We have developed a Gibbs Sampling algorithm for (Bayesian) inference, introducing efficient strategies to reduce the computational burden.

Using the model with US data for the period 1964-2016, we have found that the common component of volatility is substantial, it explains at least $50 \%$ of the overall volatility for most variables, though the share is declining over time for some real variables. Moreover, a large fraction of the common volatility component is driven by the volatility of structural demand, supply and financial shocks, in general more than 50\%, with their relative importance being variable dependent and, sometimes, changing over time.

\section{Bibliography}

Abbate, A., Eickmeier, S., Lemke, W., \& Marcellino, M. (2016). The changing international transmission of financial shocks: Evidence from a classical time-varying favar. Journal of Money, Credit and Banking, 48(4), 573-601.

Ataei, A. (2014). Improved qrginv algorithm for computing moore-penrose inverse matrices. ISRN Applied Mathematics, 2014. Article ID 641706.

Bańbura, M., Giannone, D., \& Reichlin, L. (2010). Large bayesian vector auto regressions. Journal of Applied Econometrics, 25(1), 71-92.

Benati, L. \& Surico, P. (2009). Var analysis and the great moderation. The American Economic Review, $99(4), 1636-1652$. 
Bernanke, B. S., Boivin, J., \& Eliasz, P. (2005). Measuring the effects of monetary policy: a factor-augmented vector autoregressive (favar) approach. The Quarterly journal of economics, 120(1), 387-422.

Bianchi, F. \& Civelli, A. (2015). Globalization and inflation: Evidence from a time-varying var. Review of Economic Dynamics, 18(2), 406-433.

Bloom, N. (2009). The impact of uncertainty shocks. Econometrica, 77(3), 623-685.

Bodnar, T. \& Okhrin, Y. (2008). Properties of the singular, inverse and generalized inverse partitioned wishart distributions. Journal of Multivariate Analysis, 99(10), 2389-2405.

Carriero, A., Clark, T. E., \& Marcellino, M. (2015). Bayesian vars: specification choices and forecast accuracy. Journal of Applied Econometrics, 30(1), 46-73.

Carriero, A., Clark, T. E., \& Marcellino, M. (2016). Common drifting volatility in large bayesian vars. Journal of Business \& Economic Statistics, 34(3), 375-390.

Carriero, A., Clark, T. E., \& Marcellino, M. (2018). Measuring uncertainty and its impact on the economy. The Review of Economics and Statistics, 100(5), 799-815.

Carriero, A., Clark, T. E., \& Marcellino, M. (2019). Large bayesian vector autoregressions with stochastic volatility and non-conjugate priors. Journal of Econometrics, 212(1), $137-154$.

Carriero, A., Kapetanios, G., \& Marcellino, M. (2011). Forecasting large datasets with bayesian reduced rank multivariate models. Journal of Applied Econometrics, 26(5), 735-761.

Carriero, A., Kapetanios, G., \& Marcellino, M. (2016). Structural analysis with multivariate autoregressive index models. Journal of Econometrics, 192(2), 332-348.

Carter, C. K. \& Kohn, R. (1994). On Gibbs Sampling for State Space Models. Biometrika, $81(3), 541-553$.

Centoni, M. \& Cubadda, G. (2003). Measuring the business cycle effects of permanent and transitory shocks in cointegrated time series. Economics Letters, 80(1), 45-51.

Christiano, L. J., Motto, R., \& Rostagno, M. (2010). Financial factors in economic fluctuations. ECB Working Paper, (No. 1192).

Clarida, R., Gali, J., \& Gertler, M. (2000). Monetary policy rules and macroeconomic stability: evidence and some theory. The Quarterly Journal of Economics, 115(1), $147-180$.

Clark, T. E. \& Ravazzolo, F. (2015). Macroeconomic forecasting performance under alternative specifications of time-varying volatility. Journal of Applied Econometrics, $30(4), 551-575$.

Cogley, T. \& Sargent, T. J. (2005). Drifts and volatilities: monetary policies and outcomes 
in the post wwii us. Review of Economic dynamics, 8(2), 262-302.

Corsello, F. (2018). Rank Reduction in BVARs with Time Varying Coefficients and Stochastic Volatility: Specification and Estimation. Bocconi University, mimeo.

D'Agostino, A., Gambetti, L., \& Giannone, D. (2013). Macroeconomic forecasting and structural change. Journal of Applied Econometrics, 28(1), 82-101.

de Wind, J. \& Gambetti, L. (2014). Reduced-Rank Time-Varying Vector Autoregressions. CPB Discussion Paper, (270).

Del Negro, M. \& Primiceri, G. E. (2015). Time varying structural vector autoregressions and monetary policy: a corrigendum. The Review of Economic Studies, 82(4), 13421345.

Diaz-Garcıa, J. A., Jáimez, R. G., \& Mardia, K. V. (1997). Wishart and pseudo-wishart distributions and some applications to shape theory. Journal of Multivariate Analysis, $63(1), 73-87$.

Dynan, K. E., Elmendorf, D. W., \& Sichel, D. E. (2006). Can financial innovation help to explain the reduced volatility of economic activity? Journal of Monetary Economics, 53(1), 123-150.

Eickmeier, S., Lemke, W., \& Marcellino, M. (2015). Classical time varying factoraugmented vector auto-regressive models - estimation, forecasting and structural analysis. Journal of the Royal Statistical Society: Series A (Statistics in Society), $178(3)$, 493-533.

Engle, R. F. (1982). Autoregressive conditional heteroscedasticity with estimates of the variance of united kingdom inflation. Econometrica, 50(4), 987-1007.

Fernández-Villaverde, J. \& Rubio-Ramírez, J. (2013). Macroeconomics and volatility: Data, models, and estimation. In Advances in Economics and Econometrics: Theory and Applications, Tenth World Congress of the Econometric Society, Cambridge University Press.

Fernández-Villaverde, J., Guerrón-Quintana, P., \& Rubio-Ramírez, J. F. (2015). Estimating dynamic equilibrium models with stochastic volatility. Journal of Econometrics, $185(1), 216-229$.

Fuller, W. A. (2009). Introduction to statistical time series, volume 428. John Wiley \& Sons.

Gelman, A., Carlin, J. B., Stern, H. S., Dunson, D. B., Vehtari, A., \& Rubin, D. B. (2014). Bayesian data analysis, volume 2. CRC press Boca Raton, FL.

Geweke, J. (1996). Bayesian reduced rank regression in econometrics. Journal of Econometrics, $75(1), 121-146$. 
Johansen, S. (1995). Likelihood-based inference in cointegrated vector autoregressive models. Oxford: Oxford University Press.

Jurado, K., Ludvigson, S. C., \& Ng, S. (2015). Measuring uncertainty. American Economic Review, 105(3), 1177-1216.

Justiniano, A. \& Primiceri, G. E. (2008). The Time-Varying Volatility of Macroeconomic Fluctuations. American Economic Review, 98(3), 604-41.

Kilian, L. \& Lütkepohl, H. (2017). Structural vector autoregressive analysis. Cambridge University Press.

Kim, S., Shephard, N., \& Chib, S. (1998). Stochastic volatility: likelihood inference and comparison with arch models. The Review of Economic Studies, 65(3), 361-393.

Lee, K., Ni, S., \& Ratti, R. A. (1995). Oil shocks and the macroeconomy: the role of price variability. The Energy Journal, 39-56.

Litterman, R. B. (1986). Forecasting with bayesian vector autoregressions-five years of experience. Journal of Business $\&$ Economic Statistics, 4 (1), 25-38.

Marcellino, M., Porqueddu, M., \& Venditti, F. (2016). Short-term gdp forecasting with a mixed-frequency dynamic factor model with stochastic volatility. Journal of Business Ef Economic Statistics, 34(1), 118-127.

McConnell, M. M. \& Perez-Quiros, G. (2000). Output fluctuations in the united states: What has changed since the early 1980's? American Economic Review, 90(5), 14641476 .

Omori, Y., Chib, S., Shephard, N., \& Nakajima, J. (2007). Stochastic volatility with leverage: Fast and efficient likelihood inference. Journal of Econometrics, 140(2).

Primiceri, G. E. (2005). Time Varying Structural Vector Autoregressions. The Review of Economic Studies, 72(3), 821-852.

Reinsel, G. (1983). Some results on multivariate autoregressive index models. Biometrika, $70(1), 145-156$.

Reinsel, G. \& Velu, R. (1998). Multivariate reduced-rank regression, volume 136 of lectures notes in statistics. New York: Springer-Verlag.

Sims, C. A. (1980). Macroeconomics and Reality. Econometrica, 48(1), 1.

Sims, C. A. \& Zha, T. (2006). Were there regime switches in us monetary policy? American Economic Review, 96(1), 54-81. 
Table 1: List of variables and composition of Factors

\begin{tabular}{|c|c|c|c|}
\hline Variable & F1 & F2 & F3 \\
\hline Employees (Total nonfarm) & 1 & 0 & 0 \\
\hline Average hourly earnings & $B_{0}^{(1,2)}$ & 0 & 0 \\
\hline Personal Income & $B_{0}^{(1,3)}$ & 0 & 0 \\
\hline Real Consumption & $B_{0}^{(1,4)}$ & 0 & 0 \\
\hline Industrial Production & $B_{0}^{(1,5)}$ & 0 & 0 \\
\hline Capacity Utilization & $B_{0}^{(1,6)}$ & 0 & 0 \\
\hline Unemployment rate & $B_{0}^{(1,7)}$ & 0 & 0 \\
\hline Housing starts & $B_{0}^{(1,8)}$ & 0 & 0 \\
\hline CPI all items & 0 & 1 & 0 \\
\hline Producer Price Index (Farm \& Foods) & 0 & $B_{0}^{(2,10)}$ & 0 \\
\hline Implicit price deflator for personal cons. exp. & 0 & $B_{0}^{(2,11)}$ & 0 \\
\hline Producer Price Index (Industrials) & 0 & $B_{0}^{(2,12)}$ & 0 \\
\hline Federal Funds, effective & 0 & 0 & 1 \\
\hline M1 money stock & 0 & 0 & $B_{0}^{(3,14)}$ \\
\hline M2 money stock & 0 & 0 & $B_{0}^{(3,15)}$ \\
\hline Total reserves of depository institutions & 0 & 0 & $B_{0}^{(3,16)}$ \\
\hline Nonborrowed reserves of depository institutions & 0 & 0 & $B_{0}^{(3,17)}$ \\
\hline S\&P's common stock price index & 0 & 0 & $B_{0}^{(3,18)}$ \\
\hline Interest rate on treasury bills, 10 year constant maturity & 0 & 0 & $B_{0}^{(3,19)}$ \\
\hline Effective Exchange rate & 0 & 0 & $B_{0}^{(3,20)}$ \\
\hline
\end{tabular}




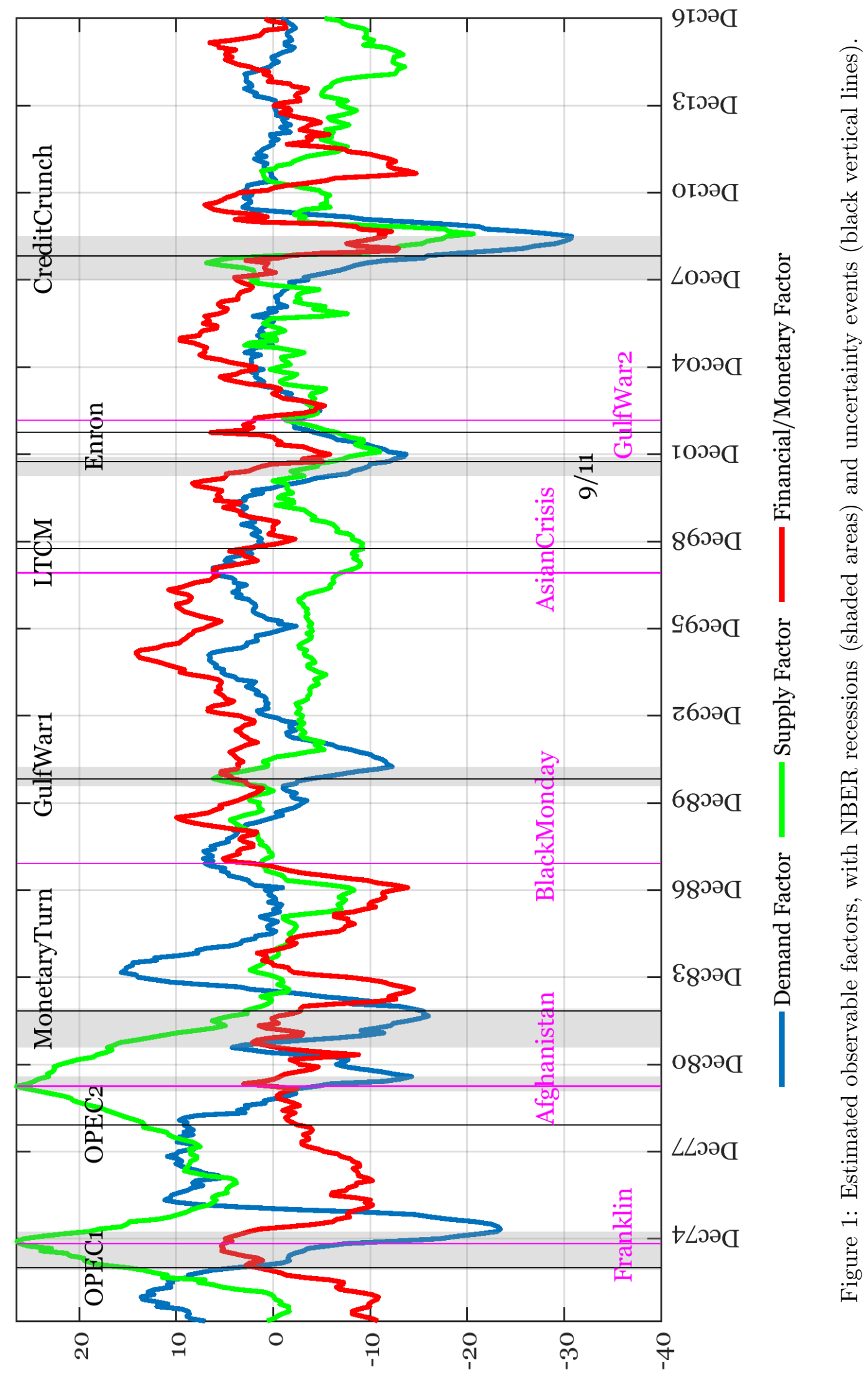



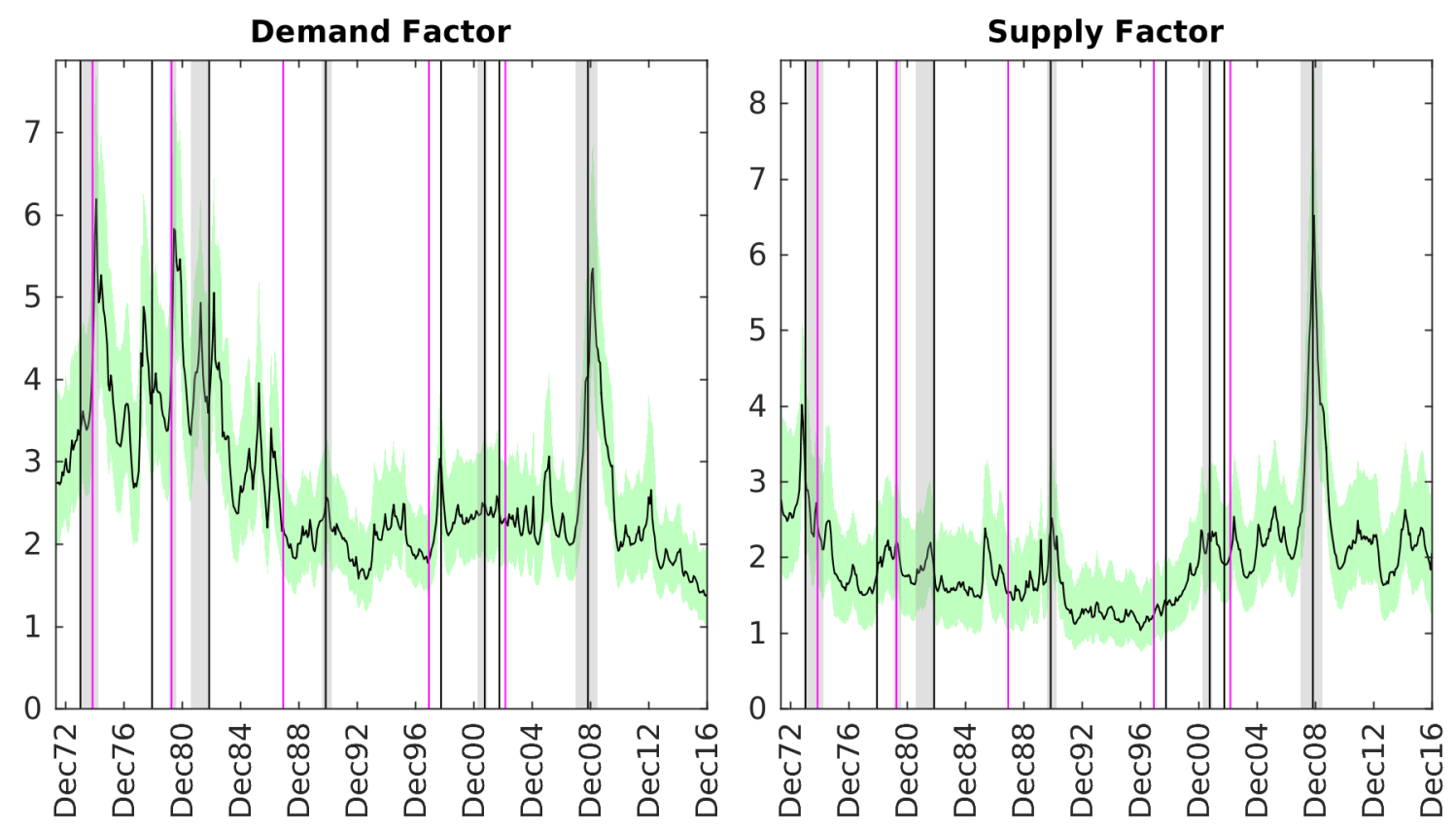

Financial/Monetary Factor

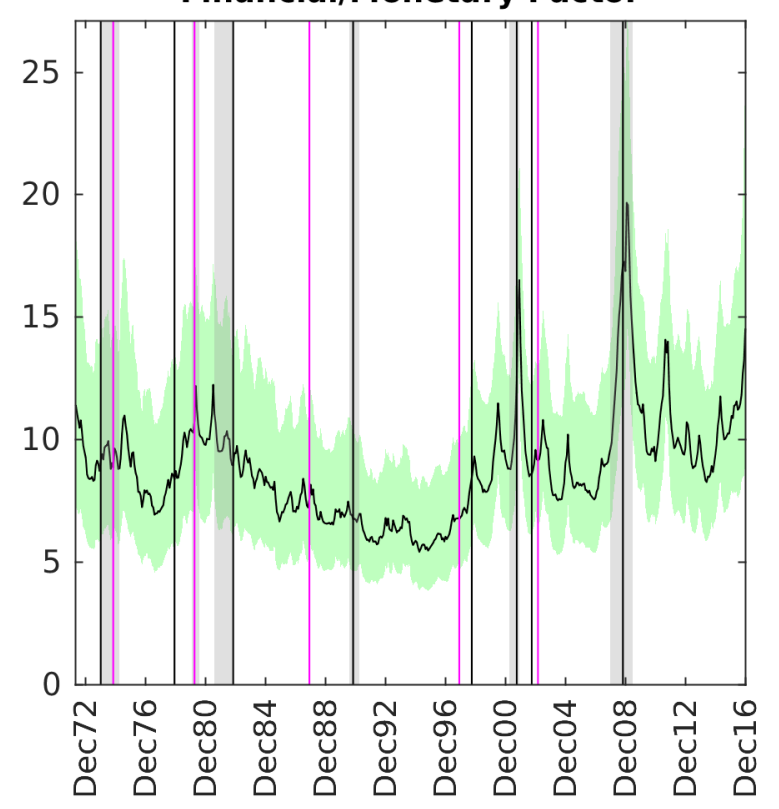

Figure 2: Volatilities of the structural shocks. Green Bands correspond to the $68 \%$ credible regions of the posterior distribution. 

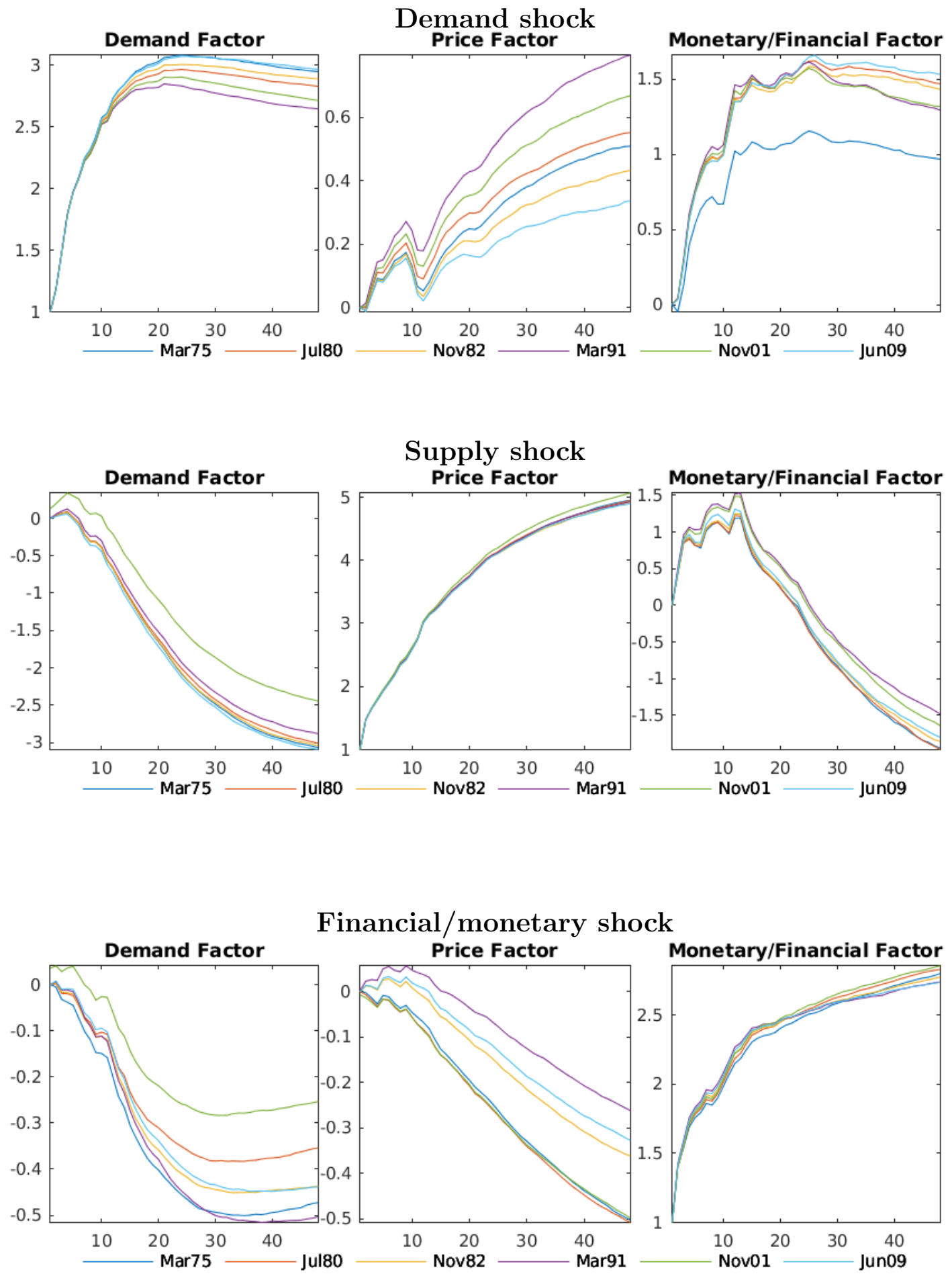

Figure 3: Response of each factor to all shocks at NBER troughs. Means of the posterior distribution. 

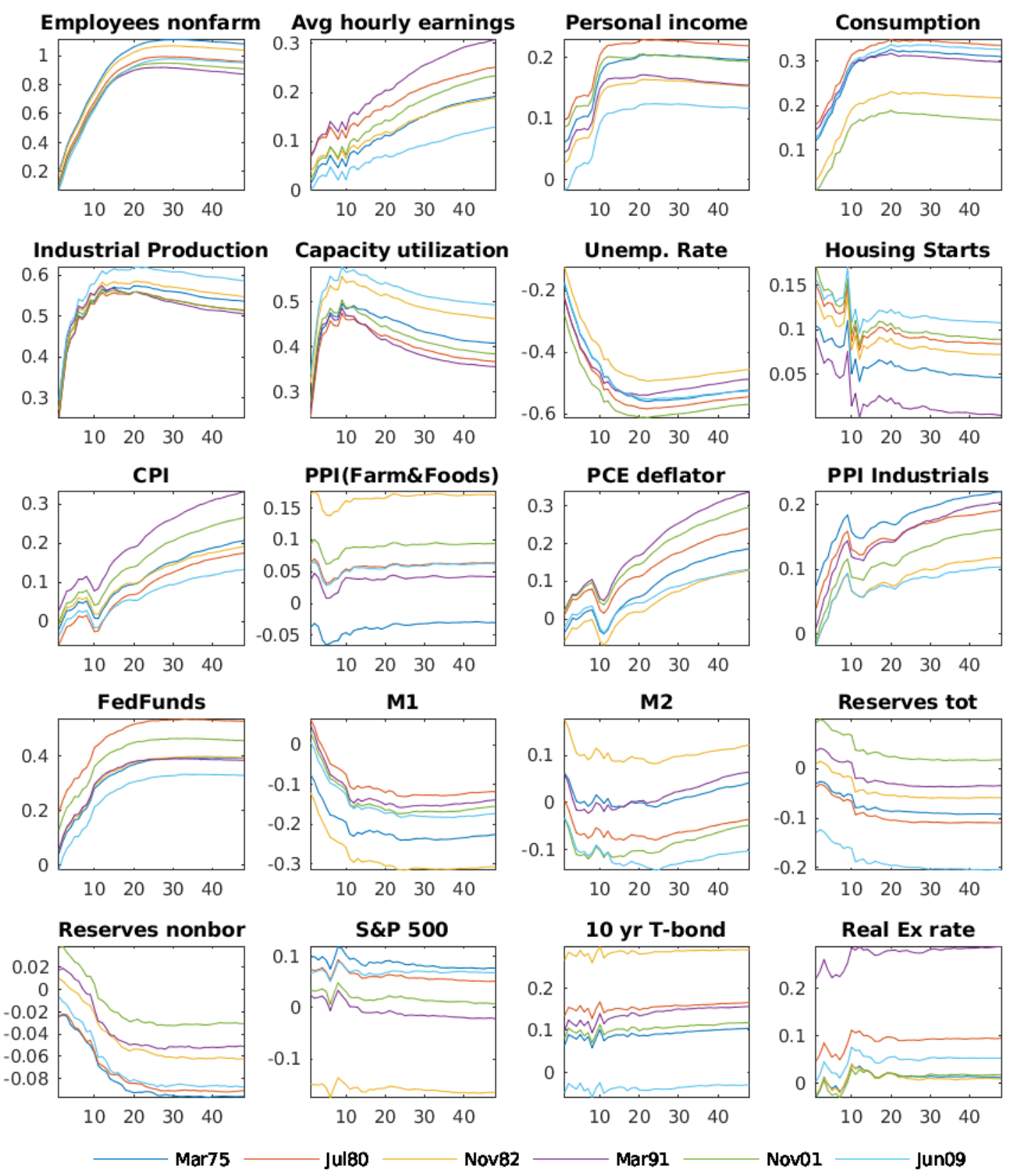

Figure 4: Response to a permanent Demand shock at NBER troughs. Means of the posterior distribution. 

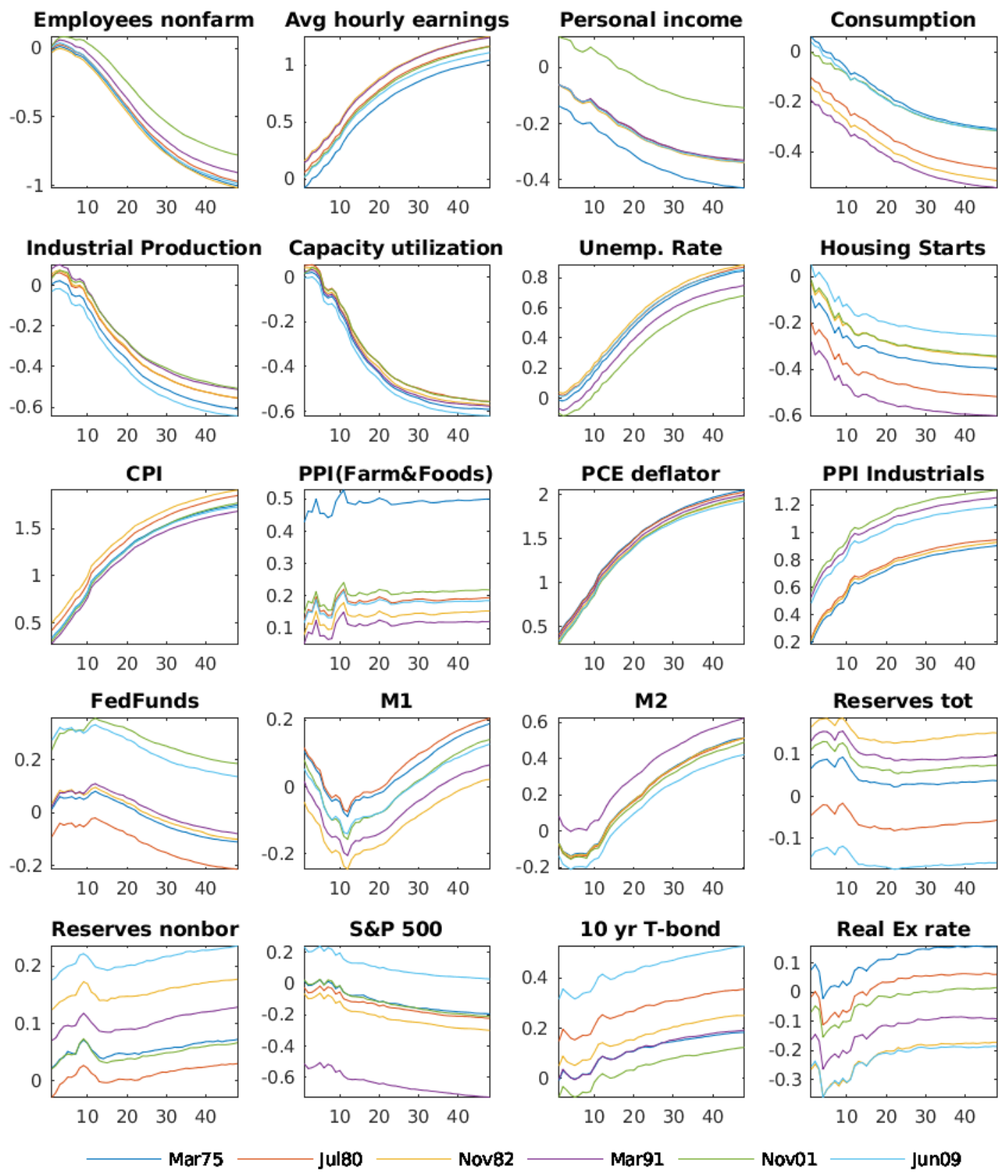

Figure 5: Response to a permanent Supply shock at NBER troughs. Means of the posterior distribution. 

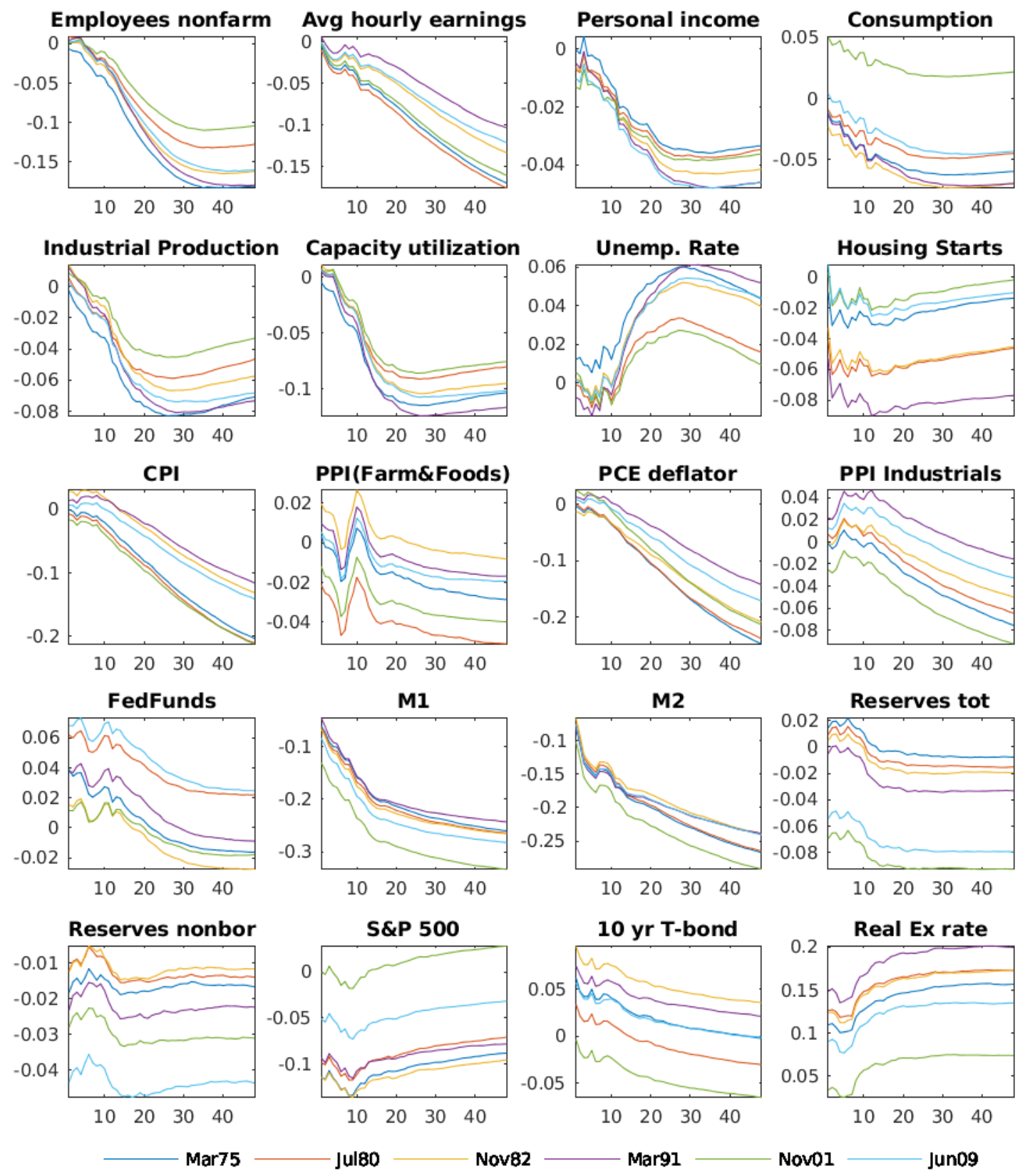

Figure 6: Response to a permanent Financial shock at NBER troughs. Means of the posterior distribution. 


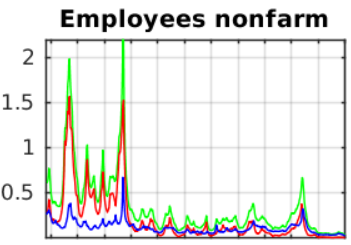

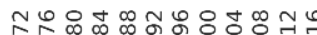

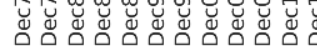

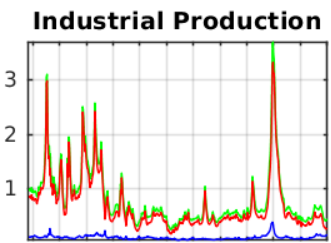

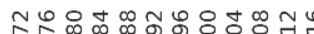

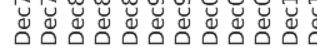

CPI

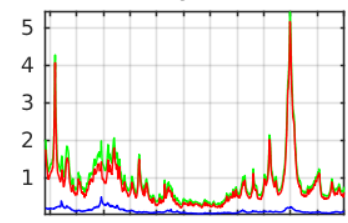

우요 ه
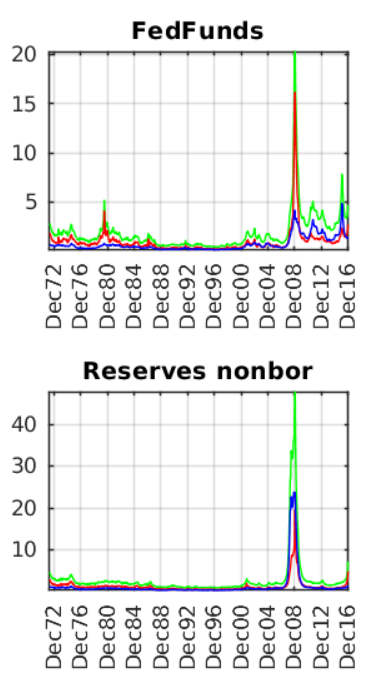

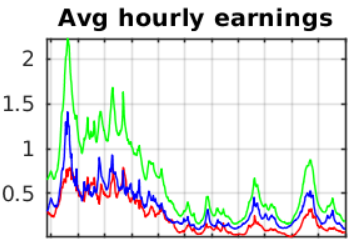

N 过

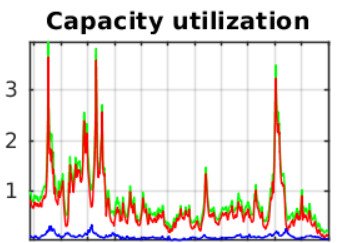

N $0 \circ+\infty N \varphi \circ+\infty$

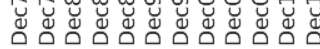

PPI(Farm\&Foods)

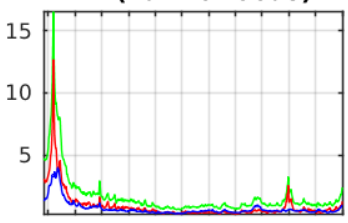

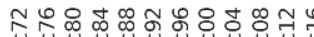

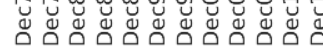

M1

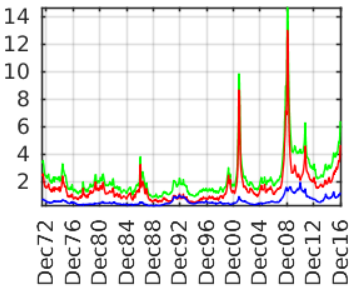

S\&P 500

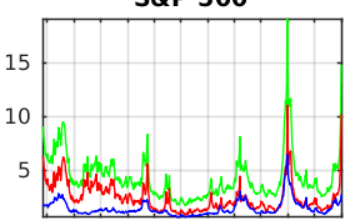

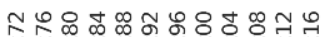

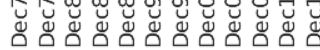

Personal income

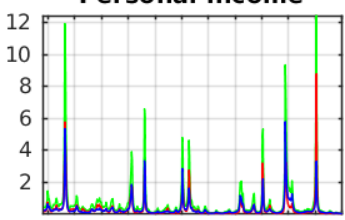

No

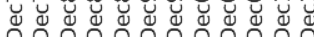

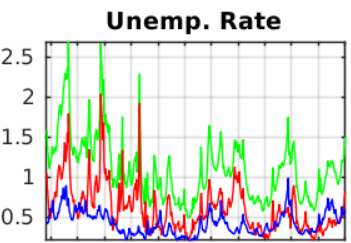

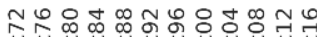

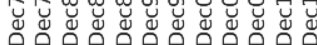

PCE deflator

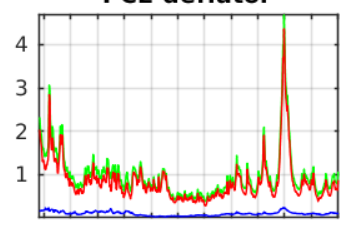

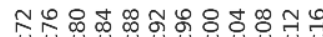

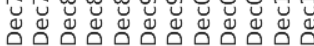

M2

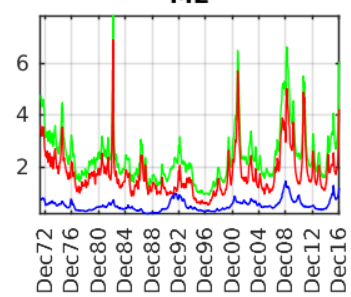

10 yr T-bond

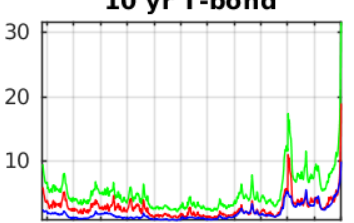

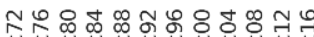

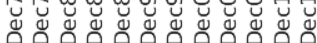

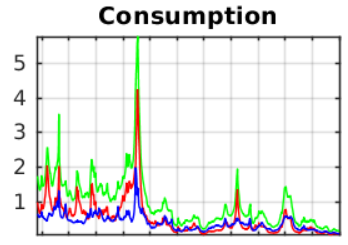

N

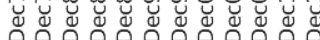

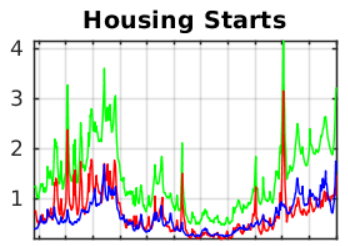

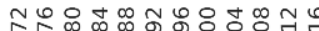

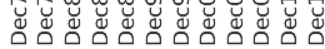

PPI Industrials

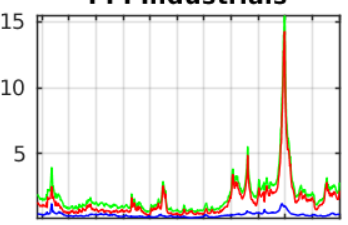

N ڤั

Reserves tot

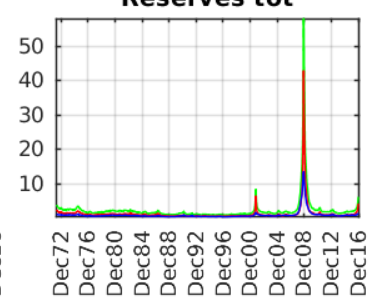

Real Ex rate

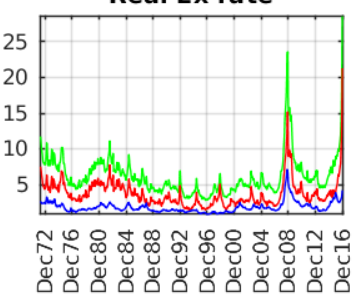

Figure 7: Residual volatility and its decomposition: total (green), common factors (red), Idiosyncratic (blue) 

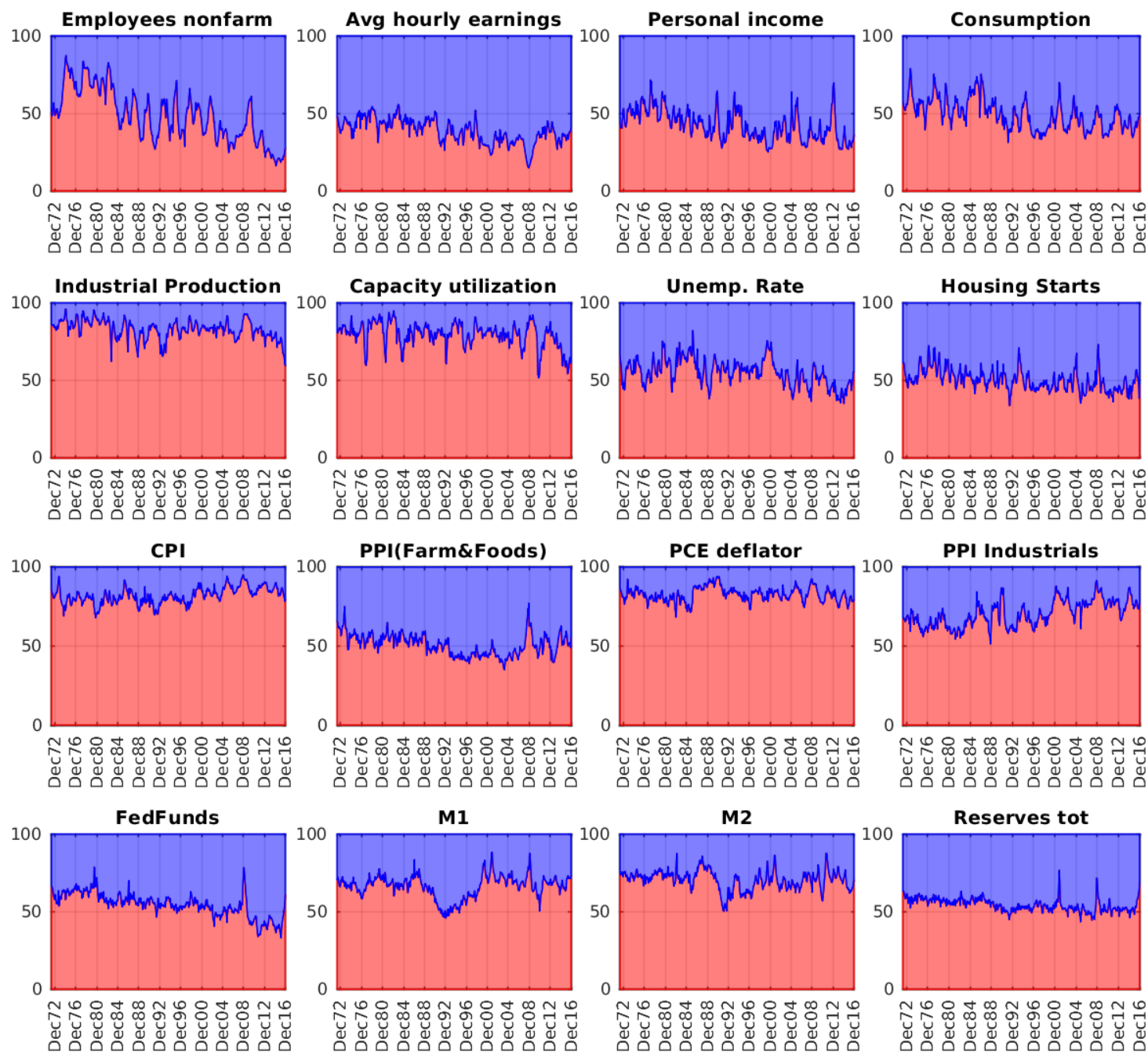

Reserves tot
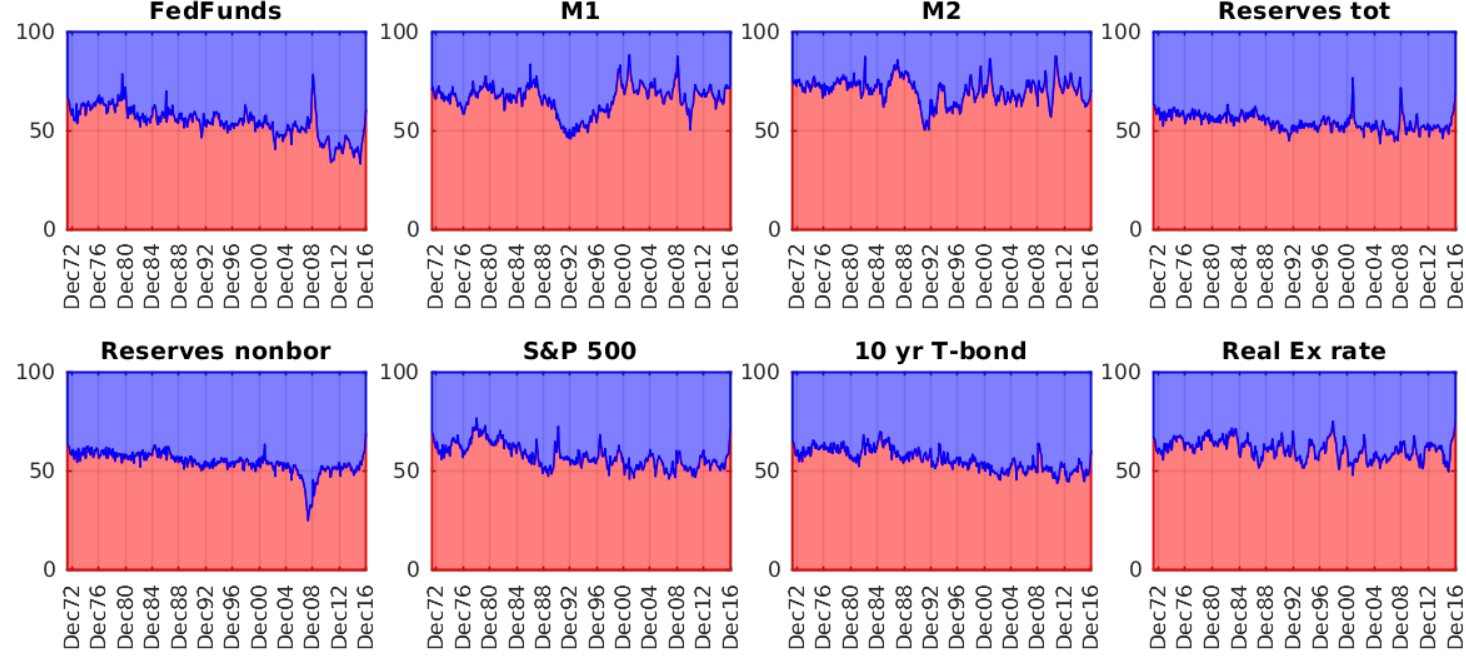

Figure 8: Residual volatility shares (\%): common factors (red), Idiosyncratic (blue) 

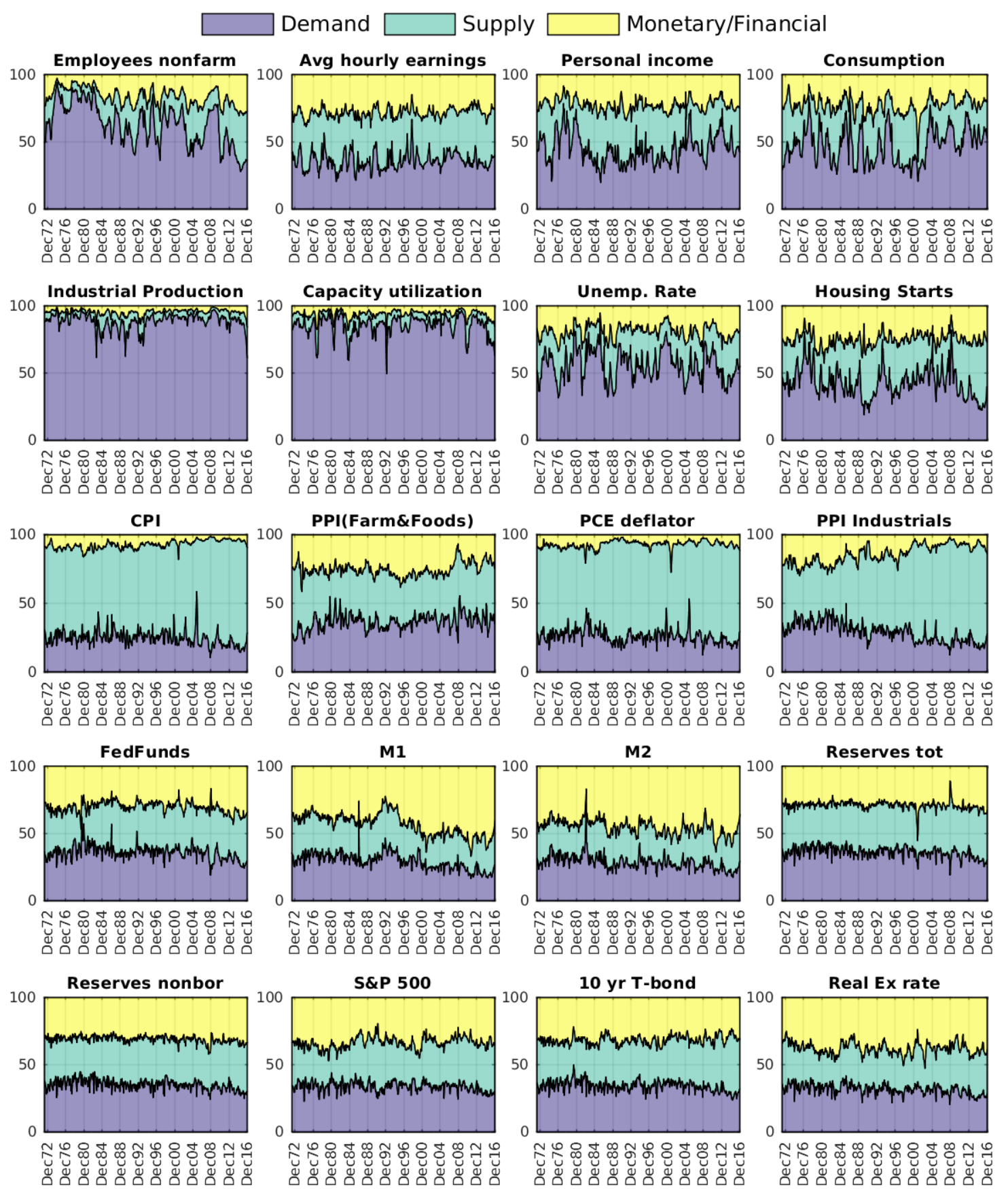

Figure 9: Contribution (\%) of the identified shocks over the common factor component of residual volatility 

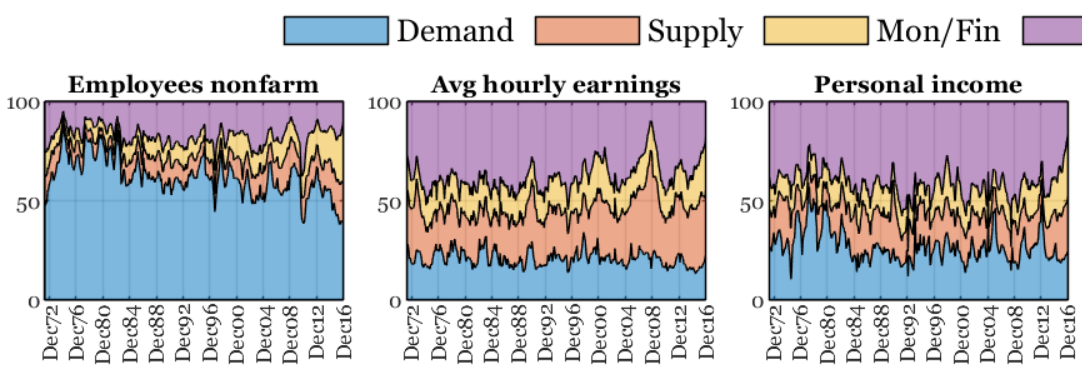

Idio
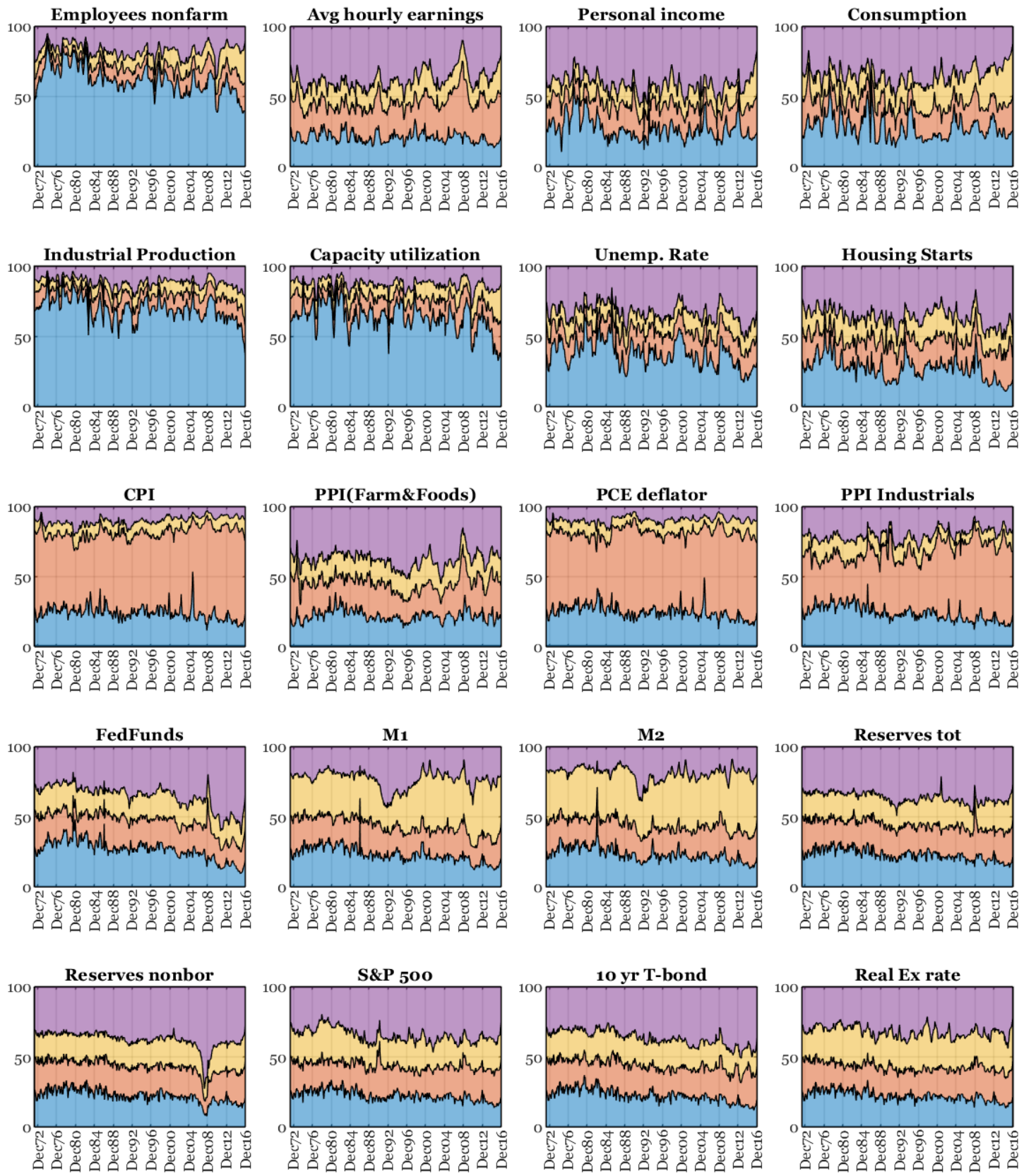

Figure 10: Contribution (\%) of the common and idiosyncratic components to the 12-steps ahead forecast error variance 


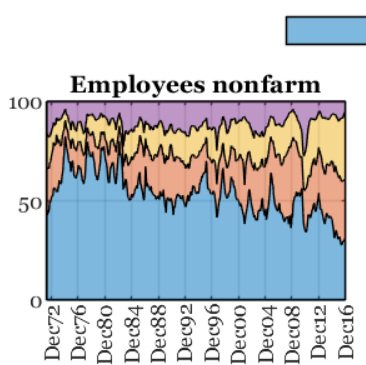

Demand $\square$ Supply

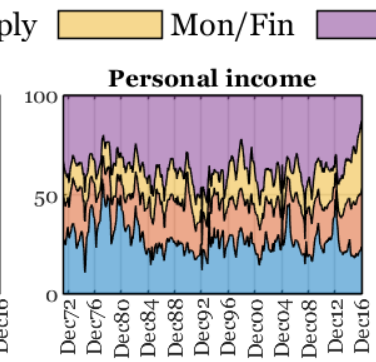
Idio
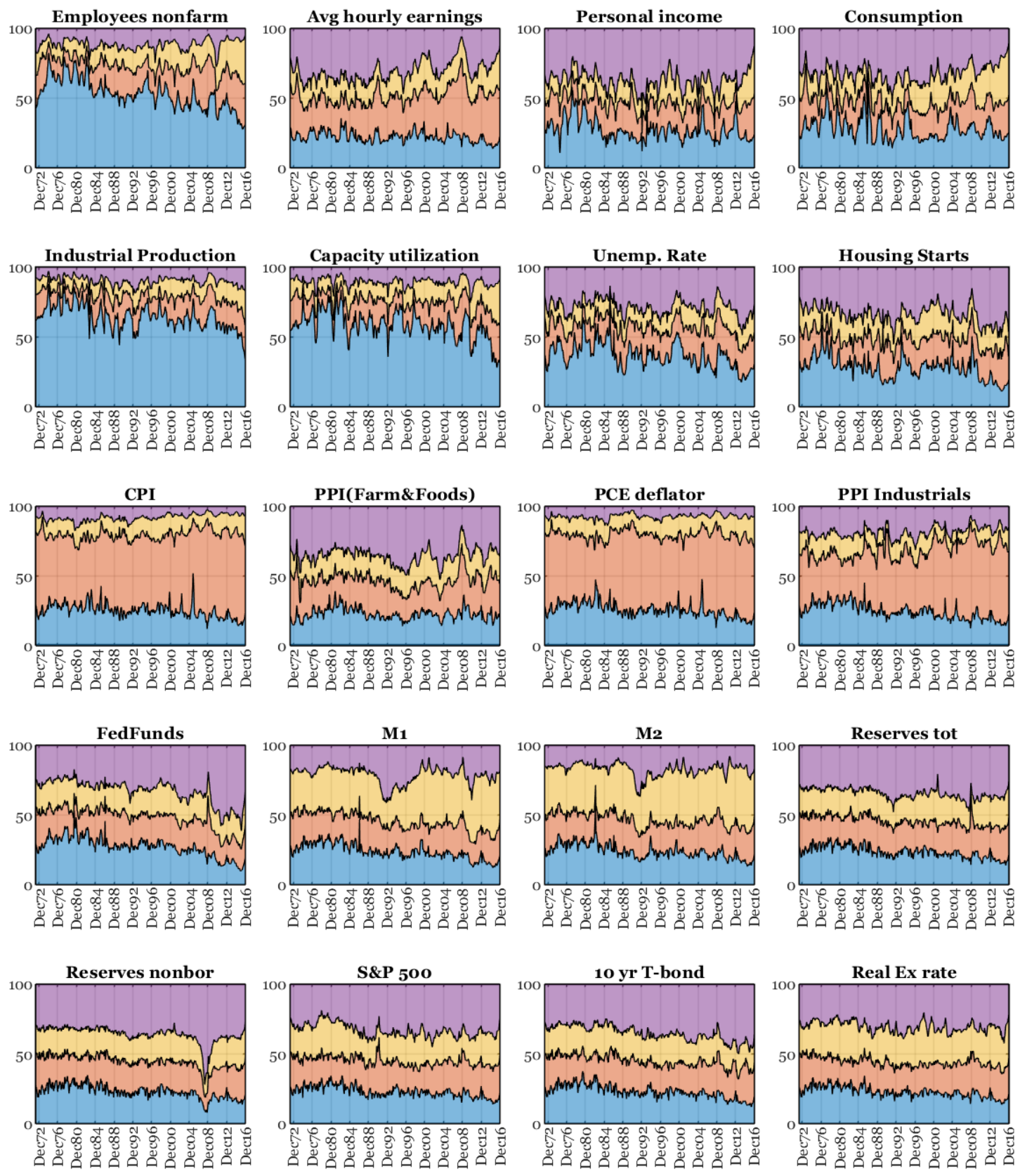

Figure 11: Contribution (\%) of the common and idiosyncratic components to the 36-steps ahead forecast error variance 
Demand
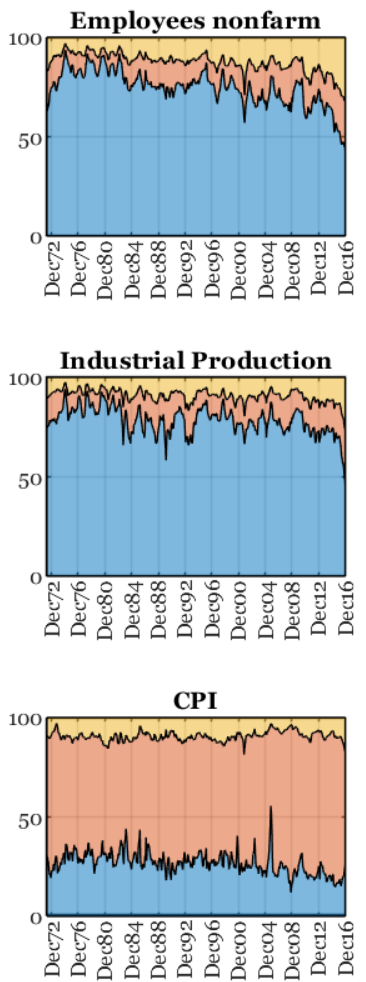

FedFunds
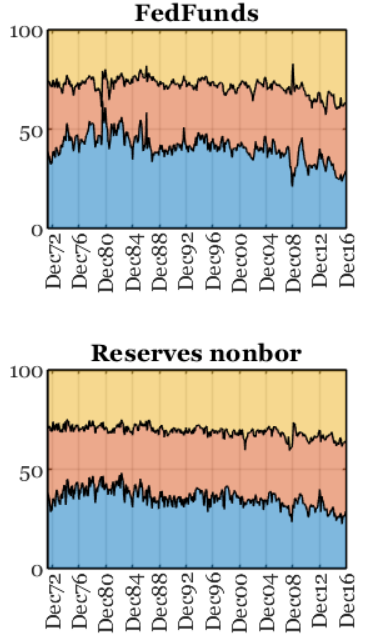

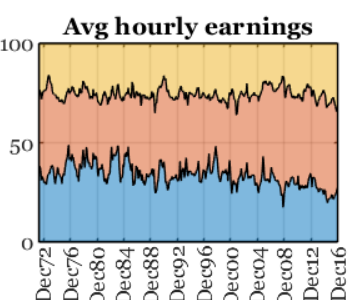

Capacity utilization

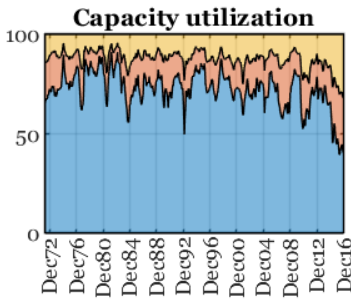

PPI(Farm\&Foods)

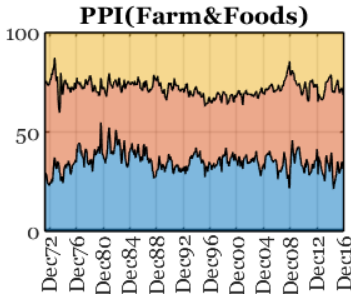

M1

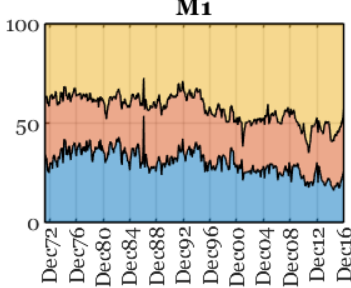

S\&P 500

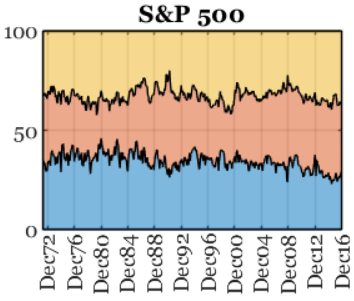

Supply $\square$ Mon/Fin
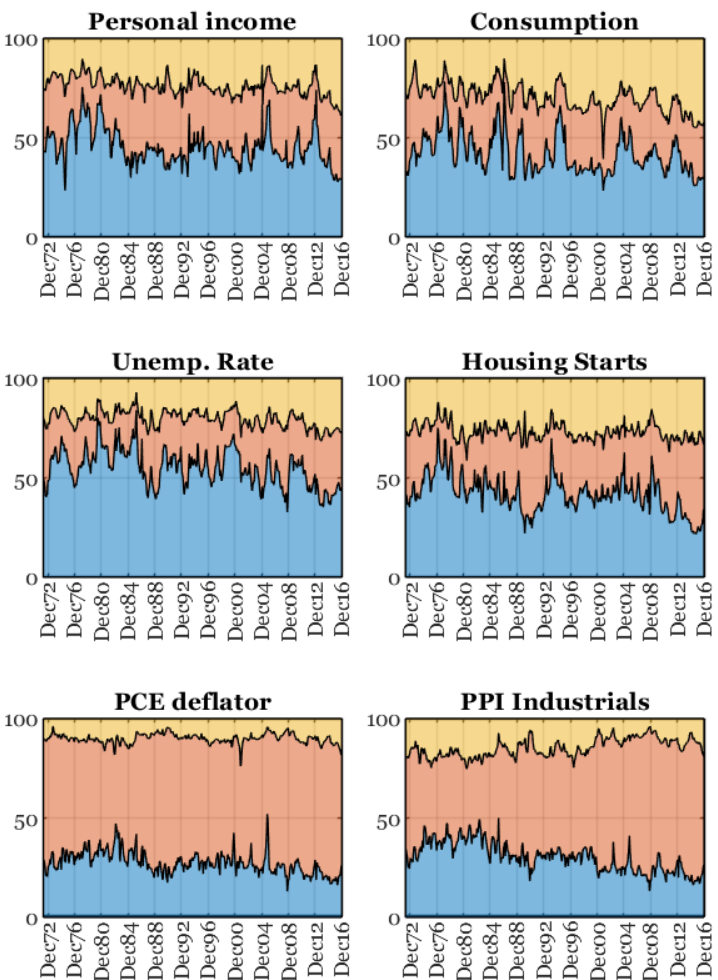

Reserves tot
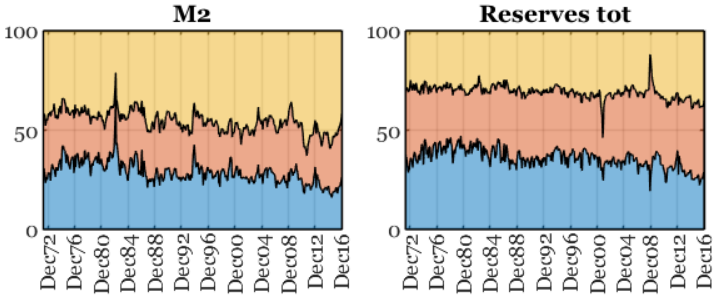

Real Ex rate
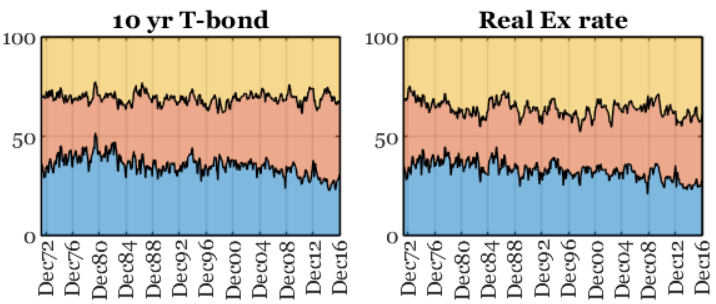

Figure 12: Contribution (\%) of the identified shocks over the common factor component to the 12 -steps ahead forecast error variance 
Demand
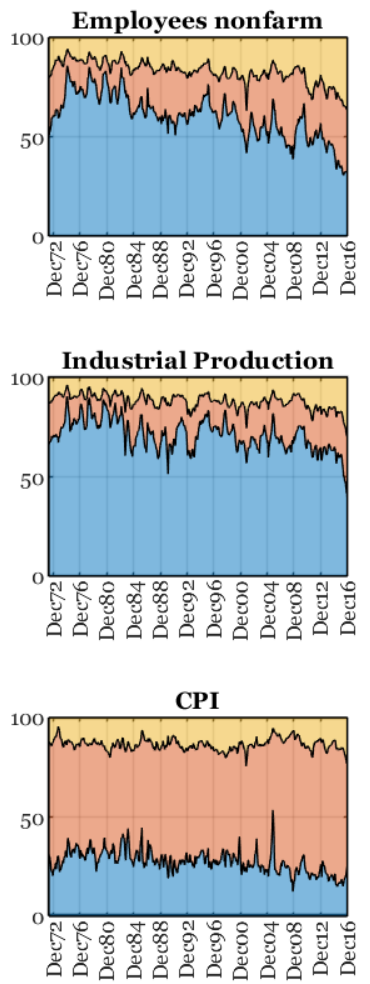

FedFunds
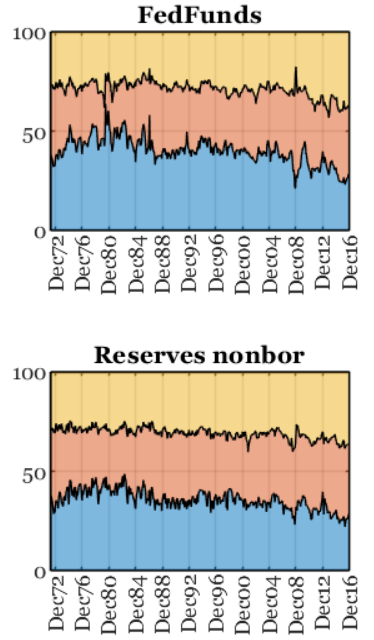

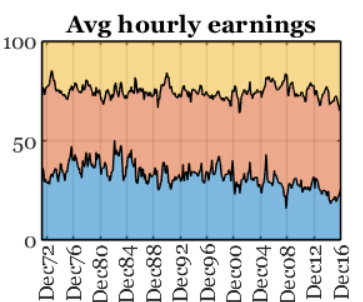

Capacity utilization

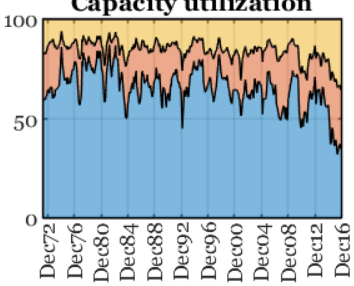

PPI(Farm\&Foods)

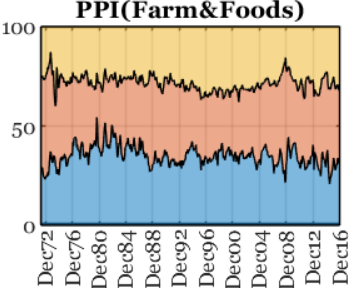

M1

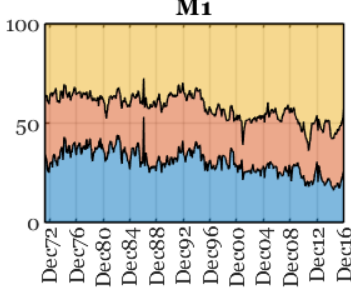

S\&P 50o

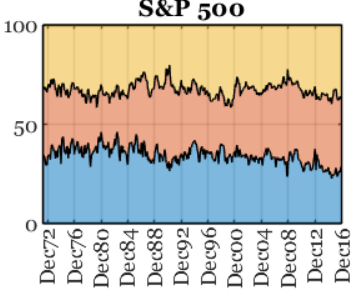

Supply $\square$ Mon/Fin
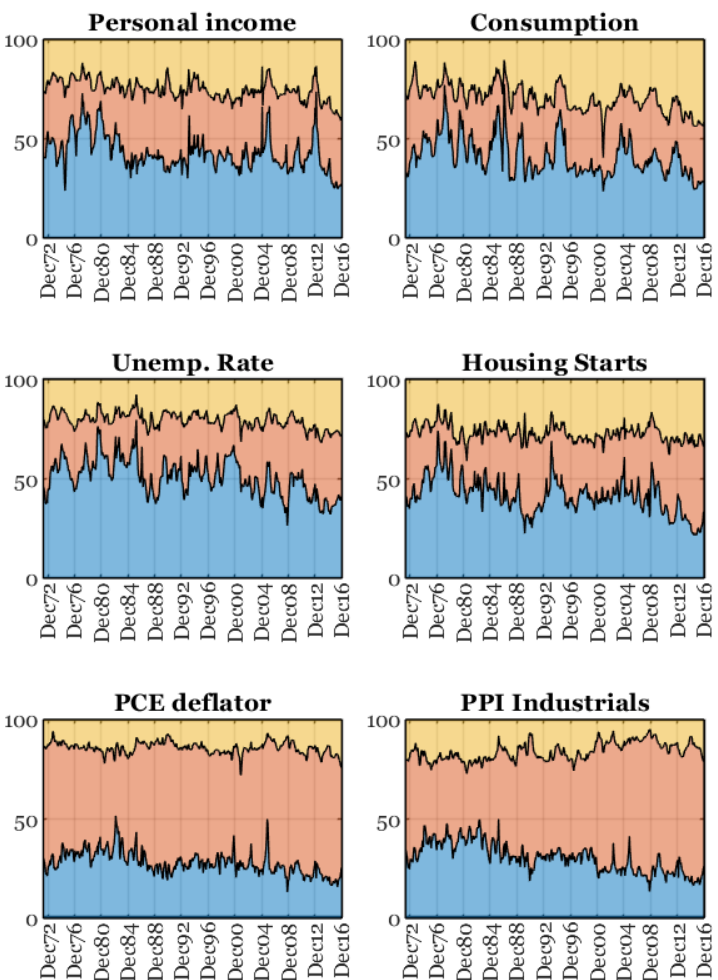

M2

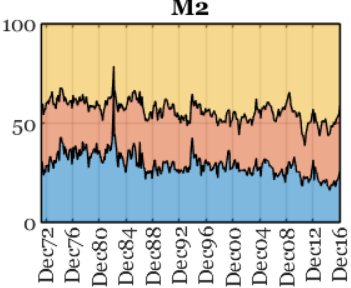

Reserves tot

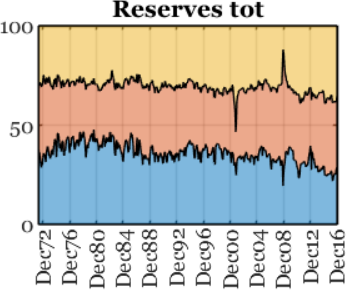

Real Ex rate
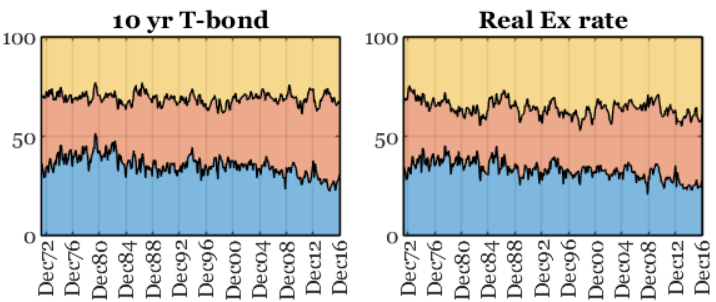

Figure 13: Contribution (\%) of the identified shocks over the common factor component to the 36 -steps ahead forecast error variance 


\section{Online Appendix for \\ "The Economic Drivers of Volatility and \\ Uncertainty"}

The four sections of this online Appendix provide additional details on Gibbs Sampler algorithm for the MAI-SV and MAI-SVCV models (Appendix A, B and C), and some additional figures for the empirical application (Appendix D).

\section{Appendix A Detailed steps of the Gibbs Sampler for the estimation of the MAI-SV model}

\section{A.1 Stacking of the model}

The observation equation of the MAI-SV model written as:

$$
\underbrace{y_{t}}_{n \times 1}=\sum_{\ell=1}^{p} \underbrace{A_{\ell}}_{n \times r} \cdot \underbrace{B_{0}}_{r \times n} y_{t-\ell}+u_{t}
$$

establishes that the observables in $y_{t}$ depend on $p$ lags of the $r$ common components $B_{0} \cdot y_{t-\ell}$, plus an error term. The equation in 11 can be stated in a more compact formulation.

Defining the $n \times r p$ matrix $A \equiv\left[\begin{array}{lll}A_{1} & \ldots & A_{p}\end{array}\right]$ and the $n \times p$ matrix $x_{t}^{\bullet} \equiv\left[\begin{array}{lll}y_{t-1} & \ldots & y_{t-p}\end{array}\right]$, we can define $Z_{t}$ as

$$
Z_{t} \equiv\left[\begin{array}{c}
B_{0} y_{t-1} \\
\vdots \\
B_{0} y_{t-p}
\end{array}\right]=\operatorname{vec}\left(B_{0} \cdot x_{t}^{\bullet}\right)
$$

and since

$$
\sum_{\ell=1}^{p} A_{\ell} B_{0} \cdot y_{t-\ell}=\left[\begin{array}{lll}
A_{1} & \ldots & A_{p}
\end{array}\right]\left[\begin{array}{c}
B_{0} y_{t-1} \\
\vdots \\
B_{0} y_{t-p}
\end{array}\right]
$$

we can finally restate the model as

$$
y_{t}=A \cdot Z_{t}+u_{t}
$$




\section{A.2 Step 1: Draw a history of volatilities $\left\{\sigma_{t}\right\}_{t=1}^{T}$}

This step concerns the draw of the (unobservable) stochastic volatilities conditional on $\theta=\left\{A, B_{0}, G, Q_{\sigma}\right\}$ and the indexes of Normal components of the mixture $\left\{S_{t}\right\}_{t=1}^{T}$. The order of these steps is in line with Del Negro \& Primiceri (2015).

In order to draw the volatilities, we apply the triangular reduction of the errors $u_{t}=$ $G^{-1} \Sigma_{t} \varepsilon_{t}$ to transform the model in the following way:

$$
\begin{aligned}
y_{t} & =A \cdot Z_{t}+G^{-1} \Sigma_{t} \varepsilon_{t}, \\
\underbrace{G\left(y_{t}-A \cdot Z_{t}\right)}_{\widetilde{y}_{t}} & =\Sigma_{t} \varepsilon_{t}, \\
\widetilde{y}_{t} & =\Sigma_{t} \varepsilon_{t} .
\end{aligned}
$$

Moreover, using the Hadamard product operator, we can first write

$$
\Sigma_{t} \varepsilon_{t}=\Sigma_{t}\left[\begin{array}{c}
\varepsilon_{1, t} \\
\varepsilon_{2, t} \\
\vdots \\
\varepsilon_{n, t}
\end{array}\right]=\left[\begin{array}{c}
\sigma_{1, t} \varepsilon_{1, t} \\
\sigma_{2, t} \varepsilon_{2, t} \\
\vdots \\
\sigma_{n, t} \varepsilon_{n, t}
\end{array}\right]=\sigma_{t} \odot \varepsilon_{t}
$$

and taking the square element by element on both sides of $\widetilde{y}_{t}=\Sigma_{t} \varepsilon_{t}$, we obtain:

$$
\left(\widetilde{y}_{t}\right)^{\cdot 2}=\left(\Sigma_{t} \varepsilon_{t}\right)^{\cdot 2}=\sigma_{t}^{\cdot 2} \odot \varepsilon_{t}^{\cdot 2} \Longleftrightarrow\left[\begin{array}{c}
\widetilde{y}_{1, t}^{2} \\
\widetilde{y}_{2, t}^{2} \\
\vdots \\
\widetilde{y}_{n, t}^{2}
\end{array}\right]=\left[\begin{array}{c}
\sigma_{1, t}^{2} \varepsilon_{1, t}^{2} \\
\sigma_{2, t}^{2} \varepsilon_{2, t}^{2} \\
\vdots \\
\sigma_{n, t}^{2} \varepsilon_{n, t}^{2}
\end{array}\right] .
$$

We add on the left hand-side a small constant ${ }^{11} \bar{c}=10^{-3}$ and apply the logarithm on

\footnotetext{
${ }^{11}$ The addition of a small constant term has numerical stability purposes, as explained in Fuller (2009) and Primiceri (2005).
} 
both sides ${ }^{12}$ in order to break the non-linearity, to obtain:

$$
\begin{gathered}
\underbrace{\left[\begin{array}{cc}
\log \left(\widetilde{y}_{1, t}^{2}+\bar{c}\right) \\
\log \left(\widetilde{y}_{2, t}^{2}+\bar{c}\right) \\
\vdots \\
\log \left(\widetilde{y}_{n, t}^{2}+\bar{c}\right)
\end{array}\right]}_{\widetilde{y}_{t}^{*}}=2\left[\begin{array}{cc}
\log & \sigma_{1, t} \\
\log & \sigma_{2, t} \\
\vdots \\
\log & \sigma_{n, t}
\end{array}\right]+\left[\begin{array}{cc}
\log & \varepsilon_{1, t}^{2} \\
\log & \varepsilon_{2, t}^{2} \\
\vdots \\
\log & \varepsilon_{n, t}^{2}
\end{array}\right], \\
\widetilde{y}_{t}^{*}=2 \log \sigma_{t}+\log \left[\left(\varepsilon_{t}\right)^{\cdot 2}\right] .
\end{gathered}
$$

Since $\varepsilon_{t} \stackrel{i i d}{\sim} \mathcal{M N}\left(\mathbf{0}, I_{n}\right)$, each term $\log \varepsilon_{j, t}^{2}$ has a $\log \chi_{1}^{2}$ distribution, and $\log \left[\left(\varepsilon_{t}\right)^{\cdot 2}\right]$ is a vector of independent $\log \chi_{1}^{2}$ random variables.

Then, conditioning on $\left\{S_{t}\right\}_{t=1}^{T}$, i.e. the sequence of $n \times 1$ vectors that specify the indexes of Normal components of the mixture, the vector $\log \left[\left(\varepsilon_{t}\right)^{\cdot 2}\right]$ has the following Gaussian distribution:

$$
\log \left[\left(\varepsilon_{t}\right)^{\cdot 2}\right] \mid\left\{S_{t}\right\}_{t=1}^{T} \sim \mathcal{M N}(\underbrace{\left[\begin{array}{c}
m_{s_{1, t}}^{m} \\
m_{s_{2, t}}^{m} \\
\vdots \\
m_{s_{n, t}}^{m}
\end{array}\right]}_{\varphi_{t}}, \underbrace{\left[\begin{array}{cccc}
m_{s_{1, t}}^{v} & 0 & \ldots & 0 \\
0 & m_{s_{2, t}}^{v} & \ddots & \vdots \\
\vdots & \ddots & \ddots & \vdots \\
0 & \ldots & 0 & m_{s_{n, t}}^{v}
\end{array}\right]}_{\Upsilon_{t}})
$$

Hence, given the Gaussian distribution of $\log \left[\left(\varepsilon_{t}\right)^{\cdot 2}\right] \mid\left\{S_{t}\right\}_{t=1}^{T}$, we can define the needed state space form as:

$$
\begin{aligned}
& \widetilde{y}_{t}^{*}=\varphi_{t}+2 \log \sigma_{t}+\zeta_{t}, \quad \zeta_{t} \stackrel{i}{\sim} \mathcal{M N}\left(\mathbf{0}, \Upsilon_{t}\right), \\
& \log \sigma_{t}=\log \sigma_{t-1}+\nu_{\sigma, t}, \quad \nu_{\sigma, t} \stackrel{i i d}{\sim} \mathcal{M N}(\mathbf{0}, \underbrace{Q_{\sigma}}_{n \times n}) \text {. }
\end{aligned}
$$

At this point, the Forward Filtering Backward Sampling (FFBS) procedure, introduced by Carter \& Kohn (1994), can be implemented to draw a history of volatilities $\left\{\sigma_{t}\right\}_{t=1}^{T}$. The procedure is described below. For simplicity we define $\widetilde{\sigma}_{t} \equiv \log \sigma_{t}$, since the FFBS procedure is implemented on the log-volatilities.

${ }^{12}$ Noticing that $\log \left[\begin{array}{l}a \\ b\end{array}\right]=\left[\begin{array}{l}\log a \\ \log b\end{array}\right]$, and $\left[\begin{array}{l}a \\ b\end{array}\right]^{\cdot 2}=\left[\begin{array}{l}a^{2} \\ b^{2}\end{array}\right]$. 
The filter can be initialized at the following values:

$$
\widetilde{\sigma}_{0 \mid 0}=\log (\bar{\sigma}), \quad P_{\sigma, 0 \mid 0}=\bar{P}_{\sigma},
$$

where $\log (\bar{\sigma})$ and $\bar{P}_{\sigma}$ are respectively the mean and the covariance matrix of the prior distribution of $\log \sigma_{0}$.

Recursively, for each $\left(\widetilde{\sigma}_{t-1 \mid t-1}, P_{\sigma, t-1 \mid t-1}\right)$, we compute the filter:

$$
\begin{aligned}
P_{\sigma, t \mid t-1} & =P_{\sigma, t-1 \mid t-1}+Q_{\sigma}, \\
K_{\sigma, t} & =2 P_{\sigma, t \mid t-1}\left(4 P_{\sigma, t \mid t-1}+\Upsilon_{t}\right)^{-1}, \\
\widetilde{\sigma}_{t \mid t} & =\widetilde{\sigma}_{t-1 \mid t-1}+K_{\sigma, t}\left(\widetilde{y}_{t}^{*}-2 \widetilde{\sigma}_{t-1 \mid t-1}-\varphi_{t}\right), \\
P_{\sigma, t \mid t} & =P_{\sigma, t \mid t-1}-2 K_{\sigma, t} P_{\sigma, t \mid t-1} .
\end{aligned}
$$

Having an entire set of updating and prediction steps $\left(\widetilde{\sigma}_{t \mid t}, P_{\sigma, t \mid t}, P_{\sigma, t \mid t-1}\right)_{t=1}^{T}$, we start to sample backward, beginning by sampling $\widetilde{\sigma}_{T}$ from $\mathcal{M N}\left(\widetilde{\sigma}_{T \mid T}, P_{\sigma, T \mid T}\right)$, and then for each $t \in\{T-1, T-2, \ldots, 2,1\}$ we sample recursively each $\widetilde{\sigma}_{t}$ from $\mathcal{M N}\left(\widetilde{\sigma}_{t \mid t+1}, P_{\sigma, t \mid t+1}\right)$ where:

$$
\begin{aligned}
\widetilde{\sigma}_{t \mid t+1} & =\widetilde{\sigma}_{t \mid t}+P_{\sigma, t \mid t} P_{\sigma, t+1 \mid t}^{-1}\left(\widetilde{\sigma}_{t+1}-\widetilde{\sigma}_{t \mid t}\right), \\
P_{\sigma, t \mid t+1} & =P_{\sigma, t \mid t}-P_{\sigma, t \mid t} P_{\sigma, t+1 \mid t}^{-1} P_{\sigma, t \mid t} .
\end{aligned}
$$

\section{A.3 Step 2(a): Draw $\theta \mid\left\{\sigma_{t}\right\}_{t=1}^{T}$}

\section{A.3.1 Substep 2(a).i: Draw the covariance of volatilities' innovations $Q_{\sigma}$}

Conditioning on $\left\{\sigma_{t}\right\}_{t=0}^{T}$, we can draw the covariance matrix $Q_{\sigma}$. Indeed, recall that:

$$
\log \sigma_{t}=\log \sigma_{t-1}+\nu_{\sigma, t}, \quad \nu_{\sigma, t} \stackrel{i i d}{\sim} \mathcal{M N}(\mathbf{0}, \underbrace{Q_{\sigma}}_{n \times n}) .
$$

But then, having a complete history of the sigmas, given the random walk law of motion, is equivalent to having a complete histories of innovations $\nu_{\sigma, t}$. Stacking the $\nu_{\sigma, t}$ across time, we get:

$$
\underbrace{\nu_{\sigma}^{*}}_{n \times T}=\left[\begin{array}{llll}
\nu_{\sigma, 1} & \nu_{\sigma, 2} & \ldots & \nu_{\sigma, T}
\end{array}\right]
$$


and we can easily compute the innovations sum of squares matrix:

$$
\underbrace{S_{\sigma}}_{n \times n}=\underbrace{\nu_{\sigma}^{*}}_{n \times T} \underbrace{\nu_{\sigma}^{* \prime}}_{T \times n}
$$

If the prior on the matrix $Q_{\sigma}$ is a $n \times n$ Inverse Wishart with scale matrix $\bar{Q}_{\sigma}$ and degrees of freedom $\tau_{\sigma, 0}$ :

$$
Q_{\sigma} \sim \mathcal{I}_{n}\left(\bar{Q}_{\sigma}, \tau_{\sigma, 0}\right)
$$

then the posterior is conjugate and given by:

$$
Q_{\sigma} \mid\left\{\sigma_{t}^{i}\right\}_{t=0}^{T} \sim \mathcal{I W}_{n}\left(S_{\sigma}+\bar{Q}_{\sigma}, \tau_{\sigma, 0}+T\right)
$$

\section{A.3.2 Substep 2(a).ii: Draw the loadings $A$}

To draw the loadings contained in A, we rewrite the model in (12) in the following stacked form:

$$
\begin{gathered}
{\left[\begin{array}{c}
y_{1}^{\prime} \\
y_{2}^{\prime} \\
\vdots \\
y_{T}^{\prime}
\end{array}\right]=\left[\begin{array}{c}
Z_{1}^{\prime} \\
Z_{2}^{\prime} \\
\vdots \\
Z_{T}^{\prime}
\end{array}\right] A^{\prime}+\left[\begin{array}{c}
u_{1}^{\prime} \\
u_{2}^{\prime} \\
\vdots \\
u_{T}^{\prime}
\end{array}\right],} \\
\underbrace{y}_{T \times n}=\underbrace{Z}_{T \times r p} \cdot \underbrace{A^{\prime}}_{r p \times n}+u .
\end{gathered}
$$

Defining $a \equiv \operatorname{vec}\left(A^{\prime}\right)$, and exploiting the Kronecker properties, the stacked form can be vectorized and transformed into:

$$
\begin{gathered}
\operatorname{vec}(y)=\operatorname{vec}\left(Z \cdot A^{\prime} \cdot I_{n}\right)+\operatorname{vec}(u), \\
\underbrace{Y}_{n T \times 1}=\underbrace{\left(I_{n} \otimes Z\right)}_{n \times n r p} \cdot \underbrace{a}_{n r p \times 1}+U,
\end{gathered}
$$

where $U$ has the following distribution:

$$
\underbrace{U}_{n T \times 1} \sim \mathcal{M N}(\mathbf{0}, \underbrace{V_{u}}_{n T \times n T})
$$


and

$$
\begin{aligned}
V_{u} \equiv\left[\begin{array}{cccccccccc}
\Omega_{1}^{(1,1)} & 0 & \ldots & 0 & \ldots & \cdots & \Omega_{1}^{(1, n)} & 0 & \cdots & 0 \\
0 & \Omega_{2}^{(1,1)} & \ddots & \vdots & \ldots & \ldots & 0 & \Omega_{2}^{(1, n)} & \ddots & \vdots \\
\vdots & \ddots & \ddots & 0 & \ldots & \ldots & \vdots & \ddots & \ddots & 0 \\
0 & \ldots & 0 & \Omega_{T}^{(1,1)} & \ldots & \ldots & 0 & \ldots & 0 & \Omega_{T}^{(1, n)} \\
\vdots & \vdots & \vdots & \vdots & \ddots & \vdots & \vdots & \vdots & \vdots & \vdots \\
\vdots & \vdots & \vdots & \vdots & \vdots & \ddots & \vdots & \vdots & \vdots & \vdots \\
\Omega_{1}^{(n, 1)} & 0 & \cdots & 0 & \ldots & \cdots & \Omega_{1}^{(n, n)} & 0 & \cdots & 0 \\
0 & \Omega_{2}^{(n, 1)} & \ddots & \vdots & \ldots & \ldots & 0 & \Omega_{2}^{(n, n)} & \ddots & \vdots \\
\vdots & \ddots & \ddots & 0 & \ldots & \ldots & \vdots & \ddots & \ddots & 0 \\
0 & \cdots & 0 & \Omega_{T}^{(n, 1)} & \ldots & \ldots & 0 & \cdots & 0 & \Omega_{T}^{(n n)}
\end{array}\right] \\
=\sum_{t=1}^{T}\left[\Omega_{t} \otimes\left(e_{t} \cdot e_{t}^{\prime}\right)\right] .
\end{aligned}
$$

To use an informative prior on $a$, we follow the approach in Gelman et al. (2014). The strategy incorporates the prior as observations. Considering a multivariate normal prior with the following moments:

$$
a \sim \mathcal{M N}\left(\bar{a}, V_{a}\right)
$$

it is possible to augment the model with nrp observations that express the prior information:

$$
\begin{aligned}
{\left[\begin{array}{c}
Y \\
\bar{a}
\end{array}\right] } & =\left[\begin{array}{c}
I_{n} \otimes Z \\
I_{n r p}
\end{array}\right] a+\left[\begin{array}{c}
U \\
U_{a}
\end{array}\right], \\
Y^{\diamond} & =Z^{\diamond} a+U^{\diamond}, \quad U^{\diamond} \sim \mathcal{M N}\left(\mathbf{0}_{n T+n r p}, V^{\diamond}\right), \\
V^{\diamond} & =\left[\begin{array}{cc}
V_{u} & \mathbf{0}_{n T \times n r p} \\
\mathbf{0}_{n r p \times n T} & V_{a}
\end{array}\right] .
\end{aligned}
$$

A draw for $a$ then comes from the following posterior:

$$
\begin{aligned}
& a \sim \mathcal{M N}\left(\widetilde{a},\left(Z^{\diamond} V^{\diamond-1} Z^{\diamond}\right)^{-1}\right), \\
& \widetilde{a}=\left(Z^{\diamond \prime} V^{\diamond-1} Z^{\diamond}\right)^{-1} Z^{\diamond \prime} V^{\diamond-1} Y^{\diamond} .
\end{aligned}
$$

In order to decrease the computational burden of this step throughout the sampling, we adopt the strategy proposed by Carriero et al. (2019). In particular, the triangular 
representation of the system is exploited, and coefficients are drawn equation by equation. The approach proposed in Carriero et al. (2019) and its generalization to allow for timevarying covariances is analytically documented in the appendix (section C.2).

\section{A.3.3 Substep 2(a).iii: Draw the factor weights elements in $B_{0}$}

Given the restrictions and the non-linear role of $B_{0}$, a Random Walk Metropolis step on the posterior kernel of each element of $B_{0}$ is implemented, nested into the Gibbs Sampling algorithm. In order to do this, we first write the likelihood of the model.

Given the reduced form VAR written as:

$$
y_{t}=A \cdot Z_{t}+u_{t}, \quad u_{t} \stackrel{i}{\sim} \mathcal{M N}\left(\mathbf{0}, \Omega_{t}\right)
$$

conditioning on all other elements and using the chain rule, we can write the likelihood kernel as:

$f\left(\left(y_{t}\right)_{t=1}^{T} \mid A,\left(\Omega_{t}\right)_{t=1}^{T}, B_{0}\right) \propto\left(\prod_{t=1}^{T}\left|\Omega_{t}\right|^{-\frac{1}{2}}\right) \exp \left\{-\frac{1}{2} \sum_{t=1}^{T}\left(y_{t}-A \cdot Z_{t}\right)^{\prime} \Omega_{t}^{-1}\left(y_{t}-A \cdot Z_{t}\right)\right\}$.

Next, let us consider the $r^{*} \equiv n-r$ scalar unrestricted elements of $B_{0}$, i.e. $\left(b_{0, j}\right)_{j=1}^{r^{*}}$. Then, $\forall j \in\left\{1, \ldots, r^{*}\right\}$, we can define the set $b_{0, j-} \equiv\left(b_{0, s}\right)_{s \neq j}$.

For a given prior $f\left(b_{0, j}\right)$ on each element $b_{0, j}$, we can write the kernel of the conditional posterior of $b_{0, j}$ as:

$$
f_{\text {post }}\left(b_{0, j} \mid\left(y_{t}, \Omega_{t}\right)_{t=1}^{T}, A, b_{0, j-}\right) \propto f\left(\left(y_{t}\right)_{t=1}^{T} \mid A, B_{0},\left(\Omega_{t}\right)_{t=1}^{T}\right) \cdot f\left(b_{0, j}\right) .
$$

We are now ready to design the Metropolis step, separately for each $j$. Given the last step $B_{0}^{i-1}$, a random walk candidate is computed as:

$$
b_{0, j}^{*}=b_{0, j}^{i-1}+c_{j} \cdot \eta_{t}
$$

where $c_{j}$ is a scaling factor calibrated to have an acceptance rate of approximately $30 \%$ $35 \%$ and $\eta_{t} \stackrel{i i d}{\sim} \mathcal{N}\left(0, v_{j}\right)$, where $v_{j}$ is the variance of the prior $f\left(b_{0, j}\right)$. The candidate draw is accepted with probability:

$$
\alpha_{j}=\min \left\{1, \frac{f_{\text {post }}\left(b_{0, j}^{*} \mid\left(y_{t}, \Omega_{t}^{i-1}\right)_{t=1}^{T}, A, b_{0, j-}^{i-1}\right)}{f_{\text {post }}\left(b_{0, j}^{i-1} \mid\left(y_{t}, \Omega_{t}^{i-1}\right)_{t=1}^{T}, A, b_{0, j-}^{i-1}\right)}\right\}
$$


When the candidate is accepted, then $b_{0, j-}^{i}=b_{0, j}^{*}$, otherwise $b_{0, j-}^{i}=b_{0, j-}^{i-1}$. Repeating this procedure for $\forall j \in\left\{1, \ldots, r^{*}\right\}$, we obtain a draw $B_{0}^{i}$ from the distribution of interest.

\section{A.3.4 Substep 2(a).iv: draw the off-diagonal elements in $G$}

To draw the off-diagonal elements in $G$, we restate the reduced form as:

$$
\begin{aligned}
y_{t} & =\underbrace{A}_{n \times r p} \cdot \underbrace{Z_{t}}_{r p \times 1}+u_{t}, \\
y_{t}-A \cdot Z_{t} & =G^{-1} \Sigma_{t} \varepsilon_{t}, \\
\widehat{y_{t}} & =G^{-1} \Sigma_{t} \varepsilon_{t}, \\
G \cdot \widehat{y_{t}} & =\Sigma_{t} \varepsilon_{t} .
\end{aligned}
$$

Removing ones from the diagonal of $G$, and bringing off-diagonal elements on the right hand side, produces:

$$
G=I_{n}+G^{*}
$$

This can be combined in the model to obtain:

$$
\begin{aligned}
\left(I_{n}+G^{*}\right) \widehat{y}_{t} & =\Sigma_{t} \varepsilon_{t}, \\
\widehat{y}_{t} & =-G^{*} \widehat{y}_{t}+\Sigma_{t} \varepsilon_{t} .
\end{aligned}
$$

Exploiting the Kronecker properties, we then get:

$$
-I_{n} \underbrace{G^{*}}_{n \times n} \underbrace{\widehat{y}_{t}}_{n \times 1}=-\underbrace{\left(I_{n} \otimes \widehat{y}_{t}^{\prime}\right)}_{n \times n^{2}} \underbrace{\operatorname{vec}\left(G^{* \prime}\right)}_{n^{2} \times 1}
$$

where vec $\left(G^{* \prime}\right)$ have zeros in positions $[(i-1) n+j]_{j \in\{1, \ldots, n\}}^{i \in\{1, \ldots, n\}}$. By removing the zeros, we obtain exactly the elements below the main diagonal of $G$, gathered in the $m$-dimensional vector $g$. Removing the corresponding columns in $-\left(I_{n} \otimes \widehat{y}_{t}^{\prime}\right)$, we construct the matrix 
$W_{t}$, which has the following form:

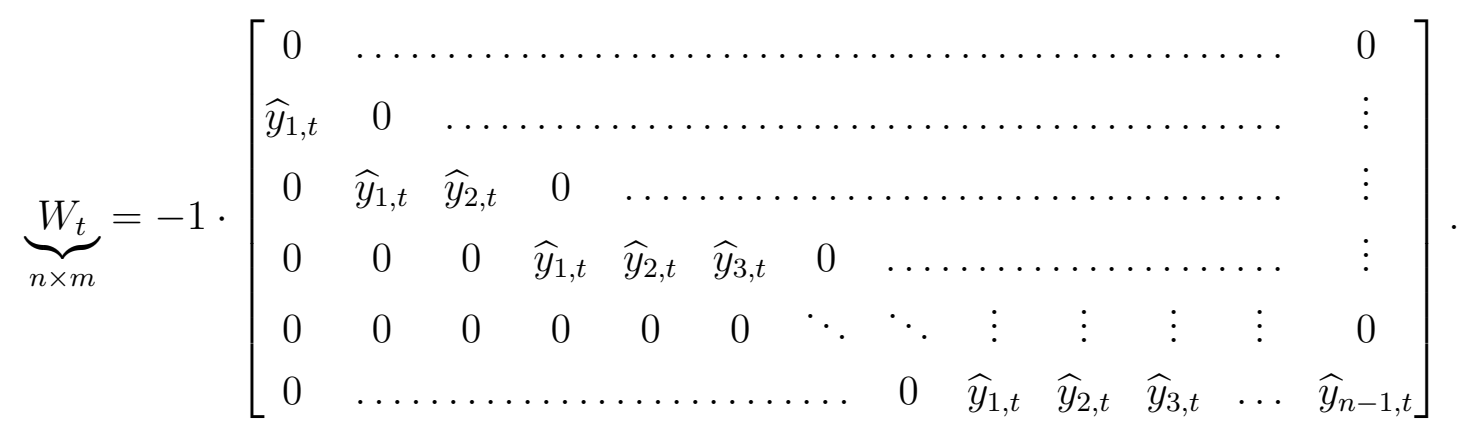

We can then rewrite the model as:

$$
\begin{aligned}
& \widehat{y}_{t}=-G^{*} \widehat{y}_{t}+\Sigma_{t} \varepsilon_{t}, \\
& \widehat{y}_{t}=-\left(I_{n} \otimes \widehat{y}_{t}^{\prime}\right) \operatorname{vec}\left(G^{* \prime}\right)+\Sigma_{t} \varepsilon_{t}, \\
& \widehat{y}_{t}=W_{t} g+\varepsilon_{t}^{*}, \quad \varepsilon_{t}^{*} \sim \mathcal{M N}\left(\mathbf{0}_{n \times 1}, \Sigma_{t}^{2}\right) .
\end{aligned}
$$

Next, we stack the model as:

$$
\begin{aligned}
& {\left[\begin{array}{c}
\widehat{y}_{1} \\
\widehat{y}_{2} \\
\vdots \\
\widehat{y}_{T}
\end{array}\right]=\left[\begin{array}{c}
W_{1} \\
W_{2} \\
\vdots \\
W_{T}
\end{array}\right] g+\left[\begin{array}{c}
\varepsilon_{1}^{*} \\
\varepsilon_{2}^{*} \\
\vdots \\
\varepsilon_{T}^{*}
\end{array}\right],} \\
& \underbrace{\widehat{y}}_{n T \times 1}=\underbrace{W}_{T n \times m} \cdot \underbrace{g}_{m \times 1}+\varepsilon^{*}, \quad \varepsilon^{*} \sim \mathcal{M N}\left(\mathbf{0}_{n T \times 1}, \Sigma^{2}\right),
\end{aligned}
$$

where $\Sigma$ is the diagonal matrix containing all the stacked stochastic volatilities vectors in the main diagonal:

$$
\Sigma=\operatorname{Diag}\left(\left[\begin{array}{llll}
\sigma_{1}^{\prime} & \sigma_{2}^{\prime} & \ldots & \sigma_{T}^{\prime}
\end{array}\right]^{\prime}\right)
$$

We can then use a similar approach as the one implemented for $a$, following Gelman et al. (2014). Specifically, given the prior :

$$
g \sim \mathcal{M N}\left(\bar{g}, V_{g}\right)
$$


we augment the model with $r$ observations that express the prior information:

$$
\begin{aligned}
{\left[\begin{array}{c}
\widehat{y} \\
\bar{g}
\end{array}\right] } & =\left[\begin{array}{l}
W \\
I_{m}
\end{array}\right] g+\left[\begin{array}{l}
\varepsilon^{*} \\
\varepsilon_{g}
\end{array}\right], \\
\widehat{Y}^{\diamond} & =W^{\diamond} g+\varepsilon^{\diamond}, \quad \varepsilon^{\diamond} \sim \mathcal{M N}\left(\mathbf{0}_{n T+m}, V_{\varepsilon}^{\diamond}\right), \\
V_{\varepsilon}^{\diamond} & =\left[\begin{array}{cc}
\Sigma^{2} & \mathbf{0}_{n T \times m} \\
\mathbf{0}_{m \times n T} & V_{g}
\end{array}\right] .
\end{aligned}
$$

A draw for $g$ then comes from the following posterior:

$$
\begin{aligned}
& g \sim \mathcal{M N}\left(\widetilde{g},\left(W^{\diamond \prime} V_{\varepsilon}^{\diamond-1} W^{\diamond}\right)^{-1}\right), \\
& \widetilde{g}=\left(W^{\diamond \prime} V_{\varepsilon}^{\diamond-1} W^{\diamond}\right)^{-1} W^{\diamond \prime} V_{\varepsilon}^{\diamond-1} \widehat{Y}^{\diamond} .
\end{aligned}
$$

\section{A.4 Step 2(b): Draw a history of indexes of the mixture $\left\{S_{t}\right\}_{t=1}^{T} \mid \theta,\left\{\sigma_{t}\right\}_{t=1}^{T}$}

Starting from the following formulation seen in Step 1 of the algorithm

$$
\widetilde{y}_{t}^{*}=2 \log \sigma_{t}+\log \left[\left(\varepsilon_{t}\right)^{\cdot 2}\right]
$$

we can notice that, since $\varepsilon_{t} \stackrel{i i d}{\sim} \mathcal{M N}\left(\mathbf{0}, I_{n}\right)$, each term $\log \varepsilon_{j, t}^{2}$ has a $\log \chi_{1}^{2}$ distribution, and $\log \left[\left(\varepsilon_{t}\right)^{\cdot 2}\right]$ is a vector of independent $\log \chi_{1}^{2}$ random variables.

Omori et al. (2007), improving upon Kim et al. (1998), show that the $\log \chi_{1}^{2}$ distribution is very well approximated by a mixture of ten Normal distributions:

$$
f_{\log \chi_{1}^{2}}(x) \approx \sum_{j=1}^{10} m_{j}^{p} f_{\mathcal{N}}\left(x \mid m_{j}^{m}, m_{j}^{v}\right)
$$

where $m_{j}^{p}, m_{j}^{m}$ and $m_{j}^{v}$ are contained in the following table:

\begin{tabular}{|l|r|r|r|r|r|r|r|r|r|r|}
\hline$j$ & 1 & 2 & 3 & 4 & 5 & 6 & 7 & 8 & 9 & 10 \\
\hline$m_{j}^{p}$ & 0.00609 & 0.04775 & 0.13057 & 0.20674 & 0.22715 & 0.18842 & 0.12047 & 0.05591 & 0.01575 & 0.00115 \\
$m_{j}^{m}$ & 1.92677 & 1.34744 & 0.73504 & 0.02266 & -0.85173 & -1.97278 & -3.46788 & -5.55246 & -8.68384 & -14.65000 \\
$m_{j}^{v}$ & 0.11265 & 0.17788 & 0.26768 & 0.40611 & 0.62699 & 0.98583 & 1.57469 & 2.54498 & 4.16591 & 7.33342 \\
\hline
\end{tabular}

Therefore, in order to have a conditionally Gaussian measurement equation, we should condition each element of the vector $\log \left[\left(\varepsilon_{t}\right)^{\cdot 2}\right]$ on the index that specifies the Normal components of the mixture. Defining the $n \times 1$ vector $S_{t}$ that contains the indexes of 
components in period $t$, we can write

$$
S_{t} \equiv\left[\begin{array}{c}
s_{1, t} \\
\vdots \\
s_{n, t}
\end{array}\right], \quad \text { where } \quad\left[\log \varepsilon_{h, t}^{2} \mid s_{h, t}=j\right] \sim \mathcal{N}\left(m_{j}^{m}, m_{j}^{v}\right)
$$

Conditioning on a history of volatilities $\left(\sigma_{t}\right)_{t=1}^{T}$, we can restate the model as

$$
\log \left[\left(\varepsilon_{t}\right)^{\cdot 2}\right]=\widetilde{y}_{t}^{*}-2 \log \sigma_{t}
$$

Then, the element $s_{h, t}$ that indexes the specific component from which log $\varepsilon_{h, t}^{2}$ is drawn, has support $J=\{1, \ldots, 10\}$ and the following discrete probability distribution:

$$
\forall j \in J, \quad \operatorname{Pr}\left[s_{h, t}=j \mid \widetilde{y}_{h, t}^{*}, \sigma_{t}\right]=\frac{m_{j}^{p} f_{\mathcal{N}}\left(\widetilde{y}_{h, t}^{*}-2 \log \sigma_{h, t} \mid m_{j}^{m}, m_{j}^{v}\right)}{\sum_{\iota=1}^{10} m_{\iota}^{p} f_{\mathcal{N}}\left(\widetilde{y}_{h, t}^{*}-2 \log \sigma_{h, t} \mid m_{\iota}^{m}, m_{\iota}^{v}\right)} .
$$

Independent draws for all variables $h \in\{1, \ldots, n\}$ at all periods $t \in\{1, \ldots, T\}$ from this distribution will form the new history of indexes of mixture's components $\left\{S_{t}\right\}_{t=1}^{T} \mid \theta,\left\{\sigma_{t}\right\}_{t=1}^{T}$.

\section{Appendix B Detailed steps of the Gibbs Sampler for the estimation of the MAI-SVCV model}

The MAI-SVCV model has time-varying off diagonal elements in the triangular reduction $u_{t}=G_{t}^{-1} \Sigma_{t} \varepsilon_{t}$. Therefore, we have to substitute SubStep 2(a).iv with two Substeps: the first one draws the elements $\left\{g_{t}\right\}_{t=1}^{T}$, and the second one the covariance matrix of their innovations $Q_{g}$. The Gibbs sampler in which the rank reduction of de Wind \& Gambetti (2014) is not applied, and hence matrix $Q_{g}$ is full rank, is similar to the one described in Primiceri (2005). If the rank reduction of de Wind \& Gambetti (2014) is applied to attenuate the curse of dimensionality, the draw of $\left\{g_{t}\right\}_{t=1}^{T}$ is further split into two substeps. The following subsections will provide further details on the procedure needed in the case of reduced rank of $Q_{g}$, following de Wind \& Gambetti (2014), which is more general than the full rank case. 


\section{B.1 Alternative SubStep 2(a).iv for the MAI-SVCV: Draw a history of TV off-diagonal elements $\left\{g_{t}\right\}_{t=1}^{T}$}

Using the rank reduction strategy of de Wind \& Gambetti (2014), the vector $g_{t}$ is decomposed as:

$$
g_{t}=\Lambda_{g} \widetilde{g}_{t}+M_{g} g_{0},
$$

with

$$
\underbrace{\Lambda_{g}}_{m \times q_{r}}=\underbrace{V_{g}}_{m \times q_{g}} \underbrace{D_{g}}_{q_{g} \times q_{g}}, \quad M_{g}=I_{m}-\Lambda_{g}\left(\Lambda_{g}^{\prime} \Lambda_{g}\right)^{-1} \Lambda_{g}^{\prime},
$$

where $D_{g}$ is the diagonal matrix containing the square roots of the $q_{g}$ non-zero eigenvalues of $Q_{g}$, while $V_{g}$ is the matrix whose columns are the associated eigenvectors (normalized to unit length). $M_{g} g_{0}$ represents the time invariant residual and $\widetilde{g}_{t}$ is the $q_{g}$-dimensional stochastic vector of TV components, having the following law of motion:

$$
\widetilde{g}_{t}=\widetilde{g}_{t-1}+\widetilde{\nu}_{g, t}, \quad \underbrace{\widetilde{\nu}_{g, t}}_{q_{g} \times 1} \stackrel{i i d}{\sim} \mathcal{M N}\left(\mathbf{0}, I_{q_{g}}\right) .
$$

As in de Wind \& Gambetti (2014), the transformed time-varying components $\Lambda_{g} \widetilde{g}_{t}$ and the non-TV component $M_{g} g_{0}$ are drawn separately.

In order to build the state space form, we first transform the reduced form of the model in the following way:

$$
\begin{aligned}
y_{t} & =A \cdot Z_{t}+G_{t}^{-1} \Sigma_{t} \varepsilon_{t}, \\
\underbrace{y_{t}-A \cdot Z_{t}}_{\widehat{y}_{t}} & =G_{t}^{-1} \Sigma_{t} \varepsilon_{t}, \\
G_{t} \widehat{y}_{t} & =\Sigma_{t} \varepsilon_{t} .
\end{aligned}
$$

Removing ones from the diagonal of $G_{t}$, and bringing off-diagonal elements on the right hand side, produces:

$$
G_{t}=I_{n}+G_{t}^{*}
$$

This can be inserted in the model to obtain:

$$
\begin{aligned}
\left(I_{n}+G_{t}^{*}\right) \widehat{y}_{t} & =\Sigma_{t} \varepsilon_{t}, \\
\widehat{y}_{t} & =-G_{t}^{*} \widehat{y}_{t}+\Sigma_{t} \varepsilon_{t} .
\end{aligned}
$$


Exploiting the Kronecker properties, we get:

$$
-I_{n} \underbrace{G_{t}^{*}}_{n \times n} \underbrace{\widehat{y}_{t}}_{n \times 1}=-\underbrace{\left(I_{n} \otimes \widehat{y}_{t}^{\prime}\right)}_{n \times n^{2}} \underbrace{\operatorname{vec}\left(G_{t}^{* \prime}\right)}_{n^{2} \times 1}
$$

where vec $\left(G_{t}^{* \prime}\right)$ have zeros in positions $[(i-1) n+j]_{j \in\{1, \ldots, n\}}^{i \in\{1, \ldots, n\}}$. By removing the zeros we obtain exactly the elements below the main diagonal of $G_{t}$, gathered in the vector $g_{t}$. Removing the corresponding columns in $-\left(I_{n} \otimes \widehat{y}_{t}^{\prime}\right)$, we construct the matrix $W_{t}$, which has the following form:

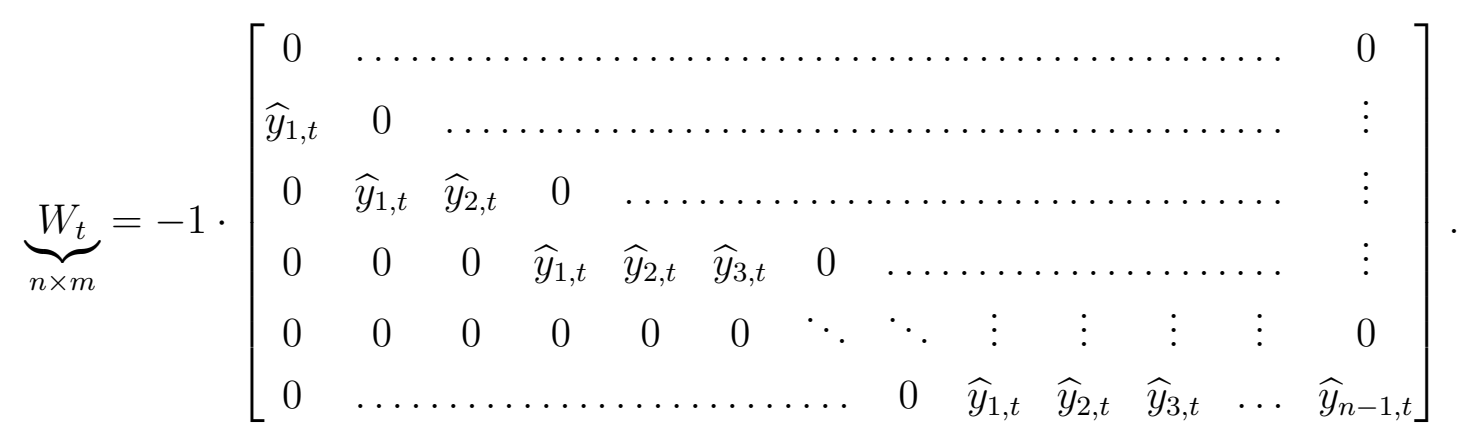

Hence, we obtain a measurement equation with $g_{t}$ as states:

$$
\begin{aligned}
& \widehat{y}_{t}=-G_{t}^{*} \widehat{y}_{t}+\Sigma_{t} \varepsilon_{t}, \\
& \widehat{y}_{t}=-\left(I_{n} \otimes \widehat{y}_{t}^{\prime}\right) \operatorname{vec}\left(G_{t}^{* \prime}\right)+\Sigma_{t} \varepsilon_{t}, \\
& \widehat{y}_{t}=W_{t} g_{t}+\Sigma_{t} \varepsilon_{t} .
\end{aligned}
$$

\section{B.1.1 SubSubStep: draw a history of TV components $\left\{\widetilde{g}_{t}^{i}\right\}_{t=1}^{T}$}

Let us consider the de Wind \& Gambetti (2014) decomposition on the $m$-dimensional process $g_{t}$ :

$$
g_{t}=\Lambda_{g} \widetilde{g}_{t}+M_{g} g_{0}, \quad Q_{g}=\underbrace{\Lambda_{g}}_{m \times q_{g}} \Lambda_{g}^{\prime}
$$

and plug it into the measurement equation:

$$
\begin{aligned}
\widehat{y}_{t} & =W_{t} g_{t}+\Sigma_{t} \varepsilon_{t}, \\
\widehat{y}_{t}-W_{t} M_{g} g_{0} & =W_{t} \Lambda_{g} \cdot \widetilde{g}_{t}+\Sigma_{t} \varepsilon_{t}, \\
\widehat{y}_{t}^{*} & =W_{t}^{*} \widetilde{g}_{t}+\Sigma_{t} \varepsilon_{t} .
\end{aligned}
$$


The resulting state space form is:

$$
\begin{array}{rlrl}
\widehat{y}_{t}^{*} & =W_{t}^{*} \widetilde{g}_{t}+\Sigma_{t} \varepsilon_{t}, & \varepsilon_{t} & \stackrel{i i d}{\sim} \mathcal{M N}\left(\mathbf{0}, I_{n}\right), \\
\underbrace{\widetilde{g}_{t}}_{q_{g} \times 1} & =\widetilde{g}_{t-1}+\widetilde{\nu}_{g, t}, \quad \underbrace{\widetilde{\nu}_{g, t}}_{q_{g} \times 1} \stackrel{i i d}{\sim} \mathcal{M N}\left(\mathbf{0}, I_{q_{g}}\right) .
\end{array}
$$

The FFBS procedure can be implemented to draw an history $\left\{\widetilde{g}_{t}^{i}\right\}_{t=1}^{T}$. The filter, following de Wind \& Gambetti (2014), can be initialized at:

$$
\widetilde{g}_{0 \mid 0}=R_{g} \bar{g} \quad P_{g, 0 \mid 0}=R_{g} \bar{P}_{g} R_{g}^{\prime}
$$

where

$$
R_{g} \equiv\left(\Lambda_{g}^{\prime} \Lambda_{g}\right)^{-1} \Lambda_{g}^{\prime}
$$

B.1.2 SubSubStep: draw a vector of time invariant component $M_{g} g_{0}$ of $g_{t}$

We operate the following transformation

$$
\begin{aligned}
\widehat{y}_{t} & =W_{t} g_{t}+\Sigma_{t} \varepsilon_{t}=W_{t}\left(\Lambda_{g} \widetilde{g}_{t}+M_{g} g_{0}\right)+\Sigma_{t} \varepsilon_{t}, \\
\underbrace{\widehat{y}_{t}-W_{t} \Lambda_{g} \widetilde{g}_{t}}_{\widehat{y}_{t}^{\bullet}} & =W_{t} \underbrace{M_{g} g_{0}}_{\mu_{g, 0}}+\underbrace{\Sigma_{t} \varepsilon_{t}}_{\widehat{\varepsilon}_{t}},
\end{aligned}
$$

to obtain the regression model of interest:

$$
\widehat{y}_{t}^{\bullet}=W_{t} \mu_{g, 0}+\widehat{\varepsilon}_{t}, \quad \widehat{\varepsilon_{t}} \stackrel{i i d}{\sim} \mathcal{M N}\left(\mathbf{0}, \Sigma_{t}^{\cdot 2}\right)
$$

We want to impose the $q_{g}<m$ restrictions given by:

$$
\underbrace{R_{g}}_{q_{g} \times r} \underbrace{\mu_{g, 0}}_{r \times 1}=\mathbf{0}_{q_{g} \times 1} .
$$

Stacking the time dimensions in columns, we write the restricted regression model as:

$$
\begin{aligned}
\underbrace{\widehat{Y}^{\bullet}}_{n T \times 1} & =\underbrace{W}_{n T \times m} \mu_{g, 0}+\underbrace{\xi}_{n T \times 1}, \quad \xi \sim \mathcal{M N}\left(\mathbf{0}_{n T \times 1}, \Sigma^{\cdot 2}\right), \\
\underbrace{R_{g}}_{q_{g} \times m} \underbrace{\mu_{g, 0}}_{r \times 1} & =\mathbf{0}_{q_{g} \times 1} .
\end{aligned}
$$


Then, given the prior for $g_{0}$ and the unrestricted Bayesian regression moments:

$$
\begin{aligned}
g_{0} & \sim \mathcal{M N}\left(\bar{g}, \bar{P}_{g}\right), \\
\Psi_{g} & =\left(W^{\prime} \Sigma^{-2} W+\bar{P}_{g}^{-1}\right)^{-1}, \\
\psi_{g} & =\Psi_{g}\left(W^{\prime} \Sigma^{-2} \widehat{Y}^{\bullet}+\bar{P}_{g}^{-1} \bar{g}\right),
\end{aligned}
$$

the sampling posterior distribution for $\mu_{g, 0}$ is given by:

$$
\begin{aligned}
& \mu_{g, 0} \sim \mathcal{M N}\left(\widetilde{\mu}_{g, 0}, P_{\mu_{g}}\right), \\
& \widetilde{\mu}_{g, 0}=\Psi_{\mu_{g}} \psi_{g}, \quad P_{\mu_{g}}=\Psi_{\mu_{g}} \Psi_{g}, \\
& \Psi_{\mu_{g}}=I_{r}-\Psi_{g} R_{g}^{\prime}\left(R_{g} \Psi_{g} R_{g}^{\prime}\right)^{-1} R_{g} .
\end{aligned}
$$

\section{B.1.3 SubSubStep: sum the TV and non-TV draws of $g_{t}$}

We can now sum the draws obtained in the two previous substeps:

$$
g_{t}=\Lambda_{g} \widetilde{g}_{t}+M_{g} g_{0}, \quad \forall t \in\{1, \ldots, T\}
$$

finally obtaining a history of time-varying off-diagonal elements $\left(g_{t}^{i}\right)_{t=1}^{T}$.

\section{B.2 Additional SubStep 2(a).v for the MAI-SVCV: Draw a re- duced rank covariance matrix $Q_{g}$}

Conditioning on the drawn $\left\{g_{t}^{i}\right\}_{t=1}^{T}$, we can draw the reduced rank covariance matrix $Q_{g}$. Indeed, since:

$$
g_{t}=g_{t-1}+\nu_{g, t}, \quad \nu_{g, t} \stackrel{i i d}{\sim} \mathcal{M N}(\mathbf{0}, \underbrace{Q_{g}}_{r \times r}),
$$

having a complete history $\left(g_{t}\right)_{t=1}^{T}$, given the random walk law of motion, is equivalent to having a complete history of innovations $\nu_{g, t}$. Stacking the $\nu_{g, t}$ across time, we get:

$$
\underbrace{\nu_{g}^{*}}_{r \times T}=\left[\begin{array}{llll}
\nu_{g, 1} & \nu_{g, 2} & \ldots & \nu_{g, T}
\end{array}\right]
$$


and we can easily compute the innovation sum of squares matrix:

$$
\underbrace{S_{g}}_{r \times m}=\underbrace{\nu_{g}^{*}}_{m \times T} \underbrace{\nu_{g}^{* \prime}}_{T \times m}
$$

By construction, the rank of $S_{g}$ would be $q_{g}<m$. Hence, if the prior on the matrix $Q_{g}$ is an $m \times m$ Singular Inverse Wishart with rank $q_{g}<m$, scale matrix $\bar{Q}_{g}$ and degrees of freedom $\tau_{g, 0}$ :

$$
Q_{g} \sim \mathcal{S} \mathcal{I} \mathcal{W}_{m}^{q_{g}}\left(\bar{Q}_{g}, \tau_{g, 0}\right)
$$

then, the posterior is conjugate and given by:

$$
Q_{g} \mid\left(g_{t}^{i}\right)_{t=0}^{T} \sim \mathcal{S} \mathcal{I} \mathcal{W}_{m}^{q_{g}}\left(S_{g}+\bar{Q}_{g}, \tau_{g, 0}+T\right)
$$

Section C.1 in the appendix discusses how to compute efficiently a draw from a Singular Inverse Wishart distribution.

\section{Appendix C Additional details for the GS}

\section{C.1 Procedure to draw from a Singular Inverse Wishart distri- bution}

Consider the $m \times m$ matrix $\Xi$ having the following $\mathcal{S I W}$ distribution:

$$
\Xi \sim \mathcal{S I H}_{m}^{q}(\underbrace{S}_{m \times m}, d),
$$

where $S$ is a scale matrix, $d$ the degrees of freedom, and $q$ is the rank of both $\Xi$ and $S$.

Following Bodnar \& Okhrin (2008) and Diaz-Garcia et al. (1997), and applying some modifications tailored at improving the algorithm efficiency, it is possible to draw from the distribution of $\Xi$ through the following steps:

1. Construct the Moore-Penrose pseudoinverse $S^{+}$of the scale matrix $S$. Moore Penrose computation follows the highly efficient Qrginv algorithm proposed by Ataei (2014).

2. Construct the diagonal matrix $\underbrace{\Lambda_{S}}_{q \times q}$ containing the non-zero eigenvalues of $S^{+}$in the main diagonal, and the matrix $\underbrace{U_{S}}_{m \times q}$ whose columns are the associated eigenvectors. 
3. Draw $d$ independent vectors $\underbrace{\widetilde{z}}_{q \times 1}$ from the multivariate normal $\mathcal{M N}\left(\mathbf{0}, \Lambda_{S}\right)$ and stack them as columns in the matrix $\underbrace{\widetilde{Z}}_{q \times d}$.

4. Construct the matrices $\underbrace{Z}_{m \times q}=U_{S} \widetilde{Z}$ and $\underbrace{W}_{m \times m}=Z Z^{\prime}$. The matrix $W$ is a draw from a Singular Wishart distribution with scale matrix $S^{+}$and $d$ degrees of freedom.

5. Compute the Moore-Penrose pseudoinverse $W^{+}$of $W$. The matrix $\widetilde{\Xi}=W^{+}$is a draw from the Singular Inverse Wishart of interest.

\section{C.2 Procedure to draw variable-specific coefficients with trian- gular structure of heteroskedastic innovations}

This approach generalizes the one proposed by Carriero et al. (2019). Consider the following multivariate regression, with variable-specific coefficients, common regressors across equations, and heteroskedastic errors, whose time variation can be decomposed through a standard triangular reduction.

We are considering the following model:

$$
\begin{gathered}
\forall t \in\{1, \ldots, T\}, \quad \underbrace{Z_{t}}_{n \times 1}=\underbrace{\Theta}_{n \times k} \cdot \underbrace{F_{t}}_{k \times 1}+\underbrace{u_{t}}_{n \times 1}, \quad u_{t} \stackrel{i}{\sim} \mathcal{M N}(\mathbf{0}, \underbrace{\Omega_{t}}_{n \times n}), \\
\Omega_{t}=W_{t} \Sigma_{t} \Sigma_{t} W_{t}^{\prime}, \quad u_{t}=W_{t} \Sigma_{t} \varepsilon_{t}, \quad \varepsilon_{t} \stackrel{i i d}{\sim} \mathcal{M N}\left(\mathbf{0}, I_{n}\right),
\end{gathered}
$$

where

$$
\begin{gathered}
\underbrace{W_{t}}_{n \times n}=\left[\begin{array}{ccccc}
1 & 0 & \ldots & \ldots & 0 \\
w_{1, t} & 1 & \ddots & \ddots & \vdots \\
w_{2, t} & w_{3, t} & 1 & \ddots & \vdots \\
\vdots & \vdots & \ddots & \ddots & 0 \\
w_{m-n+2, t} & w_{m-n+3, t} & \ldots & w_{m, t} & 1
\end{array}\right], \underbrace{w_{t}}_{m \times 1} \equiv\left[\begin{array}{c}
w_{1, t} \\
w_{2, t} \\
\vdots \\
w_{m, t}
\end{array}\right], \quad \underbrace{\sigma_{t}}_{n \times 1} \equiv\left[\begin{array}{c}
\sigma_{2, t}(n-1) \\
\vdots \\
\sigma_{1, t} \\
\sigma_{n, t}
\end{array}\right] . \\
\underbrace{\sum_{t}}_{n \times n}=\left[\begin{array}{cccc}
\sigma_{1, t} & 0 & \ldots & 0 \\
0 & \sigma_{2, t} & \ddots & \vdots \\
\vdots & \ddots & \ddots & 0 \\
0 & \ldots & 0 & \sigma_{n, t}
\end{array}\right],
\end{gathered}
$$


When $n \cdot k$ gets large, it is convenient to split the previous system in $n$ sets of univariate equations. Indeed, splitting $\Theta$ in row vectors it is possible to write the system as:

$\Theta=\left[\begin{array}{c}\theta_{[1,:]} \\ \theta_{[2,:]} \\ \vdots \\ \theta_{[n,:]}\end{array}\right] \rightarrow\left\{\begin{array}{l}z_{1, t}=\theta_{[1,:]} \cdot F_{t}+\sigma_{1, t} \varepsilon_{1, t} \\ z_{2, t}=\theta_{[2,:]} \cdot F_{t}+w_{1, t} \sigma_{1, t} \varepsilon_{1, t}+\sigma_{2, t} \varepsilon_{2, t} \\ \vdots \\ z_{n, t}=\theta_{[n,:]} \cdot F_{t}+w_{m-n+2, t} \sigma_{1, t} \varepsilon_{1, t}+\cdots+w_{m, t} \sigma_{n-1, t} \varepsilon_{n-1, t}+\sigma_{n, t} \varepsilon_{n, t}\end{array}\right.$

that, defining

$$
\underbrace{W_{t}^{*}}_{n \times n}=\left[\begin{array}{ccccc}
0 & 0 & \ldots & \ldots & 0 \\
w_{1, t} & 0 & \ddots & \ddots & \vdots \\
w_{2, t} & w_{3, t} & 0 & \ddots & \vdots \\
\vdots & \vdots & \ddots & \ddots & 0 \\
w_{m-n+2, t} & w_{m-n+3, t} & \ldots & w_{m, t} & 0
\end{array}\right]=W_{t}-I_{n}
$$

and

$$
\xi_{t}=W_{t}^{*} \Sigma_{t} \varepsilon_{t}
$$

can be written as:

$$
\left\{\begin{array}{l}
z_{1, t}-\xi_{1, t}=\theta_{[1,:]} \cdot F_{t}+\sigma_{1, t} \varepsilon_{1, t} \\
z_{2, t}-\xi_{2, t}=\theta_{[2,:]} \cdot F_{t}+\sigma_{2, t} \varepsilon_{2, t} \\
\vdots \\
z_{n, t}-\xi_{n, t}=\theta_{[n,:]} \cdot F_{t}+\sigma_{n, t} \varepsilon_{n, t}
\end{array}\right.
$$

This system is constituted by the following set of $n$ separate equations:

$$
\forall j \in\{1, \ldots, n\}, \quad z_{j, t}-\xi_{j, t}=\theta_{[j,:]} \cdot F_{t}+\varepsilon_{j, t}^{*}, \quad \varepsilon_{j, t}^{*} \sim \mathcal{N}\left(0, \sigma_{j, t}^{2}\right)
$$

Notice that for $j \geq 2$ each $\xi_{j, t}$ depends on $\left\{\varepsilon_{1, t}^{*}, \ldots, \varepsilon_{j-1, t}^{*}\right\}$, since only the first $j-1$ elements of the $j$-th row of $W_{t}^{*}$ are non-zero.

Then, conditioning on $\left(W_{t}^{*}, \sigma_{t}, F_{t}\right)_{t=1}^{T}$, and given the following priors on the elements of $\Theta$ :

$$
\forall j \in\{1, \ldots, n\}, \quad \operatorname{vec}\left(\theta_{[j,:]}\right) \sim \mathcal{M N}\left(\bar{\theta}_{[j,:]}, V_{j, \theta}\right)
$$

it is possible to design the following recursive procedure to draw from the posterior of $\Theta$. 
Starting from $j=1$ :

$$
z_{1, t}-\xi_{1, t}=\theta_{[1,:]} \cdot F_{t}+\varepsilon_{1, t}^{*}, \quad \varepsilon_{1, t}^{*} \sim \mathcal{N}\left(0, \sigma_{1, t}^{2}\right)
$$

and given that $\forall t, \xi_{1, t}=0$, it is possible to draw from the posterior of $\theta_{[1,:]}$ using the following stacked regression:

$$
\left[\begin{array}{c}
z_{1,1} \\
\vdots \\
z_{1, T}
\end{array}\right]=\left[\begin{array}{c}
F_{1}^{\prime} \\
\vdots \\
F_{T}^{\prime}
\end{array}\right] \cdot \operatorname{vec}\left(\theta_{[1,:]}\right)+\varepsilon_{1}^{*}, \quad \varepsilon_{1}^{*} \sim \mathcal{M N}\left(\mathbf{0},\left[\begin{array}{cccc}
\sigma_{1,1}^{2} & 0 & \ldots & 0 \\
0 & \sigma_{1,2}^{2} & \ddots & \vdots \\
\vdots & \ddots & \ddots & 0 \\
0 & \ldots & 0 & \sigma_{1, T}^{2}
\end{array}\right]\right)
$$

using the prior

$$
\operatorname{vec}\left(\theta_{[1,:]}\right) \sim \mathcal{M N}\left(\bar{\theta}_{[1,:]}, V_{1, \theta}\right) .
$$

Then, setting the initial condition $\widetilde{\xi}_{j-1, t}=0$ and the posterior draw $\widetilde{\theta}_{[1,:]}$, the recursive step for any $j \geq 2$ is:

1. The posterior draw $\operatorname{vec}\left(\widetilde{\theta}_{[j-1, i]}\right)$ is used to compute the following $\forall t$ :

$$
\begin{gathered}
\widetilde{\varepsilon}_{j-1, t}^{*}=z_{j-1, t}-\widetilde{\xi}_{j-1, t}-\widetilde{\theta}_{[j-1,:]} F_{t}, \\
\widetilde{\xi}_{j, t}=W_{t,[j,:]}^{*} \cdot\left[\begin{array}{c}
\widetilde{\varepsilon}_{1, t}^{*} \\
\vdots \\
\widetilde{\varepsilon}_{j-1, t}^{*}
\end{array}\right] .
\end{gathered}
$$

2. The following stacked regression is used to draw from the posterior of $\theta_{[j,:]}$ :

$$
\left[\begin{array}{c}
z_{j, 1}-\widetilde{\xi}_{j, 1} \\
\vdots \\
z_{1, T}-\widetilde{\xi}_{j, T}
\end{array}\right]=\left[\begin{array}{c}
F_{1}^{\prime} \\
\vdots \\
F_{T}^{\prime}
\end{array}\right] \cdot \operatorname{vec}\left(\theta_{[j,:]}\right)+\varepsilon_{j}^{*}, \quad \varepsilon_{j}^{*} \sim \mathcal{M N}\left(\mathbf{0},\left[\begin{array}{cccc}
\sigma_{j, 1}^{2} & 0 & \ldots & 0 \\
0 & \sigma_{j, 2}^{2} & \ddots & \vdots \\
\vdots & \ddots & \ddots & 0 \\
0 & \ldots & 0 & \sigma_{j, T}^{2}
\end{array}\right]\right),
$$

using the following prior distribution: $\quad \operatorname{vec}\left(\theta_{[j,:]}\right) \sim \mathcal{M N}\left(\bar{\theta}_{[j,:]}, V_{j, \theta}\right)$.

Repeating this iteration until $j=n$, we have drawn from the conditional posterior:

$$
\left[\begin{array}{llll}
\theta_{[1,:]}^{\prime} & \theta_{[2,:]}^{\prime} & \ldots & \theta_{[n,:]}^{\prime}
\end{array}\right]^{\prime} \mid\left(W_{t}^{*}, \sigma_{t}, F_{t}, Z_{t}\right)_{t=1}^{T}
$$


If $W_{t}^{*}$ is non time-varying, the above procedure is implemented in the same way as in the TV case, simply by considering that $\forall t$ we have $W_{t}^{*}=W^{*}$.

\section{Appendix D Additional Figures}
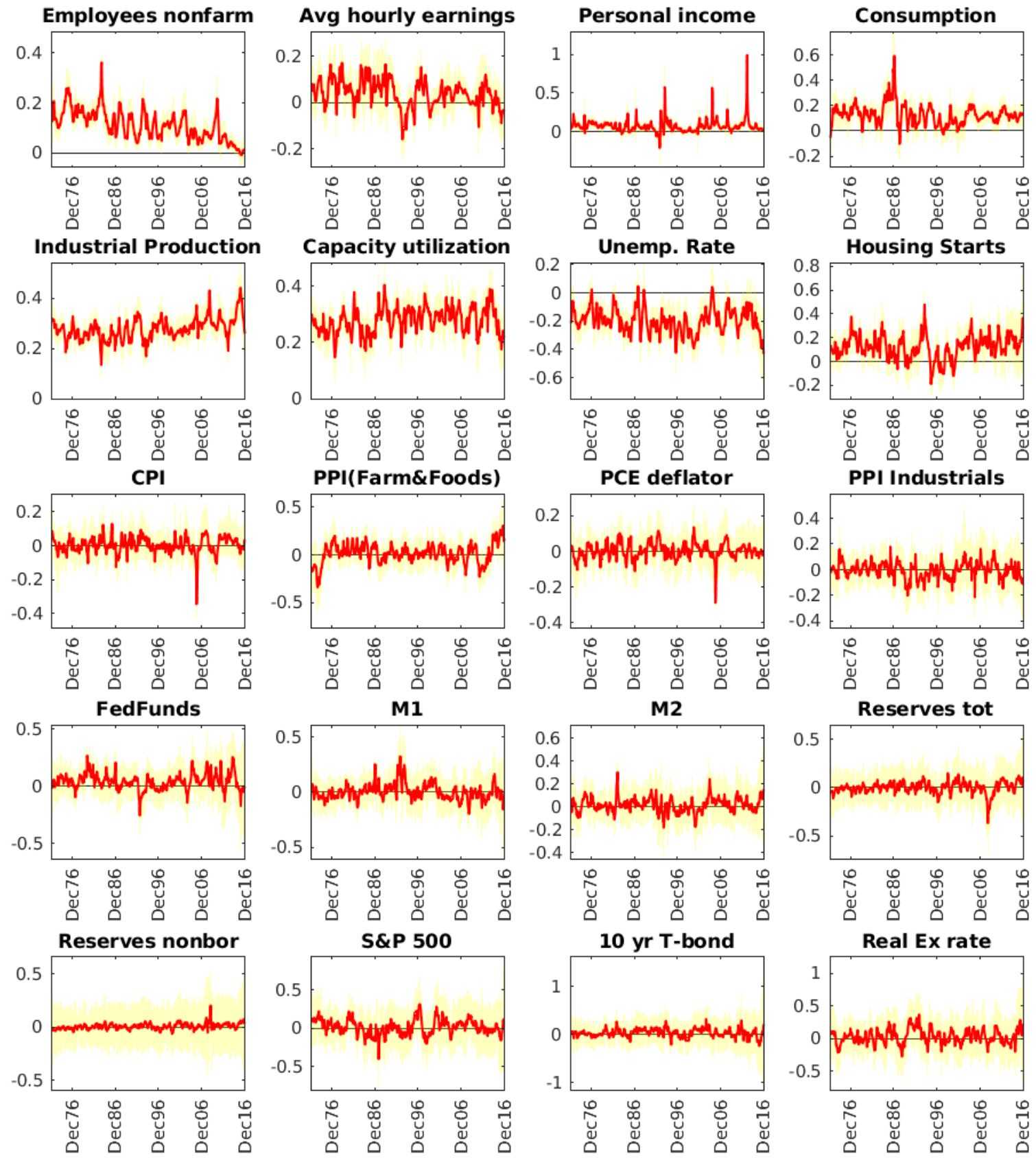

Figure 14: Response to a permanent Demand shock at horizon $h=1$. Posterior bands. 

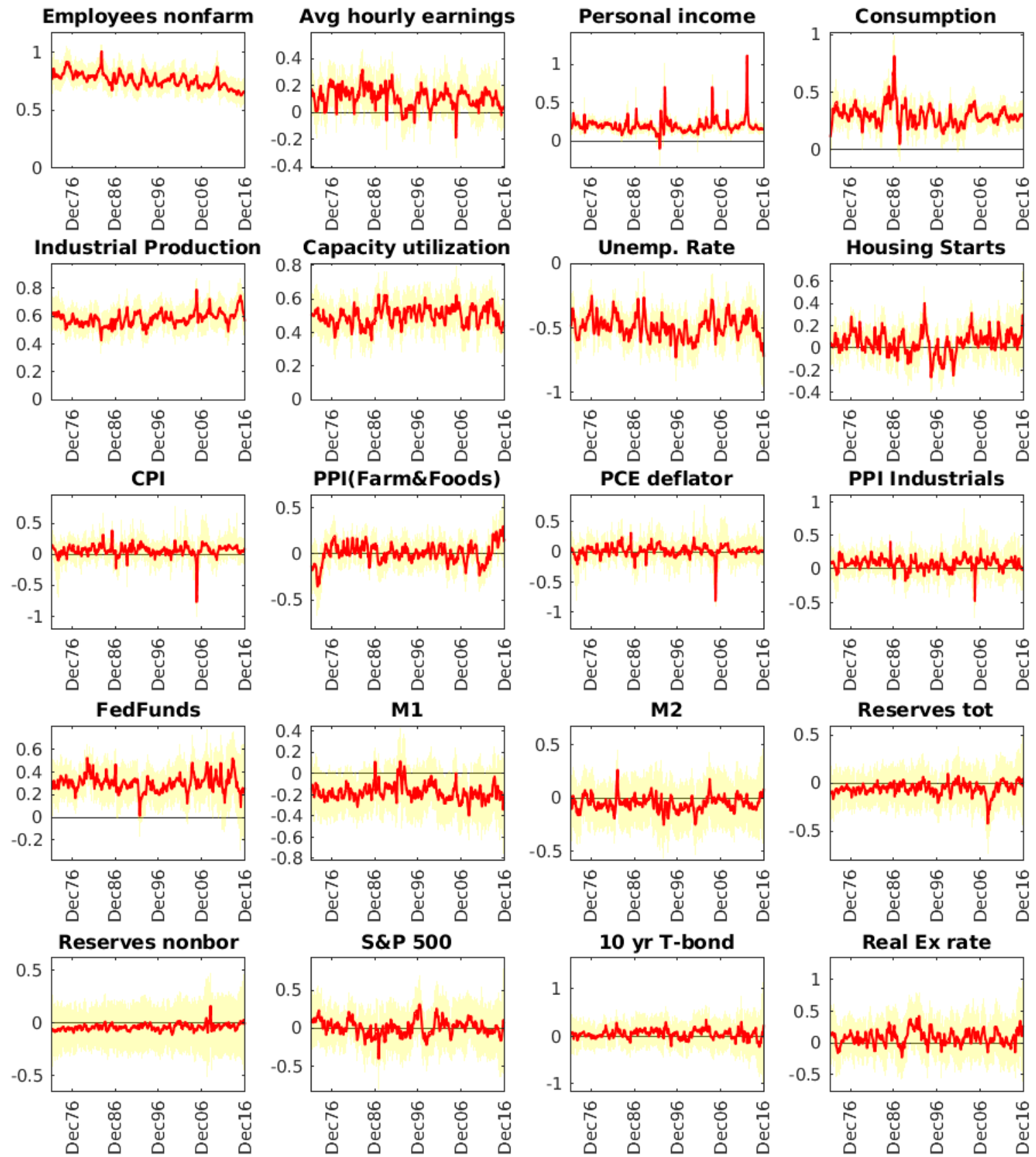

Figure 15: Response to a permanent Demand shock at horizon $h=12$. Posterior bands. 

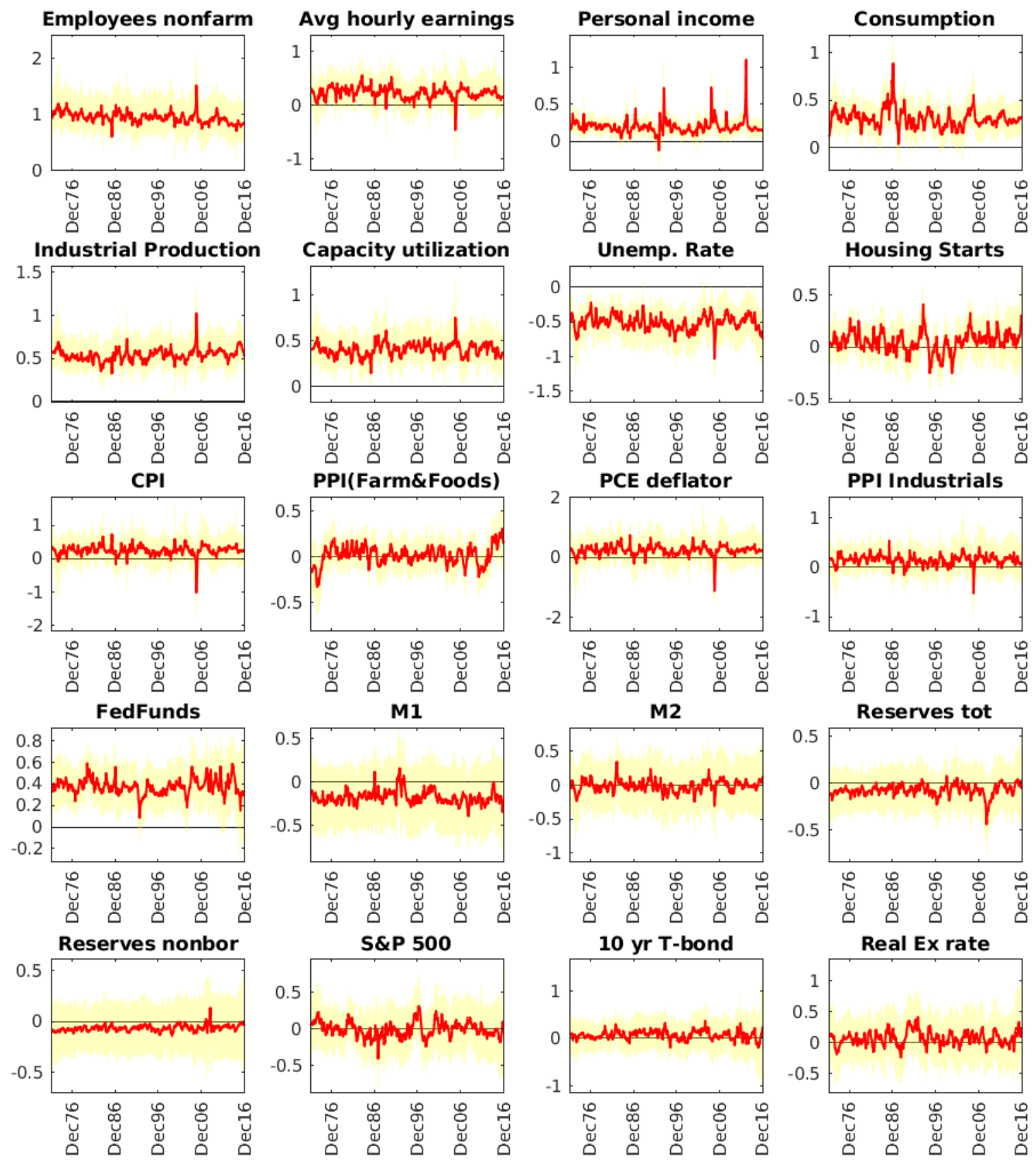

Figure 16: Response to a permanent Demand shock at horizon $h=48$. Posterior bands. 

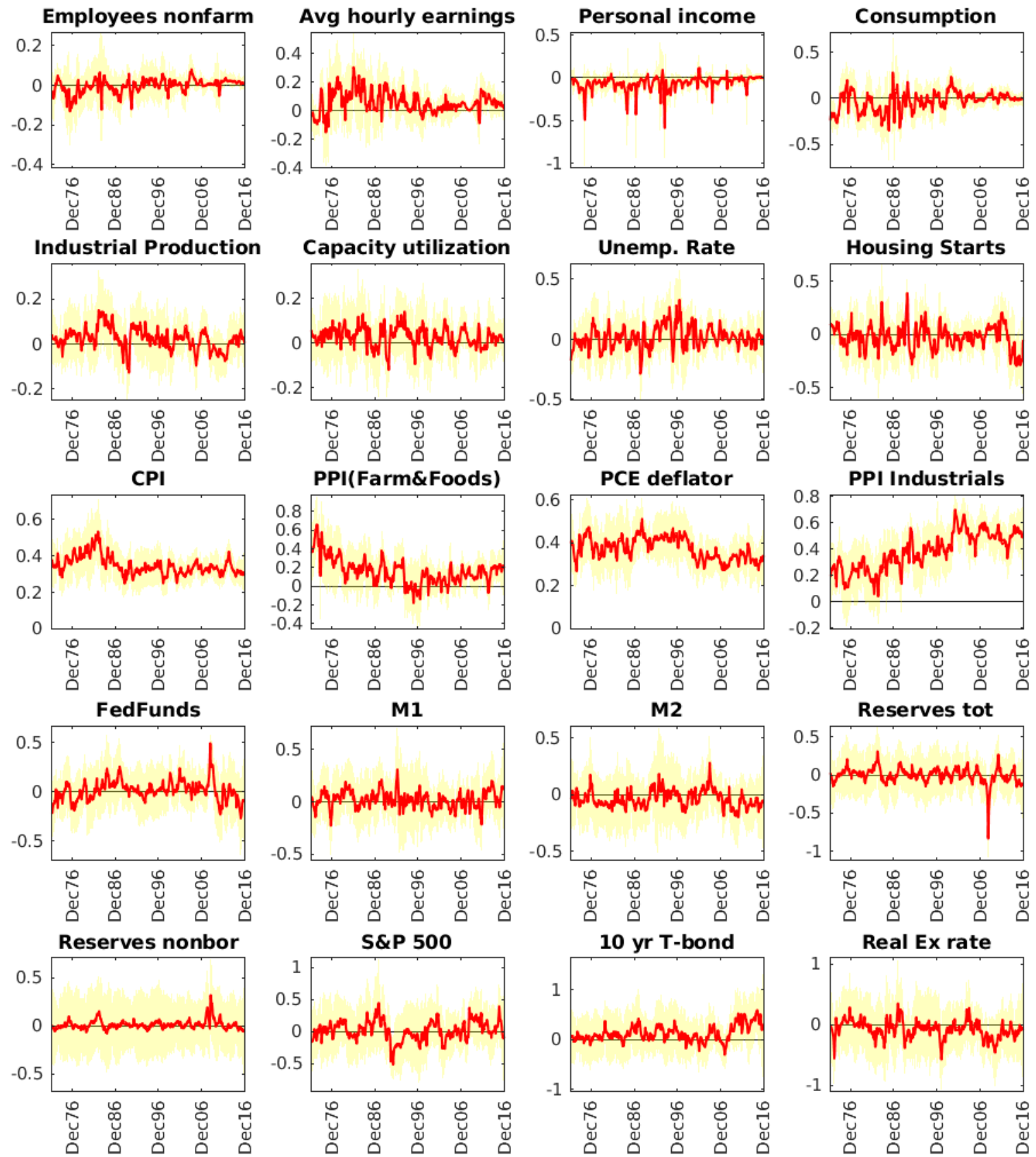

Figure 17: Response to a permanent Supply shock at horizon $h=1$. Posterior bands. 

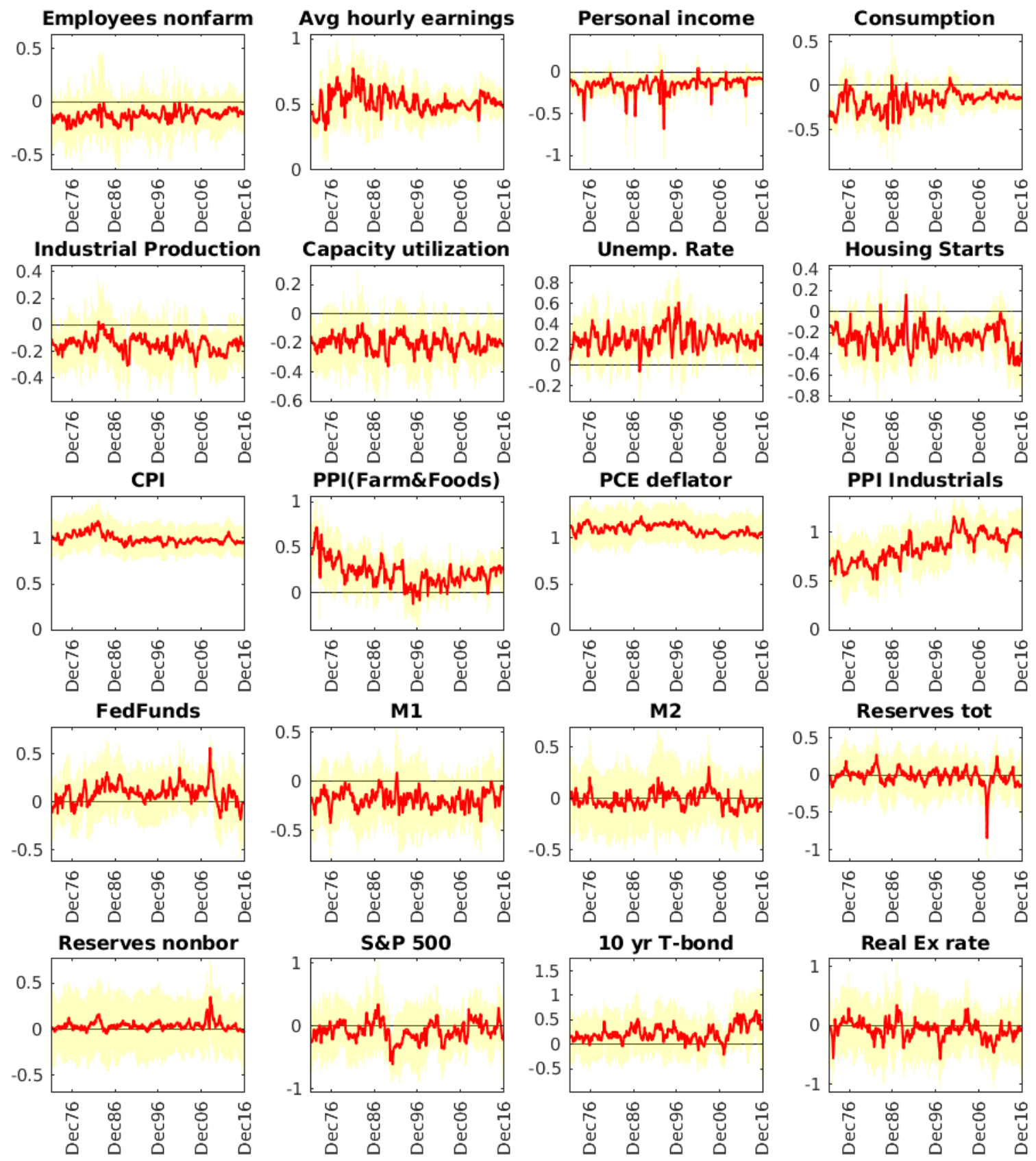

Figure 18: Response to a permanent Supply shock at horizon $h=12$. Posterior bands. 

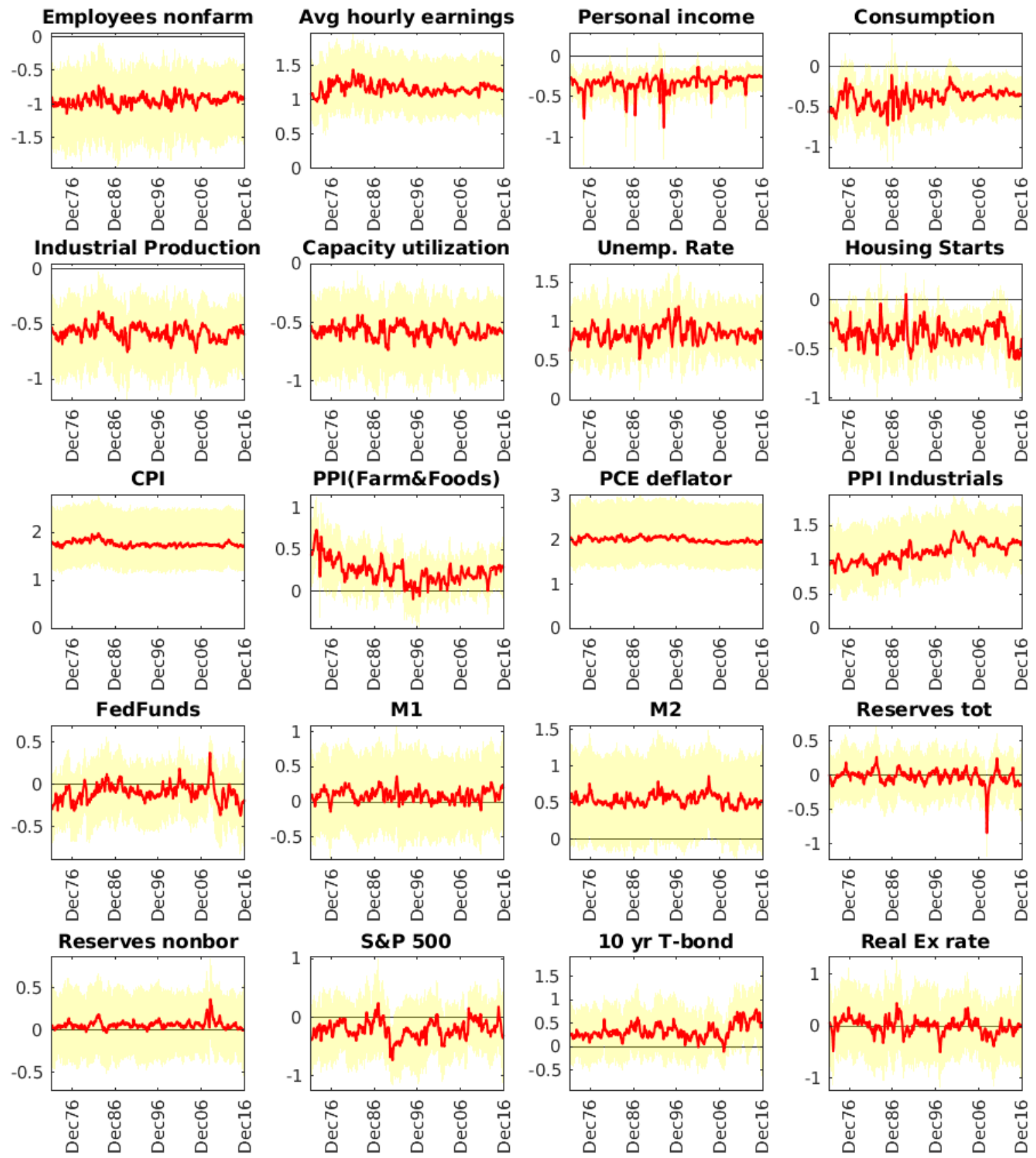

Figure 19: Response to a permanent Supply shock at horizon $h=48$. Posterior bands. 

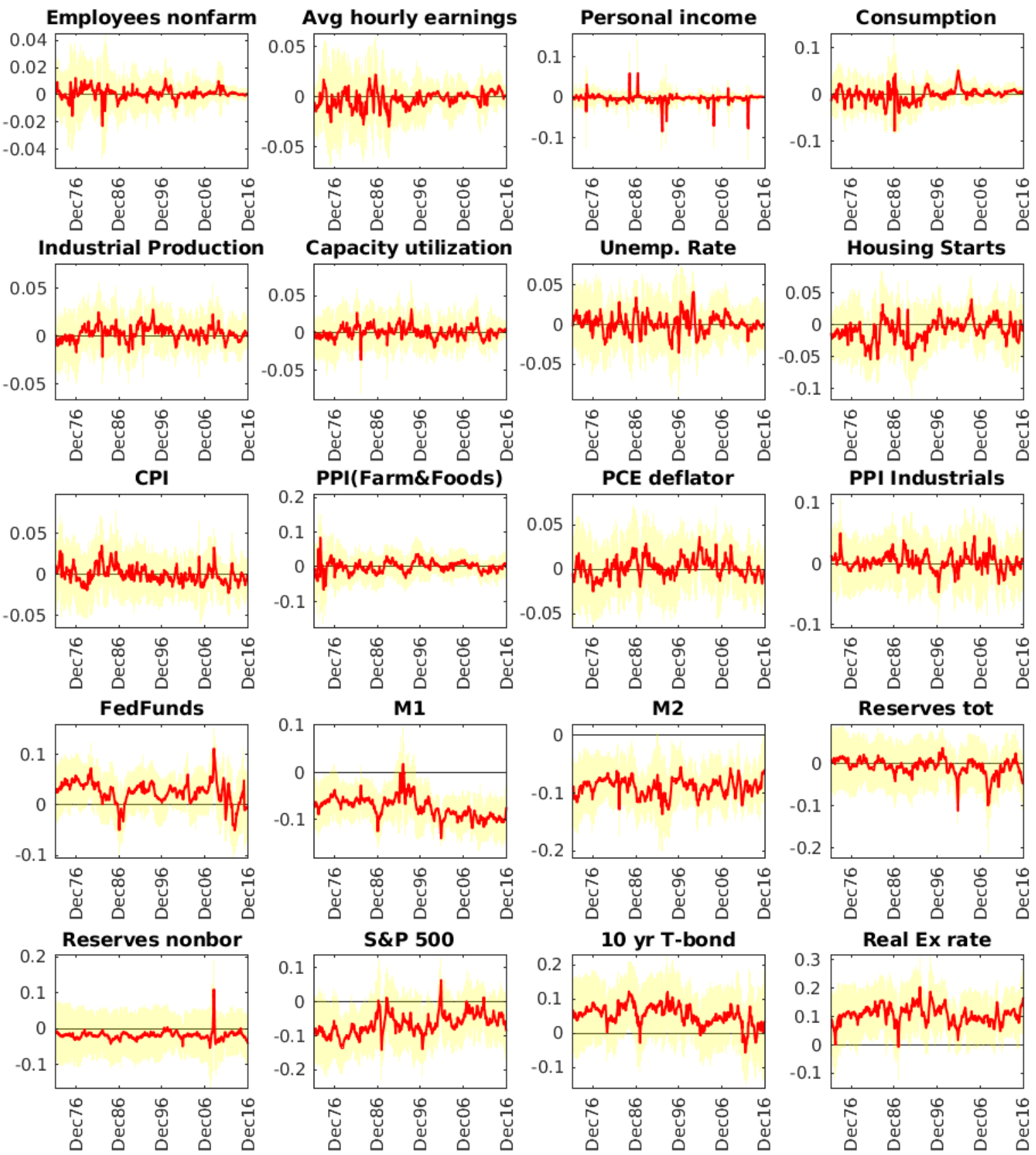

Figure 20: Response to a permanent Financial shock at horizon $h=1$. Posterior bands. 

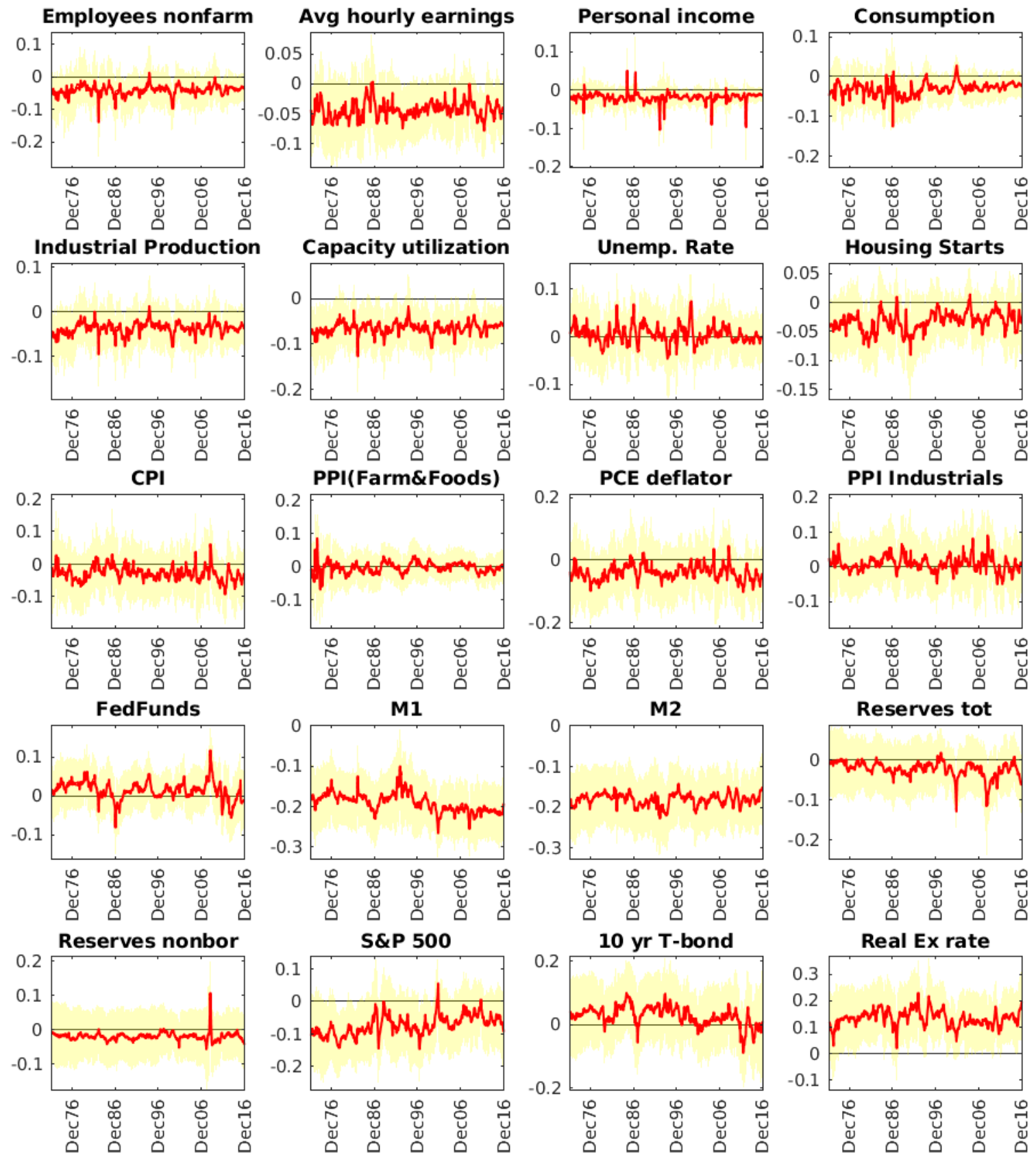

Figure 21: Response to a permanent Financial shock at horizon $h=12$. Posterior bands. 

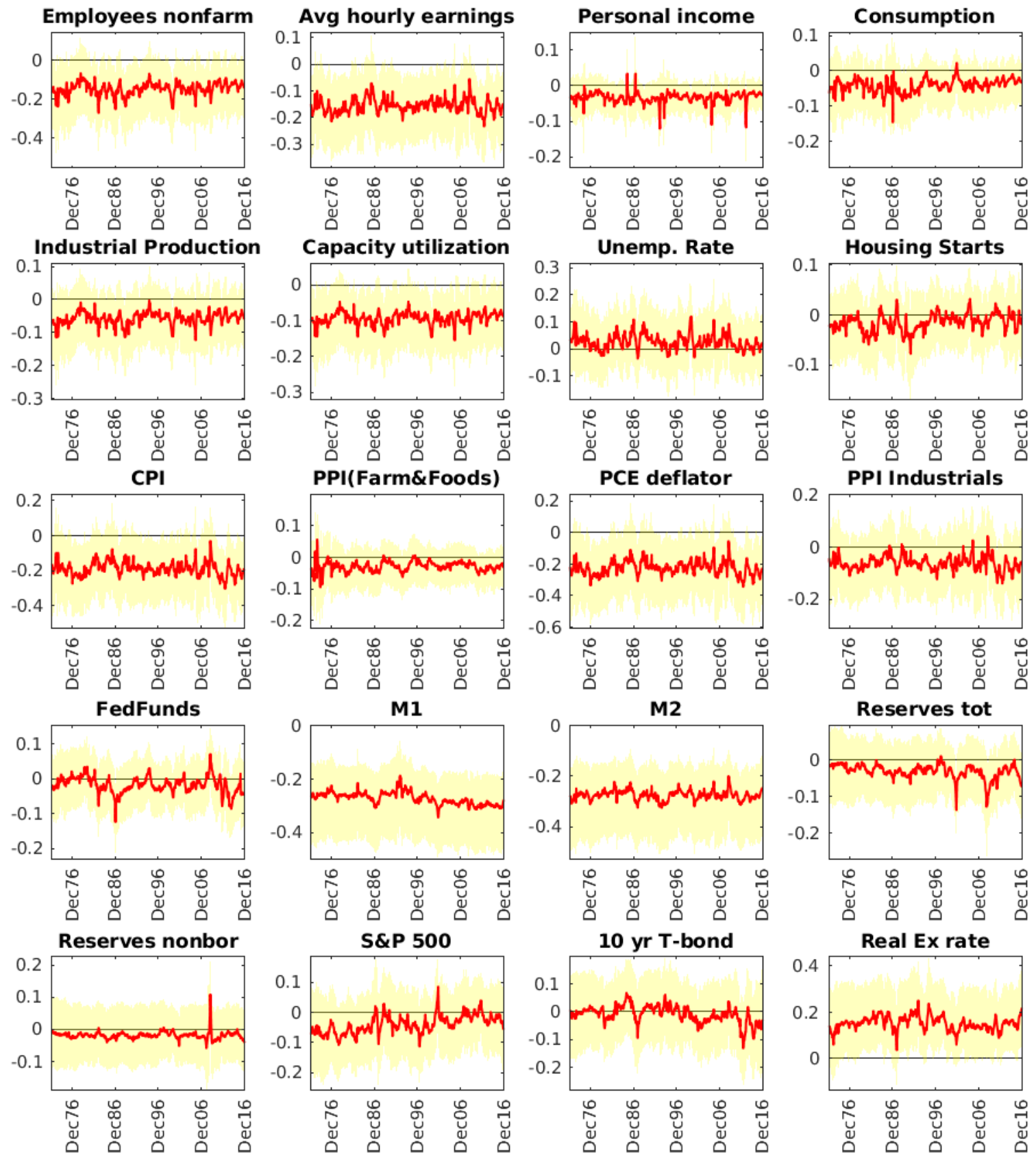

Figure 22: Response to a permanent Financial shock at horizon $h=48$. Posterior bands. 


\section{RECENTLY PUBLISHED “TEMI” (*)}

N. 1264 - The impact of TLTRO2 on the Italian credit market: some econometric evidence, by Lucia Esposito, Davide Fantino and Yeji Sung (February 2020).

N. 1265 - Public credit guarantee and financial additionalities across SME risk classes, by Emanuele Ciani, Marco Gallo and Zeno Rotondi (February 2020).

N.1266 - Determinants of the credit cycle: a flow analysis of the extensive margin, by Vincenzo Cuciniello and Nicola di Iasio (March 2020).

N.1267 - Housing supply elasticity and growth: evidence from Italian cities, by Antonio Accetturo, Andrea Lamorgese, Sauro Mocetti and Dario Pellegrino (March 2020).

N. 1268 - Public debt expansions and the dynamics of the household borrowing constraint, by António Antunes and Valerio Ercolani (March 2020).

N. 1269 - Expansionary yet different: credit supply and real effects of negative interest rate policy, by Margherita Bottero and Enrico Sette (March 2020).

N.1270 - Asymmetry in the conditional distribution of euro-area inflation, by Alex Tagliabracci (March 2020).

N.1271 - An analysis of sovereign credit risk premia in the euro area: are they explained by local or global factors?, by Sara Cecchetti (March 2020).

N. 1272 - Mutual funds' performance: the role of distribution networks and bank affiliation, by Giorgio Albareto, Andrea Cardillo, Andrea Hamaui and Giuseppe Marinelli (April 2020).

N.1273 - Immigration and the fear of unemployment: evidence from individual perceptions in Italy, by Eleonora Porreca and Alfonso Rosolia (April 2020).

N. 1274 - Bridge Proxy-SVAR: estimating the macroeconomic effects of shocks identified at high-frequency, by Andrea Gazzani and Alejandro Vicondoa (April 2020).

N.1275 - Monetary policy gradualism and the nonlinear effects of monetary shocks, by Luca Metelli, Filippo Natoli and Luca Rossi (April 2020).

N.1276 - Spend today or spend tomorrow? The role of inflation expectations in consumer behaviour, by Concetta Rondinelli and Roberta Zizza (April 2020).

N. 1277 - Going the extra mile: effort by workers and job-seekers, by Matthias S. Hertweck, Vivien Lewis and Stefania Villa (June 2020).

N.1278 - Trainspotting: board appointments in private firms, by Audinga Baltrunaite and Egle Karmaziene (June 2020).

N. 1279 - The role of bank supply in the Italian credit market: evidence from a new regional survey, by Andrea Orame (June 2020).

N. 1280 - The non-linear effects of the Fed asset purchases, by Alessio Anzuini (June 2020).

N. 1281 - The effects of shop opening hours deregulation: evidence from Italy, by Lucia Rizzica, Giacomo Roma and Gabriele Rovigatti (June 2020).

N. 1282 - How do house prices respond to mortgage supply?, by Guglielmo Barone, Francesco David, Guido de Blasio and Sauro Mocetti (June 2020).

N. 1283 - The macroeconomics of hedging income shares, by Adriana Grasso, Juan Passadore and Facundo Piguillem (June 2020).

N.1284 - Uncertainty matters: evidence from a high-frequency identifiction strategy, by Piergiorgio Alessandri, Andrea Gazzani and Alejandro Vicondoa (June 2020).

(*) Requests for copies should be sent to:

Banca d'Italia - Servizio Studi di struttura economica e finanziaria - Divisione Biblioteca e Archivio storico - Via Nazionale, 91 - 00184 Rome - (fax 003906 47922059). They are available on the Internet www.bancaditalia.it. 
Accetturo A., V. Di Giacinto, G. Micucci and M. Pagnini, Geography, productivity and trade: does selection explain why some locations are more productive than others?, Journal of Regional Science, v. 58, 5, pp. 949-979, WP 910 (April 2013).

ADAMOPOULOU A. and E. KAYA, Young adults living with their parents and the influence of peers, Oxford Bulletin of Economics and Statistics,v. 80, pp. 689-713, WP 1038 (November 2015).

Andini M., E. Ciani, G. De Blasio, A. D’Ignazio and V. Silvestrini, Targeting with machine learning: an application to a tax rebate program in Italy, Journal of Economic Behavior \& Organization, v. 156, pp. 86-102, WP 1158 (December 2017).

BARONE G., G. DE BLASIO and S. MOCETTI, The real effects of credit crunch in the great recession: evidence from Italian provinces, Regional Science and Urban Economics, v. 70, pp. 352-59, WP 1057 (March 2016).

Belotti F. and G. IlARDi Consistent inference in fixed-effects stochastic frontier models, Journal of Econometrics, v. 202, 2, pp. 161-177, WP 1147 (October 2017).

Berton F., S. Mocetti, A. Presbitero and M. Richiardi, Banks, firms, and jobs, Review of Financial Studies, v.31, 6, pp. 2113-2156, WP 1097 (February 2017).

Bofondi M., L. CARPinelli and E. SETte, Credit supply during a sovereign debt crisis, Journal of the European Economic Association, v.16, 3, pp. 696-729, WP 909 (April 2013).

Bokan N., A. Gerali, S. Gomes, P. JACQuinOt and M. PiSANI, EAGLE-FLI: a macroeconomic model of banking and financial interdependence in the euro area, Economic Modelling, v. 69, C, pp. 249280, WP 1064 (April 2016).

BRILli Y. and M. TONELlo, Does increasing compulsory education reduce or displace adolescent crime? New evidence from administrative and victimization data, CESifo Economic Studies, v. 64, 1, pp. 15-4, WP 1008 (April 2015).

BUONO I. and S. FORMAI The heterogeneous response of domestic sales and exports to bank credit shocks, Journal of International Economics, v. 113, pp. 55-73, WP 1066 (March 2018).

Burlon L., A. Gerali, A. NotarPietro and M. Pisani, Non-standard monetary policy, asset prices and macroprudential policy in a monetary union, Journal of International Money and Finance, v. 88, pp. 25-53, WP 1089 (October 2016).

CARTA F. and M. DE PHLIPPIS, You've Come a long way, baby. Husbands' commuting time and family labour supply, Regional Science and Urban Economics, v. 69, pp. 25-37, WP 1003 (March 2015).

CARTA F. and L. RIZZICA, Early kindergarten, maternal labor supply and children's outcomes: evidence from Italy, Journal of Public Economics, v. 158, pp. 79-102, WP 1030 (October 2015).

Casiraghi M., E. Gaiotti, L. Rodano and A. SECchi, A “Reverse Robin Hood"? The distributional implications of non-standard monetary policy for Italian households, Journal of International Money and Finance, v. 85, pp. 215-235, WP 1077 (July 2016).

CIANI E. and C. DEIANA, No Free lunch, buddy: housing transfers and informal care later in life, Review of Economics of the Household, v.16, 4, pp. 971-1001, WP 1117 (June 2017).

Cipriani M., A. Guarino, G. Guazzarotti, F. Tagliati and S. Fisher, Informational contagion in the laboratory, Review of Finance, v. 22, 3, pp. 877-904, WP 1063 (April 2016).

De Blasio G, S. De Mitri, S. D’Ignazio, P. Finaldi Russo and L. Stoppani, Public guarantees to SME borrowing. A RDD evaluation, Journal of Banking \& Finance, v. 96, pp. 73-86, WP 1111 (April 2017).

Gerali A., A. LocARno, A. NotARPIETRO and M. PISANI, The sovereign crisis and Italy's potential output, Journal of Policy Modeling, v. 40, 2, pp. 418-433, WP 1010 (June 2015).

LIBERATI D., An estimated DSGE model with search and matching frictions in the credit market, International Journal of Monetary Economics and Finance (IJMEF), v. 11, 6, pp. 567-617, WP 986 (November 2014).

LinAREllo A., Direct and indirect effects of trade liberalization: evidence from Chile, Journal of Development Economics, v. 134, pp. 160-175, WP 994 (December 2014).

NAtoli F. and L. SigAlotTi, Tail co-movement in inflation expectations as an indicator of anchoring, International Journal of Central Banking, v. 14, 1, pp. 35-71, WP 1025 (July 2015).

NuCCI F. and M. RigGI, Labor force participation, wage rigidities, and inflation, Journal of Macroeconomics, v. 55, 3 pp. 274-292, WP 1054 (March 2016).

RIGON M. and F. ZANETTI, Optimal monetary policy and fiscal policy interaction in a non_ricardian economy, International Journal of Central Banking, v. 14 3, pp. 389-436, WP 1155 (December 2017). 
SEGURA A., Why did sponsor banks rescue their SIVs?, Review of Finance, v. 22, 2, pp. 661-697, WP 1100 (February 2017).

AlbANESE G., M. CIOFFI and P. TOMMASINO, Legislators' behaviour and electoral rules: evidence from an Italian reform, European Journal of Political Economy, v. 59, pp. 423-444, WP 1135 (September 2017).

Aprigliano V., G. ArdizzI and L. MonTEForte, Using the payment system data to forecast the economic activity, International Journal of Central Banking, v. 15, 4, pp. 55-80, WP 1098 (February 2017).

ARNAUdo D., G. MiCUCCI, M. RigON and P. Rossi, Should I stay or should I go? Firms' mobility across banks in the aftermath of the financial crisis, Italian Economic Journal / Rivista italiana degli economisti, v. 5, 1, pp. 17-37, WP 1086 (October 2016).

BASSO G., F. D’AMURI and G. PERI, Immigrants, labor market dynamics and adjustment to shocks in the euro area, IMF Economic Review, v. 67, 3, pp. 528-572, WP 1195 (November 2018).

BAtini N., G. MelinA and S. Villa, Fiscal buffers, private debt, and recession: the good, the bad and the ugly, Journal of Macroeconomics, v. 62, WP 1186 (July 2018).

Burlon L., A. Notarpietro and M. Pisani, Macroeconomic effects of an open-ended asset purchase programme, Journal of Policy Modeling, v. 41, 6, pp. 1144-1159, WP 1185 (July 2018).

Busetti F. and M. CAIVANO, Low frequency drivers of the real interest rate: empirical evidence for advanced economies, International Finance, v. 22, 2, pp. 171-185, WP 1132 (September 2017).

CAppelletti G., G. GuAzZAROtTi and P. TOMmasino, Tax deferral and mutual fund inflows: evidence from a quasi-natural experiment, Fiscal Studies, v. 40, 2, pp. 211-237, WP 938 (November 2013).

CARDANi R., A. PACCAGNINI and S. VILla, Forecasting with instabilities: an application to DSGE models with financial frictions, Journal of Macroeconomics, v. 61, WP 1234 (September 2019).

Chiades P., L. Greco, V. Mengotto, L. Moretti and P. Valbonesi, Fiscal consolidation by intergovernmental transfers cuts? The unpleasant effect on expenditure arrears, Economic Modelling, v. 77, pp. 266-275, WP 985 (July 2016).

CIANI E., F. DAVID and G. DE BLASIO, Local responses to labor demand shocks: a re-assessment of the case of Italy, Regional Science and Urban Economics, v. 75, pp. 1-21, WP 1112 (April 2017).

CIANI E. and P. FISHER, Dif-in-dif estimators of multiplicative treatment effects, Journal of Econometric Methods, v. 8. 1, pp. 1-10, WP 985 (November 2014).

CIAPANNA E. and M. TABOGA, Bayesian analysis of coefficient instability in dynamic regressions, Econometrics, MDPI, Open Access Journal, v. 7, 3, pp.1-32, WP 836 (November 2011).

Coletta M., R. De Bonis and S. PIERMATteI, Household debt in OECD countries: the role of supply-side and demand-side factors, Social Indicators Research, v. 143, 3, pp. 1185-1217, WP 989 (November 2014).

Cova P., P. PAgAno and M. PISAni, Domestic and international effects of the Eurosystem Expanded Asset Purchase Programme, IMF Economic Review, v. 67, 2, pp. 315-348, WP 1036 (October 2015).

ERColani V. and J. VAlle E AzEVEDo, How can the government spending multiplier be small at the zero lower bound?, Macroeconomic Dynamics, v. 23, 8. pp. 3457-2482, WP 1174 (April 2018).

FERrero G., M. Gross and S. NerI, On secular stagnation and low interest rates: demography matters, International Finance, v. 22, 3, pp. 262-278, WP 1137 (September 2017).

FoA G., L. GAmbacorta, L. Guiso and P. E. Mistrulli, The supply side of household finance, Review of Financial Studies, v.32, 10, pp. 3762-3798, WP 1044 (November 2015).

Giordano C., M. MARINUCCI and A. Silvestrini, The macro determinants of firms' and households' investment: evidence from Italy, Economic Modelling, v. 78, pp. 118-133, WP 1167 (March 2018).

Gomellini M., D. Pellegrino and F. GifFoni, Human capital and urban growth in Italy,1981-2001, Review of Urban \& Regional Development Studies, v. 31, 2, pp. 77-101, WP 1127 (July 2017).

MAGRI S., Are lenders using risk-based pricing in the Italian consumer loan market? The effect of the 2008 crisis, Journal of Credit Risk, v. 15, 1, pp. 27-65, WP 1164 (January 2018).

MAKINEN T., A. MERCATANTI and A. SiLVESTRINI, The role of financial factors for european corporate investment, Journal of International Money and Finance, v. 96, pp. 246-258, WP 1148 (October 2017).

Miglietta A., C. Picillo and M. Pietrunt, The impact of margin policies on the Italian repo market, The North American Journal of Economics and Finance, v. 50, WP 1028 (October 2015). 
MONTEFORTE L. and V. RAPONI, Short-term forecasts of economic activity: are fortnightly factors useful?, Journal of Forecasting, v. 38, 3, pp. 207-221, WP 1177 (June 2018).

Neri S. and A. NOTARPIETRO, Collateral constraints, the zero lower bound, and the debt-deflation mechanism, Economics Letters, v. 174, pp. 144-148, WP 1040 (November 2015).

PEREDA FERnANDEZ S., Teachers and cheaters. Just an anagram?, Journal of Human Capital, v. 13, 4, pp. 635-669, WP 1047 (January 2016).

RigGi M., Capital destruction, jobless recoveries, and the discipline device role of unemployment, Macroeconomic Dynamics, v. 23, 2, pp. 590-624, WP 871 (July 2012).

2020

BRIPI F., D. LOSCHIAVO and D. REVELLI, Services trade and credit frictions: evidence with matched bankfirm data, The World Economy, v. 43, 5, pp. 1216-1252, WP 1110 (April 2017).

CoIBION O., Y. GORODNICHENKO and T. ROPELE, Inflation expectations and firms' decisions: new causal evidence, Quarterly Journal of Economics, v. 135, 1, pp. 165-219, WP 1219 (April 2019).

CORSELlO F. and V. NiSPI LANDI, Labor market and financial shocks: a time-varying analysis, Journal of Money, Credit and Banking, v. 52, 4, pp. 777-801, WP 1179 (June 2018).

D'IGNAZIO A. and C. MENON, The causal effect of credit Guarantees for SMEs: evidence from Italy, The Scandinavian Journal of Economics, v. 122, 1, pp. 191-218, WP 900 (February 2013).

RAINONE E. and F. VACIRCA, Estimating the money market microstructure with negative and zero interest rates, Quantitative Finance, v. 20, 2, pp. 207-234, WP 1059 (March 2016).

RIzzICA L., Raising aspirations and higher education. Evidence from the UK's widening participation policy, Journal of Labor Economics, v. 38, 1, pp. 183-214, WP 1188 (September 2018).

\section{FORTHCOMING}

ARduINi T., E. PATACCHINI and E. RAINONE, Treatment effects with heterogeneous externalities, Journal of Business \& Economic Statistics, WP 974 (October 2014).

Baltrunaite A., C. Giorgiantonio, S. Mocetti and T. Orlando, Discretion and supplier selection in public procurement, Journal of Law, Economics, and Organization, WP 1178 (June 2018).

Bologna P., A. Miglietta and A. Segura, Contagion in the CoCos market? A case study of two stress events, International Journal of Central Banking, WP 1201 (November 2018).

BotTero M., F. MEZZANOTTI and S. LENZU, Sovereign debt exposure and the Bank Lending Channel: impact on credit supply and the real economy, Journal of International Economics, WP 1032 (October 2015).

Bronzini R., G. CARAMELlino and S. MAGRI, Venture capitalists at work: a Diff-in-Diff approach at latestages of the screening process, Journal of Business Venturing, WP 1131 (September 2017).

Bronzini R., S. MocetTi and M. MONGARDini, The economic effects of big events: evidence from the Great Jubilee 2000 in Rome, Journal of Regional Science, WP 1208 (February 2019).

COVA P. and F. NATOLI, The risk-taking channel of international financial flows, Journal of International Money and Finance, WP 1152 (December 2017).

COVA P., P. PAGANO, A. NotARPIETRO and M. PISANI, Secular stagnation, $R \& D$, public investment and monetary policy: a global-model perspective, Macroeconomic Dynamics, WP 1156 (December 2017).

DEL PRETE S. and S. FEDERICO, Do links between banks matter for bilateral trade? Evidence from financial crises, Review of World Economics, WP 1217 (April 2019).

GerAli A. and S. NeRI, Natural rates across the Atlantic, Journal of Macroeconomics, WP 1140 (September 2017).

LiBERATI D. and M. LOBERTO, Taxation and housing markets with search frictions, Journal of Housing Economics, WP 1105 (March 2017).

LosCHIAVo D., Household debt and income inequality: evidence from Italian survey data, Review of Income and Wealth, WP 1095 (January 2017).

Mocetti S., G. RomA and E. RuBOLINO, Knocking on parents' doors: regulation and intergenerational mobility, Journal of Human Resources, WP 1182 (July 2018). 
NiSPI LANDI V. and A. SCHIAVONE, The effectiveness of capital controls, Open Economies Review, WP 1200 (November 2018).

PANCRAZI R. and M. PIETRUNTI, Natural expectations and home equity extraction, Journal of Housing Economics, WP 984 (November 2014).

PeReda Fernandez S., Copula-based random effects models for clustered data, Journal of Business \& Economic Statistics, WP 1092 (January 2017).

RAINONE E., The network nature of otc interest rates, Journal of Financial Markets, WP 1022 (July 2015).

SANTIONI, R., F. SCHIANTARELLI and P. STRAHAN, Internal capital markets in times of crisis: the benefit of group affiliation, Review of Finance, WP 1146 (October 2017).

SChiAnTARELli F., M. STACCHINI and P. STRAHAN, Bank Quality, judicial efficiency and loan repayment delays in Italy, Journal of Finance, WP 1072 (July 2016). 